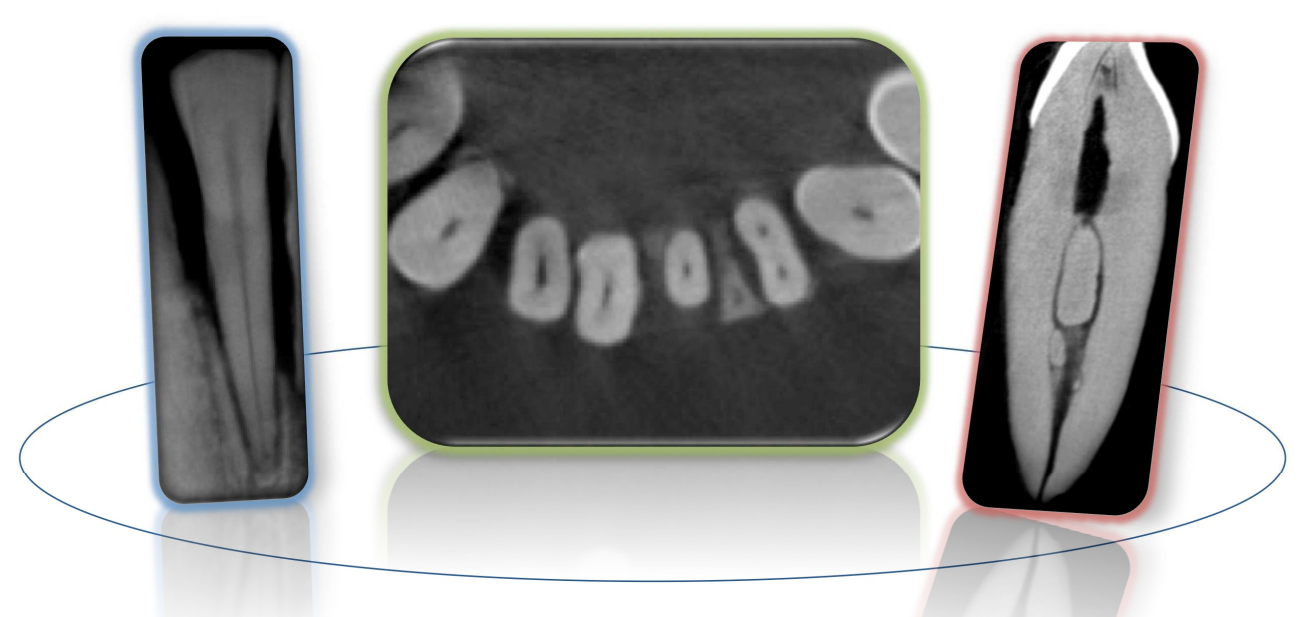

Identificacão de dois canais radiculares em incisivos inferiores com imagens radiográficas, tomográficas e microtomográficas 



\section{LUCIANA MARIA PAES DA SILVA RAMOS FERNANDES}

Identificação de dois canais radiculares em incisivos inferiores com imagens radiográficas, tomográficas e microtomográficas

Tese apresentada à Faculdade de Odontologia de Bauru da Universidade de São Paulo para obtenção do título de doutor em Ciências Odontológicas Aplicadas.

Área de concentração:Estomatologia

Orientadora: Profa. Dra. Ana Lúcia Álvares Capelozza

\section{Versão corrigida}

BAURU 


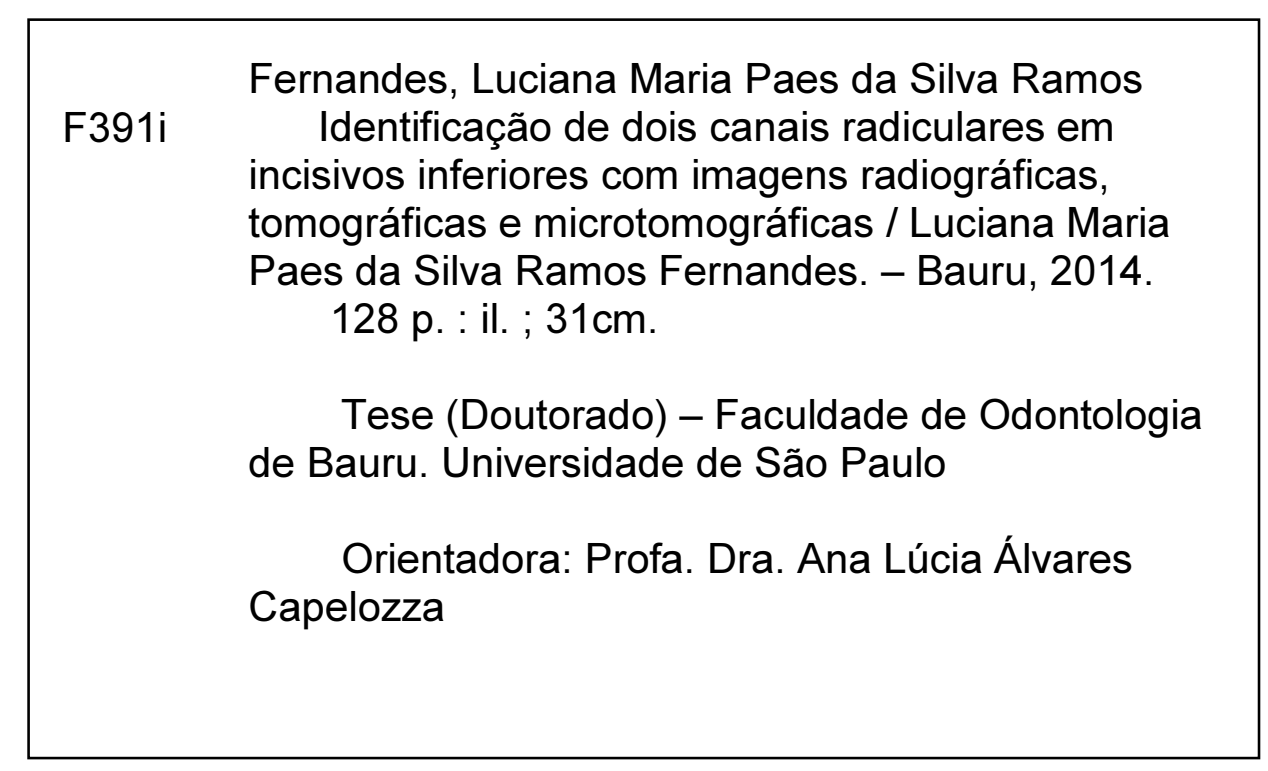

Nota: A versão original desta tese encontra-se disponível no Serviço de Biblioteca da Faculdade de Odontologia de Bauru - FOB/USP.

Autorizo, exclusivamente para fins acadêmicos e científicos, a reprodução total ou parcial desta tese, por processos fotocopiadores e outros meios eletrônicos.

Assinatura:

Data:

Comitê de Ética da FOB-USP

Número CAAE: 01229812.0.0000.5417

Data: $28 / 03 / 2012$ 


\title{
Dados Guryiculares
}

\author{
Luciana Maria Paes da Silva Ramos Fernandes
}

16 de maio de 1983:

Nascimento em São Paulo, SP, Brasil.

2001-2004:

Graduação em Odontologia

pela Faculdade de Odontologia de Araraquara, Universidade Estadual Paulista (FOAr/UNESP).

2005:

Curso de Atualização em Endodontia pela FAEPO (Fundação Araraquarense de Ensino e

Pesquisa em Odontologia)

da Faculdade de Odontologia de Araraquara, Universidade Estadual Paulista (FOAr, UNESP).

2006-2007:

Especialização em Radiologia pela FUNDECTO (Fundação para o Desenvolvimento Científico e Tecnológico da Odontologia), da Faculdade de Odontologia da Universidade de São Paulo (FOUSP).

2009-2011:

Curso de Pós-Graduação em

Ciências Odontológicas Aplicadas, área de concentração Estomatologia, em nível de Mestrado, pela Faculdade de Odontologia de Bauru, Universidade de São Paulo (FOB-USP).

Associações:

IADR- International Association for Dental Research APCD- Associação Paulista de Cirurgiões-Dentistas. 



\section{Dedicatória}

A Deus, o meu criador e guia de meus passos, sem O qual seria impossível qualquer realização em minha vida pessoal e profissional;

À minha mãe Maria Eugênia da Silva Fernandes, minha melhor amiga, conselheira e mentora, por sempre me apoiar em todos os aspectos de minha vida e por ser um exemplo de mulher íntegra e corajosa;

A meu esposo Ronald Ordinola Zapata, por ser grande incentivador de minha carreira e um companheiro maravilhoso em todos os momentos;

A eles, de coração, dedico este trabalho. 



\section{Mradecimentos}

A Deus, pelo dom da vida, pela inspiração, pela saúde e pelas oportunidades.

À minha mãe Maria Eugênia, pelo amor, cuidado e apoio em todos os momentos de minha vida, e também por transmitir o gosto pela vida acadêmica. "Mãe, quero que saiba que a minha gratidão por tudo que você fez e faz por mim é enorme. Você é um verdadeiro exemplo de mulher virtuosa e, a cada dia que passa, isso se torna mais evidente. Quero que se sinta amada e devidamente reconhecida pela grandeza de seus atos e por seu caráter. Obrigada por tudo! Em Cristo somos mais do que vencedoras!"

A meu amado esposo Ronald, pelo amor, amizade, orientação, incentivo, e por ser um exemplo de professor e pesquisador dedicado. "Eres un regalo de Dios para mi vida. Contigo aprendo todos los días. Gracias por siempre aconsejarme y darme fuerzas. ¡Te amo!". A minha gratidão também a meus sogros e à minha cunhada, por quem tenho enorme carinho: Luciano, Paula e Daisy. "iLos llevo en mi corazón!”

Por ter-me concedido a vida e incentivado para que eu fizesse pósgraduação, sou grata a meu pai José Carlos (in memoriam).

A meus queridos avós Eurico (in memoriam) e Odila (in memoriam), que ajudaram a me criar e que me ensinaram tantas coisas fundamentais ao longo dos anos que convivemos. "Saudades!" 

À Universidade de São Paulo (USP), na pessoa de seu Excelentíssimo Reitor Prof. Dr. Marco Antonio Zago; à Faculdade de Odontologia de Bauru (FOBUSP), na pessoa de sua Excelentíssima Diretora Profa. Dra. Maria Aparecida de Andrade Moreira Machado; à Comissão de Pós-Graduação da FOB-USP, na pessoa do Prof. Dr. Paulo César Rodrigues Conti; ao Comitê de Ética em Pesquisa da FOB-USP, na pessoa da Profa. Dra. Izabel Regina Fischer RubiraBullen e à CAPES, na pessoa do Prof. Dr. Jorge Almeida Guimarães, pela possibilidade de realização e concretização do meu curso de doutorado.

À minha orientadora Profa. Dra. Ana Lúcia Álvares Capelozza, pelos ensinamentos, pela solidariedade e pela alegria transmitidos constantemente. Sou grata pela confiança depositada e por me receber para estudar na FOB-USP.

Aos estimados Professores Doutores do Departamento de Estomatologia da FOB-USP José Humberto Damante, Izabel Regina Fischer Rubira-Bullen, Luiz Eduardo Montenegro Chinellato, Paulo Sérgio da Silva Santos, Cássia Maria Fischer Rubira, Osny Ferreira Júnior, Eduardo Sant'Ana, Eduardo Sanches Gonçales e Renato Yassutaka Faria Yaedú, pelos ensinamentos, pelo companheirismo e pela dedicação.

Aos doutores Heidi Christensen, Dwight Rice e David Jaramillo da Faculdade de Odontologia da Universidade de Loma Linda, na California, Estados Unidos, por me receberem de braços abertos para a realização de parte dessa pesquisa em seus departamentos. Foi uma experiência de grande valia para minha vida pessoal e profissional e uma parceria científica que rende ótimos frutos. 

Ao Prof. Dr. Clovis Monteiro Bramante da Disciplina de Endodontia e a meu esposo Prof. Dr. Ronald Ordinola Zapata, por viabilizarem o uso do microtomógrafo computadorizado para escaneamento dos dentes utilizados nessa pesquisa.

A meus colegas de pós-graduação em Estomatologia Thaís Imada, Bruna Centurion, Otávio Pagin, Marcelo Sampieri, Thaís Feitosa, Lyzete Berriel, Alexandre Nogueira, Carla Ikuta, José Endrigo Tinoco, Vitor Tieghi, Vitor Hugo Rodrigues, Leandro Scomparin, Daniel Salgueiro, Danilo Correa, Gustavo Zanna, Annie Tanaka, Maíra Battisti, Maria Fernanda Madeira, Edson Zen, Andrea Gonçales, Ingrid Souza, Dayane Grandizoli, Ivna Lopes, Rosana Tucunduva, Emanoele Silva, Gabriela Chicrala, Wilson Cral e Mariana Soares pelo companheirismo, boas risadas e aprendizado conjunto ao longo desse período. Agradeço especialmente à querida Laura Nicolielo e a Rubens de Castro Jr., pela agradável parceria na clínica de pós-graduação.

Às minhas grandes amigas Sylvia Matsumura, Camila Cardoso e Kellen Tjioe, pela amizade, parceria e torcida por mim em todos os momentos durante essa etapa.

Aos funcionários do Departamento de Estomatologia da FOB-USP, Roberto Salles, Alexandre Garcia, Andrea Cruz, Marco Aurélio de Podestá, Fernanda Cavalari, Marília Gião, Maria Cristina do Nascimento, Josieli Tripodi e Luciana Zanon por serem sempre prestativos para comigo. Agradeço pela simpatia e companheirismo de cada um de vocês.

Aos pacientes que realizaram exames de tomografia computadorizada de feixe cônico na FOB-USP para outros fins em seu benefício, mas que indiretamente contribuíram para essa pesquisa. 

Muito obrigada a todos!

"Dou graças ao meu Deus todas as vezes que me lembro de vós..."

(Filipenses 1.3, Bíblia Sagrada) 

"Dans la vie, rien n'est à craindre, tout est à comprendre." 



$$
=(1)
$$





\section{RESUMO}

Os dentes incisivos inferiores apresentam, em sua maioria, canal radicular único, que pode ter conformações distintas. De acordo com a literatura científica, a presença de um segundo canal radicular pode ser constatada em 10 a $40 \%$ dos casos. A não-detecção do segundo canal é um importante fator para o insucesso do tratamento endodôntico. Esta pesquisa foi realizada com os seguintes objetivos: 1) comparar a eficácia na identificação de padrões anatômicos internos em incisivos inferiores permanentes extraídos com uso de imagem radiográfica periapical digital e de tomografia computadorizada de feixe cônico (TCFC); e 2) determinar a prevalência de 2 canais radiculares em incisivos inferiores em imagens de TCFC de um banco de dados de exames previamente realizados, associando com localização do dente, gênero e idade do paciente. Na primeira etapa da pesquisa, 40 dentes incisivos inferiores foram submetidos a escaneamento em microtomógrafo computadorizado da FOB-USP (Skyscan 1074) para estabelecer o padrão ouro do tipo anatômico interno de cada dente. Os dentes foram então classificados em: Tipo I ( 1 canal radicular regular, $n=12$ ), Tipo la ( 1 canal radicular oval, $n=12$ ) e Tipo III (2 canais radiculares, $n=16)$. Em seguida, os dentes foram divididos em 10 grupos de 4 dentes e posicionados em alvéolos de uma mandíbula humana para exposição radiográfica periapical digital direta com duas tomadas variando o ângulo horizontal de incidência (Schick CDR) e para escaneamento em 3 tomógrafos (Kodak 9000 3D, Veraviewepocs 3De e NewTom 5G) da Universidade de Loma Linda, CA, EUA. Dois examinadores treinados classificaram o tipo anatômico de cada dente e suas respostas foram comparadas ao padrão ouro estabelecido por microtomografia. Para descrição dos resultados, utilizou-se a porcentagem (\%) de respostas certas / erradas. Aplicou-se o teste do qui-quadrado $\left(\chi^{2}\right)$, com nível de significância estatística de $5 \%$, para verificação da associação entre variáveis. As concordâncias inter e intraexaminador foram determinadas por teste de kappa. Na segunda etapa da pesquisa, foram interpretadas imagens de incisivos inferiores de 100 pacientes, cujos exames estavam disponíveis no banco de dados do tomógrafo i-CAT Classic da FOB-USP. Dois examinadores avaliaram a anatomia interna de incisivos inferiores, em reconstruções axiais, sagitais e coronais, classificando-a de acordo com o número de canais radiculares. A prevalência de 2 canais radiculares foi relacionada à localização do dente e ao gênero e idade do paciente. Para descrição dos dados coletados, utilizou-se a porcentagem (\%). Para verificar a associação entre variáveis, utilizou-se o teste do qui-quadrado $\left(\chi^{2}\right)$, com nível de significância estatística de $5 \%$. Para a concordância intra e interexaminador, utilizou-se o teste de kappa. 

Como resultado da primeira etapa da pesquisa, obteve-se alto índice de detecção de tipos anatômicos para todos os métodos avaliados $(p<0,05)$. Para dentes com Tipo I (1 canal radicular regular), as imagens de TCFC foram superiores em comparação à radiografia periapical digital com dupla exposição ( $\mathrm{RP}=67 \%$ de acerto; TCFC $=98 \%$ de acerto, $p<0,05$ ). Considerando os 3 aparelhos de TCFC, não houve diferença estatística significante entre eles para identificação do Tipo I. Já para dentes com Tipo la (1 canal radicular oval), houve diferença estatística significante somente entre radiografia periapical digital com dupla exposição e o tomógrafo NewTom (RP $=44 \%$ de acerto; TCFC NewTom $=88 \%$ de acerto). Não houve diferença significante entre os outros 2 tomógrafos e radiografia periapical ou entre os 3 tomógrafos. Considerando dentes com Tipo III (2 canais radiculares), não houve diferença estatística significante entre nenhum dos métodos. Todos os métodos apresentaram números de respostas certas semelhantes para o Tipo III, sugerindo que a radiografia periapical com dupla angulação é suficiente para identificação de 2 canais radiculares em incisivos inferiores. A concordância intraexaminador para radiografia periapical foi regular (kappa $=0,40$ a 0,66 ) e de boa a excelente para os aparelhos de TCFC (kappa=0,62 a 0,85). A concordância interexaminador para radiografia periapical foi de ruim a regular (kappa $=0,25$ a 0,32) e de boa a excelente para os aparelhos de TCFC (kappa $=0,62$ a 0,92). Na segunda etapa da pesquisa, o total de 386 incisivos inferiores foi avaliado, sendo 192 incisivos centrais e 194 incisivos laterais. A prevalência de 2 canais radiculares constatada no total de dentes foi de $16,5 \%$, sendo de $13 \%$ em incisivos centrais e de $20 \%$ nos incisivos laterais ( $p>0,05$ ). Não houve diferença estatisticamente significante entre gêneros e idades. A concordância intra e interexaminador foi regular (kappa intra $=0,60$; kappa inter $=0,57$ ). Como conclusão da primeira etapa da pesquisa, observou-se que a identificação do número de canais radiculares foi efetiva em todos os métodos. No entanto, limitações foram encontradas para a diferenciação da forma do canal radicular. Na segunda etapa da pesquisa, concluiuse que a presença de 2 canais radiculares em incisivos inferiores de pacientes da região de Bauru é de aproximadamente $20 \%$ e não depende da localização do dente ou de gênero e idade do paciente.

Palavras-chave: Incisivos inferiores. Radiografia periapical. Tomografia computadorizada de feixe cônico. Microtomografia computadorizada. Variação anatômica. 



$$
\text { (I) }
$$





\section{ABSTRACT \\ Identification of two root canals in mandibular incisors using radiographic, tomographic and microtomographic images}

Mandibular incisors most commonly have a single root canal, which can present with different anatomic configurations. According to the literature, the presence of a second root canal can be observed in $10-40 \%$ of the teeth. Difficulty in detecting the second root canal is an important factor for the endodontic treatment failure. The aim of this research was: 1) to compare the efficacy of digital periapical radiography (PA) with double exposure and cone beam computed tomography (CBCT) in the identification of internal anatomic patterns in mandibular incisors, and 2) to determine the prevalence of 2 root canals in mandibular incisors using cone beam computed tomographic images of a patient database, comparing to tooth position and patient's gender and age. In the first part of this research, 40 extracted mandibular incisors underwent microcomputed tomographic (micro-CT) scanning (Skyscan 1074) in order to establish the gold standard for internal anatomic pattern. The teeth were classified according to: Type I ( 1 regular root canal, $n=12)$, Type la ( 1 oval root canal, $n=12$ ), and Type III (2 root canals, $n=16$ ). Then, the teeth were divided into 10 groups of 4 teeth and placed in a preserved human mandible for direct digital periapical radiographic double exposure (Schick CDR) and CBCT scans using Kodak 9000 3D, Veraviewepocs 3De and NewTom 5G. Two blinded examiners classified the anatomic pattern of each tooth and their answers were compared to the gold standard (microtomographic images). Percentage (\%) of right / wrong answers was used for the statistical analysis of the results. Chi-square test $\left(\chi^{2}\right)$ was used to verify the association between variables $(p<.05)$. Inter and intraexaminer agreements were determined using kappa values. In the second part of this research, CBCT images of a 100 patients' database from FOB-USP were examined. Two examiners assessed the internal anatomy of mandibular incisors in axial, sagittal and coronal reconstructions and classified the teeth according to the number of root canals. The prevalence of 2 root canals was related to the tooth location and patient's gender and age. Percentage (\%) was used to describe the collected data. Chi-square test $\left(\chi^{2}\right)$ was used to verify the association between variables $(p<.05)$. Inter and intraexaminer agreements were determined using kappa values. The results of the first part of the research showed a high level of identification of anatomic patterns for all the methods $(p<0.05)$. Considering Type I $(1$ regular root canal), CBCT images were better in comparison to PA (PA=67\%; CBCT $=98 \%, p$ $<0.05)$. There was no significant difference between the 3 CBCT scanners. For Type la (1 oval root canal), there was a significant difference between PA and CBCT 

imaging using the NewTom unit only (PA= 44\%, NewTom CBCT=88\%). No significant differences were found between the other 2 СВCT units and PA or between the 3 CBCT units. Considering Type III (2 root canals), there was no significant difference between the various methods. All the methods presented similar corrected answers index for Type III, which may suggest that PA with double exposure is sufficient for the identification of 2 root canals in mandibular incisors. The intraexaminer agreement was fair for PA (kappa $=0.40$ to 0.66 ) and good to very good for the CBCT units (kappa $=0.62$ to 0.85 ). The interexaminer agreement was poor to fair for PA (kappa $=0.25$ to 0.32 ) and good to very good for CBCT units (kappa $=0.62$ to 0.92 ). In the second part of this research, the total amount of 386 mandibular incisors was assessed in CBCT images (192 mandibular central incisors and 194 mandibular lateral incisors). The overall prevalence of 2 root canals was $16.5 \%$, and $13 \%$ in mandibular central incisors and $20 \%$ in mandibular lateral incisors $(p>0.05)$. There was no significant difference between gender and age. The intra and interexaminer agreement was fair (kappa intra $=0.60$; kappa inter $=0.57$ ). For the first part of this research, it is possible to conclude that the identification of the number of root canals was effective using all the methods. However, limitations were found in differentiating the shape of the root canal. As a conclusion of the second part of this research, the presence of 2 root canals in mandibular incisors of Bauru region patients is approximately $20 \%$ and it does not depend on tooth location or patient's gender and age.

Key words: Mandibular incisor. Periapical radiography. Cone beam computed tomography. Micro-computed tomography. Anatomic variation. 



\section{LISTA DE ILUSTRAÇÕES}

- FIGURAS

Figura 1: Exemplo de marcação feita em incisivo inferior da amostra.

Figura 2: Microtomógrafo Skyscan 1074. 62

Figura 3: Esquema representativo das configurações do sistema de canais radiculares propostas por Vertucci, com destaque para os padrões encontrados em incisivos inferiores.

Figura 4: Imagens de micro-TC de vistas em sentido coronal, sagital e axial, respectivamente, de 3 incisivos inferiores da amostra, ilustrativos do critério adotado para determinação dos 3 padrões anatômicos. As imagens axiais são dos terços cervical (c), médio $(\mathrm{m})$ e apical (a). (A) Tipo I corresponde a um dente com 1 canal radicular regular, (B) Tipo la corresponde a um dente com 1 canal radicular oval, e (C) Tipo III corresponde a um dente com 2 canais radiculares.

Figura 5: (A) Representação da mandíbula e dos alvéolos correspondentes ao dentes $42,41,31$ e 32 , nos quais os incisivos da pesquisa foram posicionados para obtenção de imagens ( $d=$ lado direito; e=esquerdo). (B) Esquema representativo dos 10 grupos de 4 dentes, indicando a posição pré-determinada de cada dente: círculos verdes (dentes tipo I); círculos azuis (dentes tipo la); círculos vermelhos (dentes tipo III).

Figura 6: Posicionamento da mandíbula com os incisivos para tomada radiográfica periapical digital direta.

Figura 7: Posicionamento da mandíbula com os incisivos para escaneamento nos aparelhos de TCFC: (A) Kodak 9000 3D; (B) Veraviewepocs 3De; (C) NewTom 5G.

Figura 8: Exemplo de parte da planilha Excel com o "gabarito", ilustrando que os dentes da amostra receberam identificações diferentes em cada imagem e a ordem de análise foi variada para não haver memorização. 

Figura 9: (A) Imagens radiográficas com identificação da ordem de análise; (B) Folha de respostas distribuída aos examinadores para que apontassem o tipo anatômico que julgavam correto ao ver imagens radiográficas de cada dente.

Figura 10: Exemplo de telas dos programas de cada aparelho de TCFC: (A) software CS 3D (Kodak); (B) software One Volume Viewer (Veraviewepocs); (C) software NNT Viewer (NewTom).

Figura 11: Exemplo de parte da tabela Excel criada para avaliação de resultados: "MET": identificação do dente no referido método; "TIPO 1" : resposta do avaliador na primeira avaliação de imagens daquele método; "C/E $1^{\text {a" }}$ : resposta do examinador na primeira avaliação de acordo com o padrão ouro ("C"- certa) ou não correspondente ao padrão ouro ("E"- errada); "TIPO $2^{\text {a": }}$ resposta do avaliador na segunda avaliação de imagens daquele método; "C/E $2^{\mathrm{a}}$.": resposta do examinador na segunda avaliação de acordo com o padrão ouro ("C"- certa) ou não correspondente ao padrão ouro ("E"- errada); "PADRÂO OURO": classificação anatômica determinada nas imagens de micro-TC.

Figura 12: Tela "preview screen" do programa i-CAT Vision................................75

Figura 13: Imagens representativas das reformatações nas quais os dentes foram avaliados.

Figura 14: Imagens representativas dos tipos anatômicos considerados nessa etapa da pesquisa. Vista axial: (A) 4 incisivos com 1 canal radicular; (B) 3 incisivos com 1 canal radicular e 1 incisivo com 2 canais (apontado pela seta); (C) 4 incisivos com 2 canais radiculares. Vista sagital: (D) incisivo com 1 canal radicular; (E) incisivo com 2 canais radiculares. 

- GRÁFICOS

Gráfico 1 - Respostas certas e erradas em relação ao Tipo I.

Gráfico 2 - Respostas certas e erradas em relação ao Tipo la.

Gráfico 3 - Respostas certas e erradas em relação ao Tipo III. 84

Gráfico 4 - Prevalência de 1 ou 2 canais em incisivos centrais inferiores da amostra.

Gráfico 5 - Prevalência de 1 ou 2 canais em incisivos laterais inferiores da amostra. 



\section{LISTA DE TABELAS}

Tabela 1 - Comparação entre os métodos para identificação do Tipo I: total de respostas corretas por avaliador.

Tabela 2 - Comparação entre os métodos para identificação do Tipo la: total de respostas corretas por avaliador.

Tabela 3 - Comparação entre os métodos para identificação do Tipo III: total de respostas corretas por avaliador.

Tabela 4 - Concordância intraexaminador. 85

Tabela 5 - Concordância interexaminador. 85

Tabela 6 - Distribuição numérica e percentual de incisivos centrais inferiores, em relação a tipos anatômicos. 86

Tabela 7 - Distribuição numérica e percentual de incisivos laterais inferiores, em relação a tipos anatômicos. 86

Tabela 8 - Distribuição percentual de incisivos centrais e laterais inferiores em relação a tipos anatômicos e gênero dos pacientes.

Tabela 9 - Distribuição percentual de incisivos centrais inferiores em relação a tipos anatômicos e idade dos pacientes.

Tabela 10 - Distribuição percentual de incisivos laterais inferiores em relação a tipos anatômicos e idade dos pacientes.

Tabela 11 - Concordâncias intra e interexaminador. 



\section{LISTA DE ABREVIATURAS, SIGLAS E SÍMBOLOS}

\begin{tabular}{ll} 
RP & Radiografia Periapical \\
TC & Tomografia Computadorizada \\
TCFC & Tomografia Computadorizada de Feixe Cônico \\
Micro-TC & Microtomografia computadorizada \\
FOV & Campo de visão (Field of View) \\
Voxel & Elemento de imagem volumétrico (Volumetric Picture Element) \\
Pixel & Elemento de imagem (Picture Element) \\
MPR & Reformatação multiplanar (Multiplanar reconstruction) \\
3D & Tridimensional \\
ALARA & Tão baixo quanto razoavelmente exequível (As Low As Reasonably \\
Achievable) & \\
FOB & Faculdade de Odontologia de Bauru \\
USP & Universidade de São Paulo \\
Tipo I & 1 canal radicular regular \\
Tipo la & 1 canal radicular oval \\
Tipo III & 2 canais radiculares \\
$\mathrm{s}$ & segundos \\
cm & centímetros \\
mm & milímetros \\
\hline & maior \\
p & maior e igual \\
\hline & menor \\
\hline & tamanho da amostra \\
\hline &
\end{tabular}





\section{SUMÁRIO}

1 INTRODUÇÃO

21

2 REVISÃO DE LITERATURA

2.1 Anatomia interna dos incisivos inferiores permanentes ............................... 31

2.2 Variações anatômicas internas e implicações clínicas .................................. 38

2.3 Considerações sobre tomadas radiográficas periapicais............................41

2.4 Considerações sobre tomografia computadorizada de feixe

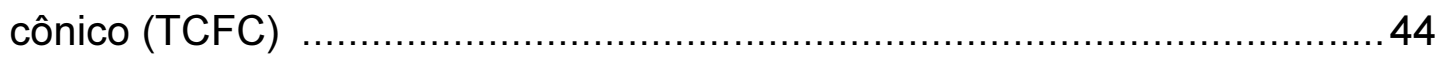

2.5 Considerações sobre microtomografia computadorizada ...........................50

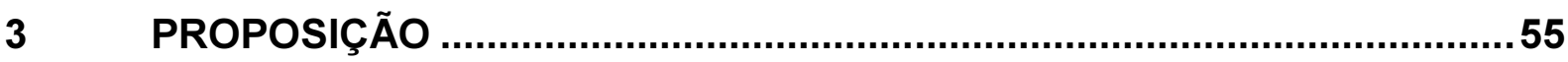

$4 \quad$ METODOLOGIA

4.1 PRIMEIRA ETAPA DA PESQUISA: Identificação de padrões da anatomia interna de incisivos inferiores extraídos utilizando imagem radiográfica periapical digital e imagem obtida por tomografia computadorizada de feixe cônico.

4.1.1 Seleção da amostra / estabelecimento do padrão ouro (micro-TC) 61

4.1.2 Divisão dos grupos de dentes da amostra. 64

4.1.3 Tomadas radiográficas periapicais digitais 65

4.1.4 Escaneamentos em aparelhos de tomografia computadorizada de feixe cônico (TCFC) 66

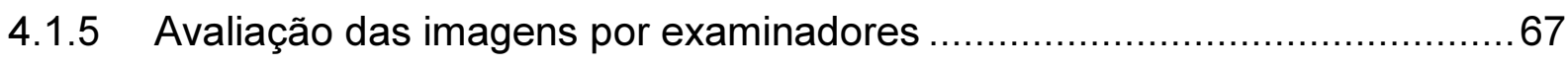

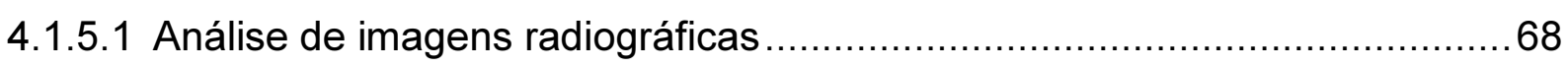

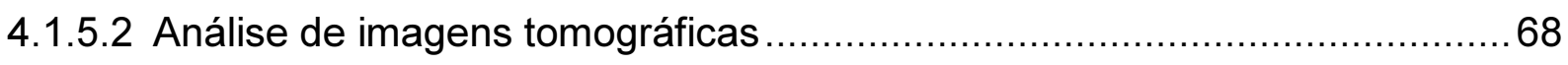

4.1.6 Comparação ao padrão ouro e análise dos resultados .............................73 

4.2 SEGUNDA ETAPA DA PESQUISA: Determinação da prevalência de 2 canais radiculares em incisivos inferiores de pacientes da FOB-USP no banco de imagens de tomografia computadorizada de feixe cônico 74

4.2.1 Seleção da amostra / critérios de inclusão ........................................ 74

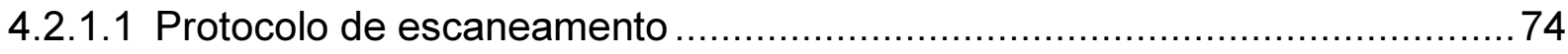

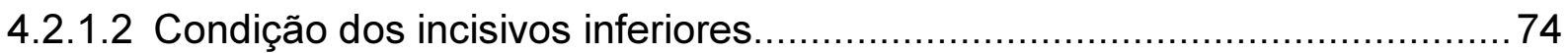

4.2.2 Registro dos dados e interpretação das imagens ................................ 75

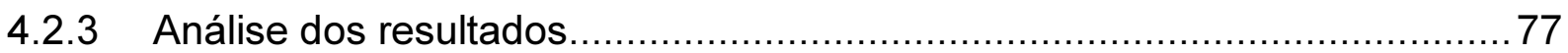

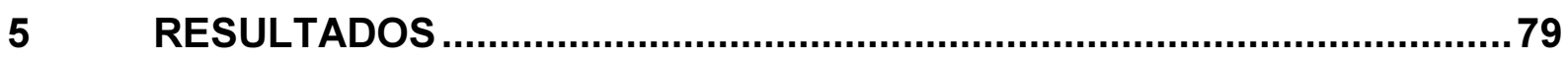

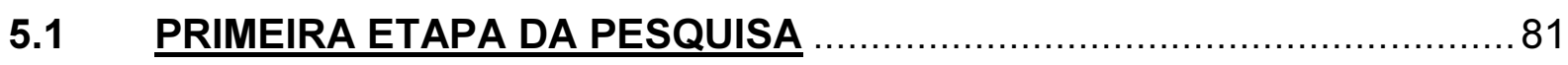

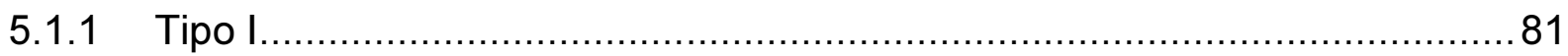

5.1 .2 Tipo la

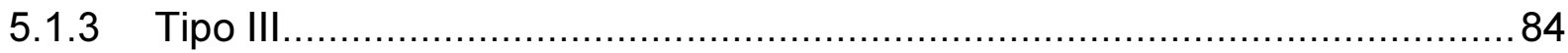

5.1.4 Concordância entre avaliações ................................................. 85

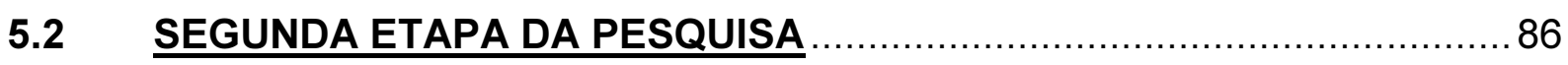

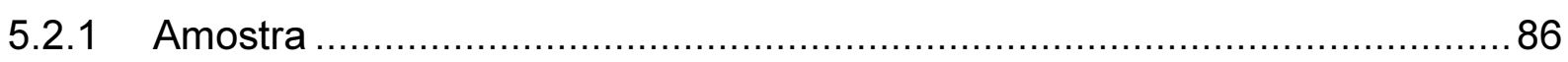

5.2.2 Prevalência de incisivos inferiores com 1 ou 2 canais radiculares em relação à localização do dente.

5.2.3 Prevalência de incisivos inferiores com 1 ou 2 canais radiculares em relação a gênero

5.2.4 Prevalência de incisivos inferiores com 1 ou 2 canais radiculares em relação à idade. 88

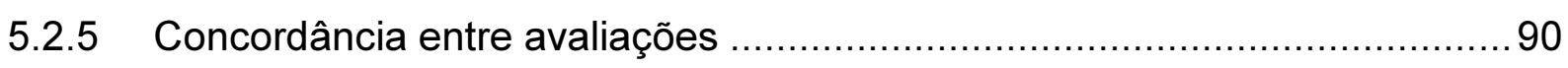

6 DISCUSSÃO .................................................................................. 91

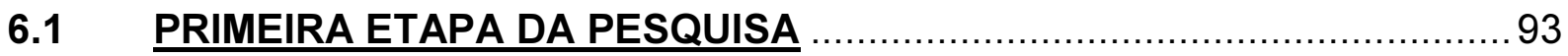

6.1.1 Anatomia interna dos incisivos inferiores e suas implicações clínicas. 93

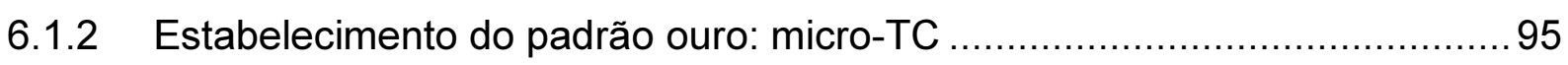

6.1.3 Posicionamento dos dentes para tomadas radiográficas e escaneamentos tomográficos. 

6.1.4 Tomadas radiográficas digitais com diferentes angulações horizontais

6.1.5 Escaneamentos em tomógrafos computadorizados de feixe cônico 98

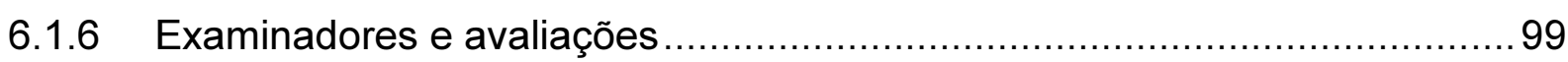

6.1.7 Detecção dos padrões anatômicos internos ..............................................99

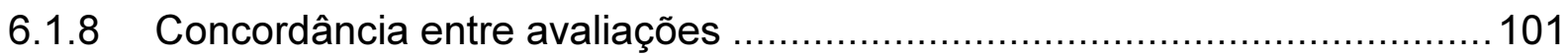

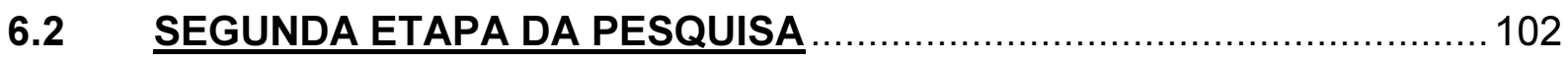

6.2.1 Seleção da amostra de exames / critérios de inclusão............................102

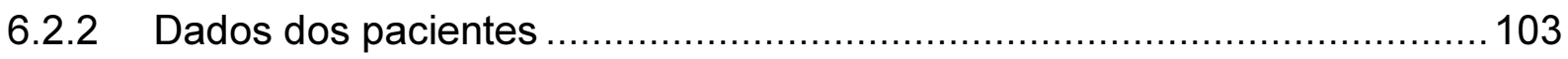

6.2.3 Prevalência de 2 canais radiculares em relação à localização

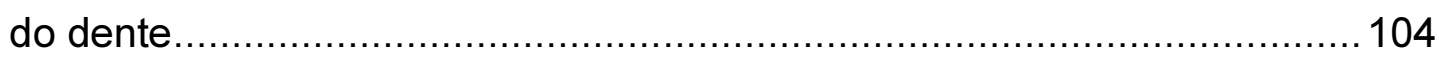

6.2.4 Prevalência de 2 canais radiculares em relação a gênero ........................ 106

6.2.5 Prevalência de 2 canais radiculares em relação à idade......................... 106

6.2.6 Concordância entre avaliações ................................................... 107

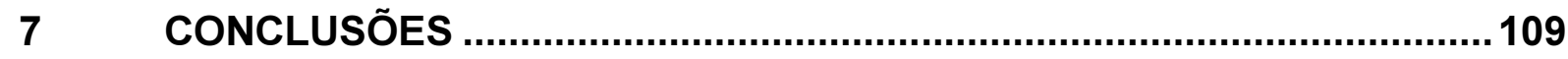

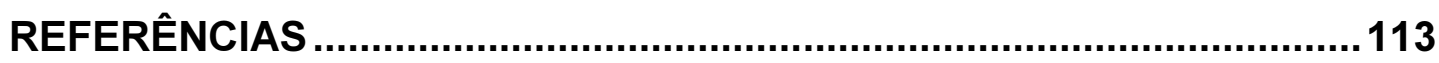

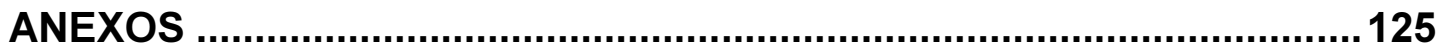





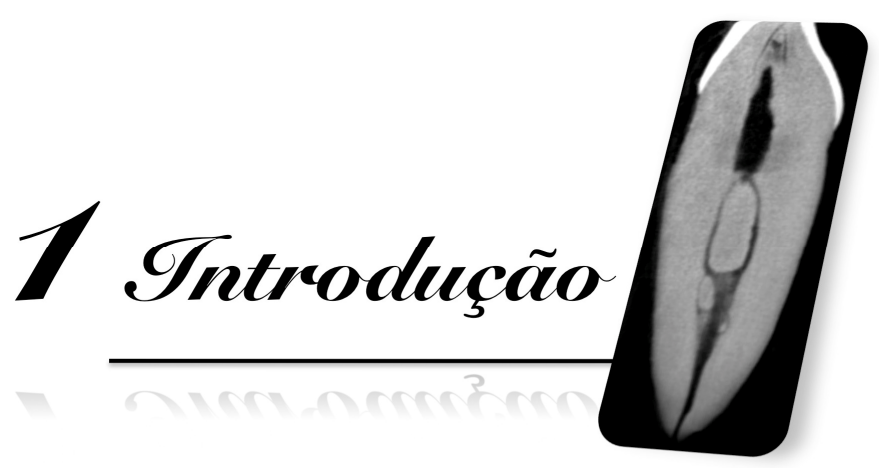





\section{INTRODUÇÃO}

O tratamento do sistema de canais radiculares dos dentes engloba várias etapas, que devem ser realizadas de forma adequada, a fim de promover cura e reparo da região periapical, previamente afetados por processos patológicos (CARROTTE, 2004a; NAIR, 2004). O entendimento da arquitetura dos dentes e do sistema de canais radiculares é um pré-requisito essencial para o êxito do tratamento endodôntico (CARROTTE, 2004b). O cirurgião-dentista necessita conhecer profundamente a anatomia interna de todos os grupos dentários, com o propósito de realizar eficaz abertura coronária e acesso aos canais radiculares para limpeza, modelagem e posterior obturação. É sabido que variações anatômicas do endodonto também podem ser encontradas no cotidiano da clínica odontológica e o reconhecimento das mesmas é muito importante (LOUSHINE; JURCAK; JEFFALONE, 1993; FUNATO; FUNATO; MATSUMOTO, 1998; TIKU; KALASKAR; DAMLE, 2005; VERTUCCI, 2005; KABAK; ABBOTT, 2007). Para isso, é fundamental que a avaliação prévia à abertura coronária seja bem executada, com uso de métodos por imagem confiáveis.

Os incisivos centrais e laterais inferiores apresentam morfologia semelhante (LEONI et al., 2013) e possuem, na maioria dos casos, um único canal radicular (HESS, 1925; VERTUCCI, 1984). No entanto, variações anatômicas de forma e de número de canais radiculares nesse grupo dentário podem ser observadas (WU et al., 2000). A presença de canal radicular com forma ovalada ou achatada nos incisivos inferiores promove dificuldade nas etapas de limpeza, modelagem e obturação do tratamento endodôntico, o que pode comprometer o sucesso do mesmo (WU; WESSELINK, 2001; BARBIZAM et al., 2002; WEIGER, ELAYOUTI, LÖST, 2002; DE-DEUS et al., 2008; ALVES et al., 2011). Já a presença de um segundo canal radicular pode ser observada em 10 a $43 \%$ dos dentes, de acordo com a literatura (HESS, 1925; PINEDA; KUTTLER, 1972; GREEN, 1973; MADEIRA; HETEM, 1973; BENJAMIN; DOWSON, 1974; WARREN; LAWS, 1981; VERTUCCI, 1984; KAFFE et al., 1985; PÉCORA; SAVIOLI; MURGEL, 1990; KARTAL; YANIKOGLU, 1992; CALISKAN et al., 1995; MIYASHITA et al., 1997; AL-QUDAH; AWAWDEH, 2006; BORUAH; BHUYAN, 2011; LIN et al., 2014; LIU et al. 2014). O 
fracasso do tratamento endodôntico em incisivos inferiores está relacionado principalmente à não-detecção do segundo canal radicular (FUNATO; FUNATO; MATSUMOTO, 1998; TIKU; KALASKAR; DAMLE, 2005). A falta de instrumentação ou de obturação do canal supranumerário permite que microorganismos se instalem ou permaneçam no sistema de canais radiculares, perpetuando o processo patológico do dente (BENJAMIN; DOWSON, 1974; NAIR, 2004).

A radiografia periapical (RP) é o método mais utilizado para avaliação dos dentes e do periápice. É uma técnica de fácil e rápida execução, que promove baixa dose de radiação e que traz pouco desconforto ao paciente. Além disso, a interpretação radiográfica é mais simples do que a interpretação em métodos mais avançados de imagem (NAIR; NAIR, 2007). Atualmente, a radiografia periapical pode ser obtida pelo método convencional ou pelos métodos digitais, sendo que esses dispensam a utilização de filmes e a necessidade de processamento, uma vez que se utilizam de sensores conectados diretamente a um computador (sistema direto) ou placas de fósforo que, posteriormente, são colocadas em um scanner específico (sistema indireto). Os métodos digitais trazem como principais vantagens: rapidez, melhor qualidade da imagem e redução da dose de radiação (NAIR; NAIR, 2007, TEWARY; LUZZO; HARTWELL, 2011).

A radiografia periapical é o recurso de imagem adotado antes, durante e após o tratamento endodôntico, na medida em que permite a visualização do sistema de canais radiculares previamente à abertura coronária e exploração clínica; serve como guia para determinação do comprimento real de instrumentação e é referência para a proservação do dente tratado (FAVA; DUMMER, 1997). Nas pesquisas sobre anatomia dentária, a radiografia tem sido empregada para avaliação do sistema de canais radiculares quanto à prevalência de múltiplos canais, à presença de ramificações de canais principais, à localização do forame apical (BENJAMIN; DOWSON, 1974; KAFFE et al., 1985; NATTRESS; MARTIN, 1991; KLEIN et al., 1997; MAUGER et al., 1999; MARTÍNEZ-LOZANO; FORNER-NAVARRO; SÁNCHEZ-CORTÉS, 1999; DE OLIVEIRA et al., 2009), bem como para mensuração da curvatura de canais radiculares (WILLERSHAUSEN et al., 2008; ZHENG et al., 2009). 
No entanto, as imagens radiográficas convencionais ou digitais permitem a visualização em 2 dimensões de uma estrutura tridimensional (TYNDALL; RATHORE, 2008; PATEL et al., 2009; ÖZEN et al., 2009). Por esse motivo, há sobreposição de estruturas anatômicas, bem como falta de informação no plano vestíbulo-lingual (YOSHIOKA et al., 2011). Outras desvantagens das imagens bidimensionais são a magnificação e a distorção das estruturas a serem avaliadas (SCARFE; FARMAN, 2008; PATEL et al., 2009). Em relação à anatomia dentária interna, sabe-se que o sistema de canais radiculares é complexo e tridimensional. As imagens radiográficas oferecem informação limitada sobre as características dos canais de um dente, pois não há visualização do plano transversal. Além disso, em dentes multirradiculados ou que apresentem múltiplos canais radiculares, frequentemente ocorre sobreposição de raízes e de canais, dificultando a interpretação da anatomia do dente e de suas possíveis variações (DOMARK et al., 2013). A fim de minimizar essas desvantagens, autores recomendam que sejam feitas de 2 a 3 tomadas radiográficas do dente a ser analisado, com diferentes angulações horizontais de incidência da radiação $X$. Dessa forma, o profissional tem melhores condições de avaliar o dente em questão, principalmente por dissociar raízes e canais radiculares que possam estar sobrepostos na imagem radiográfica ortorradial (CLARK, 1910; KAFFE et al., 1985; NATTRESS; MARTIN, 1991; KLEIN et al., 1997; MARTÍNEZ-LOZANO; FORNER-NAVARRO; SÁNCHEZ-CORTÉS, 1999; VERTUCCI, 2005; DE OLIVEIRA et al., 2009; DOMARK et al., 2013).

A tomografia computadorizada de feixe cônico (TCFC), também conhecida como tomografia computadorizada cone beam é um recurso diagnóstico moderno, cada vez mais utilizado em Odontologia, que apresenta vantagens em relação aos exames radiográficos convencionais (COTTON et al., 2007; HOWERTON; MORA, 2008). A TCFC é útil para os mais variados propósitos, tais como: avaliação da quantidade e qualidade óssea para colocação de implantes (SCARFE; FARMAN, 2008; HOWERTON; MORA, 2008); planejamento de tratamentos ortodônticos e cirurgias ortognáticas (GARIB et al., 2007; HANS; VALIATHAN; PALOMO, 2011); estudo de lesões no complexo maxilo-mandibular (PAES DA SILVA RAMOS FERNANDES et al., 2013) e de dentes retidos, supranumerários e terceiros molares com indicação para extração; avaliação de fraturas, reabsorções internas ou externas (MAINI; DURNING; DRAGE, 2008), entre outros. A principal vantagem da 
TCFC é a possibilidade de avaliação das regiões de interesse em 3 planos, simultaneamente, sem presença de sobreposições e com ótima qualidade de imagem (MICHETTI et al., 2010). As reconstruções ilustrativas em 3D também são de grande utilidade e permitem avaliação suplementar da área de interesse de forma interativa (COTTON et al., 2007; PATEL et al., 2007; SHERRARD et al., 2010; TYNDALL; KOHLTFARBER, 2012).

Ao realizar-se o exame de TCFC, o protocolo de escaneamento deve ser selecionado, sendo composto por 3 parâmetros: FOV (do inglês, Field of View) ou campo de visão $(\mathrm{em} \mathrm{cm})$, tamanho de voxel (do inglês, Volumetric Picture Element, em $\mathrm{mm}$ ) e tempo (em s). O protocolo a ser escolhido depende principalmente do tamanho da região que se deseja examinar e do grau de qualidade da imagem que se pretende obter (HASSAN et al., 2012). O campo de visão ou FOV corresponde ao tamanho máximo da região a ser escaneada, sendo o volume de dados capturados pelo feixe cônico de raios $X$ (PATEL et al., 2007). Assim, os tomógrafos apresentam diferentes FOVs, tais como: localizado $(5 \mathrm{~cm})$; para um arco dentário $(5$ a $7 \mathrm{~cm})$; para ambos arcos dentários (7 a $10 \mathrm{~cm}$ ); para região maxilofacial (10 a $15 \mathrm{~cm})$ e para a região craniofacial $(>15 \mathrm{~cm}$ ) (SCARFE; FARMAN, 2008). Voxel é a menor unidade da imagem na espessura do corte, arranjado em uma matriz tridimensional. Cada voxel é caracterizado com altura, largura e profundidade (KAU et al., 2009), equivalente ao pixel com terceira dimensão (COTTON et al., 2007; PATEL et al., 2007). Quanto menor o voxel, melhor a qualidade da imagem. No entanto, o tempo de escaneamento e de reformatação também é maior. A TCFC é capaz de captar a imagem em volume da região de interesse em uma única rotação (PATEL et al., 2009; DE VOS; CASSELMAN; SWENNEN, 2009). A fonte de radiação e o detector giram em torno de um fulcro fixado no centro da região de interesse. Durante essa rotação, reformatações multiplanares (MPR) são obtidas. Como a TCFC engloba o FOV inteiro em apenas uma rotação, a dose de radiação e o tempo de exame são muito menores em relação a outras tecnologias de TC (SCARFE; FARMAN, 2008; KAU et al., 2009; DE VOS; CASSELMAN; SWENNEN, 2009; TYNDALL; KOHLTFARBER, 2012; LI, 2013). O exame de TCFC é de fácil execução e oferece comodidade ao paciente (PATEL et al., 2007). 
Porém, a TCFC também apresenta desvantagens, tais como a presença de artefatos resultantes de objetos metálicos em suas imagens (KATSUMATA et al., 2006; PATEL, 2009) e custo e dose de radiação elevados em comparação a exames radiográficos convencionais (LUDLOW et al., 2006; SCARFE; FARMAN, 2008; TYNDALL; KOHLTFARBER, 2012; LI, 2013). Em função da radiação ionizante, esse exame deve ser prescrito criteriosamente. É essencial manter a exposição à radiação no nível mais baixo possível (princípio ALARA- As Low As Reasonably Achievable) (PATEL et al., 2007; PAUWELS et al., 2012). Para interpretação das imagens de TCFC requer-se amplo conhecimento dos reparos anatômicos do complexo maxilo-facial e entendimento das estruturas visualizadas por meio de reconstruções em distintos planos (SCARFE; FARMAN; SUKOVIC, 2006; COTTON et al., 2007; HOWERTON; MORA, 2008). Diferentemente da TC utilizada em Medicina, essa tecnologia não permite a observação de tecidos moles (COTTON et al., 2007; SCARFE; FARMAN, 2008; DE VOS et al., 2009; KAU et al., 2009). Em virtude do custo dos tomógrafos, o acesso a essa nova tecnologia ainda é restrito, sobretudo em países menos desenvolvidos.

A TCFC também pode ser utilizada na avaliação da morfologia do sistema de canais radiculares, quer seja no âmbito clínico ou de pesquisa (SOMMA et al., 2009; LA et al., 2010; MICHETTI et al., 2010; WANG et al., 2010; LEE et al., 2011; CONNERT et al., 2013; JUNQUEIRA et al., 2013; LIANG et al., 2013; YANG et al., 2013; LIN et al., 2014; LIU et al., 2014). Alguns autores constataram a superioridade da TCFC em relação às imagens radiográficas para detecção de canais radiculares (MATHERNE et al., 2008; BLATTNER et al., 2010; NEELAKANTAN; SUBBARAO; SUBBARAO, 2010; DOMARK et al., 2013), uma vez que a TCFC fornece maior riqueza de informações. É importante destacar que a TCFC não pretende substituir a radiografia convencional ou digital, mas servir como coadjuvante na aquisição de informação adicional para o diagnóstico (COTTON et al., 2007; TYNDALL; RATHORE, 2008). Para avaliação da morfologia dos canais radiculares de um dente, o uso do protocolo de escaneamento com FOV localizado (de até $5 \mathrm{~cm}$ ) é recomendado (HASSAN et al., 2012). Dessa forma, apenas a região de interesse restrita será irradiada, evitando exposição desnecessária e respeitando o princípio ALARA (PAUWELS et al., 2012). 
A microtomografia computadorizada (micro-TC) é uma ferramenta avançada para pesquisas científicas, que vem sendo cada vez mais utilizada para avaliação da anatomia dentária (PETERS et al., 2000; GUILLAUME et al., 2006; SOMEDA et al., 2009; SOMMA et al., 2009; YAMADA et al., 2011; VILLAS-BÔAS et al., 2011; LEONI et al., 2013; MARCA et al., 2013; MILANEZI DE ALMEIDA et al., 2013; ORDINOLAZAPATA et al., 2013). Essa tecnologia moderna permite a reconstrução tridimensional precisa da morfologia externa e interna do dente (GRANDE et al., 2012; ORDINOLA-ZAPATA et al., 2013), bem como o estudo in vitro do sistema de canais radiculares de maneira qualitativa e quantitativa (LEONI et al., 2013). O tamanho de voxel de imagens microtomográficas é muito menor do que o de imagens de TCFC, promovendo maior resolução e qualidade da imagem. Entretanto, essa tecnologia consome muito tempo de escaneamento e promove alta dose de radiação, não sendo aplicável para uso em pacientes ou em pesquisas clínicas (SWAIN; XUE, 2009; MICHETTI et al., 2010). A micro-TC é uma ferramenta que utiliza técnica não-destrutiva da amostra, o que é uma vantagem em relação a outras técnicas para estudo de anatomia dentária mencionadas na literatura, tais como diafanização ou secção macroscópica (GUILLAUME et al., 2006). Os autores apontam que essa tecnologia é promissora e será cada vez mais adotada como padrão ouro nos estudos laboratoriais da anatomia dentária (SWAIN; XUE, 2009) e como ferramenta para treinamento pré-clínico (GRANDE et al., 2012). 
2 Revisão de Siteratura 



\section{REVISÃO DE LITERATURA}

A revisão de literatura apresenta-se subdividida em temas, bem como em ordem cronológica de publicação dos artigos pesquisados.

\subsection{Anatomia interna dos incisivos inferiores permanentes}

Ao longo dos anos, muitos estudos foram realizados com o objetivo de descrever aspectos da anatomia interna dos incisivos inferiores, tais como número de canais radiculares e seus tipos, presença de ramificações do canal principal e localização do forame apical. Diferentes métodos para observação in vitro e in vivo da anatomia dentária interna foram utilizados, tais como diafanização, secção macroscópica, radiografias e, mais recentemente, tomografia computadorizada de feixe cônico (TCFC) e microtomografia computadorizada (micro-TC). Os autores mostram seus achados e concluem que os incisivos inferiores podem apresentar variações anatômicas importantes, sobre as quais o profissional deve ter conhecimento, a fim de realizar acesso, limpeza, modelagem e obturação adequados dos canais radiculares nesse grupo dentário. De acordo com Jou et al. (2004), o conhecimento da morfologia do canal radicular é parte crítica e fundamental do tratamento endodôntico convencional e cirúrgico.

Hess (1925), em um estudo clássico sobre o sistema de canais radiculares, utilizou a diafanização para avaliar a anatomia interna de 2.789 dentes extraídos de todos os grupos dentários. Considerando os incisivos inferiores, o autor não fez distinção entre incisivo central e lateral, tendo avaliado o total de 136 dentes desse grupo. A presença de bifurcação do canal radicular principal foi observada em $37,6 \%$ dos incisivos.

Pineda e Kuttler (1972) avaliaram radiografias de 4.183 dentes extraídos, tomadas em sentido mésio-distal e vestíbulo-lingual, a fim de estudar: o número de canais radiculares e suas divisões em cada raiz de cada tipo de dente, a influência da idade no aspecto do canal radicular, as curvaturas dos canais radiculares, as 
ramificações do canal principal, a localização de forame apical e a frequência de deltas apicais. Do total de incisivos inferiores avaliados, 179 eram incisivos centrais e 184 eram laterais. A presença de 2 canais radiculares foi observada em $27,6 \%$ dos incisivos centrais e em $23,8 \%$ dos incisivos laterais. A imensa maioria dos dentes apresentava apenas 1 forame apical (97,9\% e 98,7\%, em incisivos centrais e laterais, respectivamente). Em relação à idade, os autores concluíram que pacientes mais velhos apresentam redução do diâmetro dos canais radiculares.

Green (1973) seccionou longitudinalmente 1.300 dentes de vários grupos dentários para estudo da morfologia do canal radicular. O autor avaliou 500 incisivos inferiores, sem diferenciar centrais de laterais, e encontrou $79 \%$ de canais únicos. A prevalência de dois canais principais foi de $21 \%$.

Madeira e Hetem (1973) realizaram estudo sobre a presença de bifurcações em canais radiculares de incisivos inferiores permanentes. Para isso, avaliaram 1.333 dentes extraídos diafanizados. Os autores encontraram $11 \%$ de dentes com 2 canais radiculares que terminavam em forame apical único, e apenas 0,5\% com bifurcações completas, ou seja, com 2 canais radiculares terminando em forames apicais distintos.

Benjamin e Dowson (1974) avaliaram 364 incisivos inferiores permanentes extraídos. Sondas foram colocadas no interior dos canais para determinação da incidência de 2 canais radiculares principais nos dentes avaliados, que, em seguida, foram radiografados. Os autores tiveram como resultado que 41,4\% da amostra apresentava 2 canais radiculares com 1 forame apical. Apenas 1,3\% da amostra apresentava 2 canais com 2 forames apicais distintos. Os autores ressaltam a necessidade de identificar e tratar o segundo canal, a fim de que restos de polpa necrótica não permaneçam no interior do dente.

Warren e Laws (1981) realizaram estudo para determinar se havia relação entre o tamanho da coroa dentária e a presença de canais bífidos no interior da raiz de incisivos inferiores. Para isso, avaliaram 286 dentes, sendo 172 incisivos centrais e 114 incisivos laterais, que foram medidos e radiografados. Os autores encontraram canais bífidos em $43 \%$ dos incisivos centrais e em $35,9 \%$ dos incisivos laterais. No total, a prevalência de canais bífidos em incisivos inferiores foi de $40,2 \%$. Os autores 
concluíram que canais bífidos ocorrem com maior frequência em dentes cuja relação entre máximo diâmetro mésio-distal e o máximo diâmetro vestíbulo-lingual era menor.

Vertucci (1984), em um estudo muito citado na literatura sobre anatomia dos dentes permanentes humanos, avaliou 2.400 dentes diafanizados com o objetivo de determinar o número de canais radiculares e seus tipos, as ramificações de canais principais, a localização do forame apical e a frequência de deltas apicais. $O$ autor estabeleceu uma classificação para o sistema de canais radiculares, sendo: Tipo I- 1 único canal se estende da câmara pulpar ao ápice; Tipo II- 2 canais separados deixam a câmara pulpar e se unem próximo ao ápice formando 1 único canal; Tipo III- 1 único canal deixa a câmara pulpar, divide-se em 2 no interior da raiz, e se une terminando em canal único novamente; Tipo IV- 2 canais separados se estendem da câmara pulpar ao ápice; Tipo V- 1 único canal deixa a câmara pulpar e divide-se em 2 canais separados com forames apicais separados em região próxima ao ápice; Tipo VI- 2 canais separados deixam a câmara pulpar, unem-se no corpo da raiz e redividem-se próximo ao ápice, terminando como 2 canais separados; Tipo VII- 1 único canal deixa a câmara pulpar, divide-se em 2 e esses se fundem no corpo da raiz, redividindo-se em 2 canais separados próximo ao ápice; Tipo VIII- 3 canais separados estendem-se desde a câmara pulpar ao ápice. Considerando incisivos centrais e laterais inferiores, o autor encontrou respectivamente $70 \%$ e $75 \%$ de anatomia Tipo I (1 único canal); $5 \%$ e $5 \%$ de anatomia Tipo II (2 canais separados desde a câmara pulpar até o ápice); $22 \%$ e 18\% de anatomia Tipo III (2 canais que terminam em 1 forame) e $3 \%$ e $2 \%$ de anatomia Tipo IV ( 2 canais que terminam em 2 forames). A imensa maioria ( $97 \%$ e $98 \%$, respectivamente) dos incisivos inferiores apresentava apenas 1 forame apical. Os demais tipos V, VI, VII e VIII não foram observados em incisivos inferiores. 


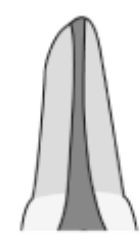

Type I

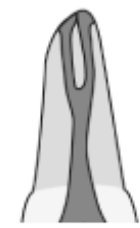

Type V

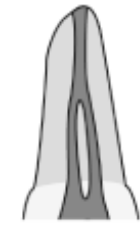

Type II

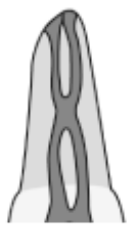

Type VI

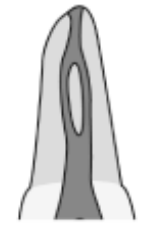

Type III

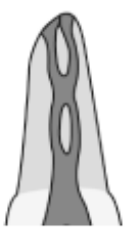

Type VII

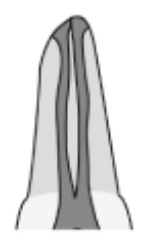

Type IV

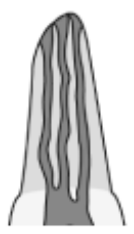

Type VIII

(Extraído do artigo: Vertucci FJ. Root canal morphology and its relationship to endodontic procedures. Endod Top. 2005;10(1):3-29).

Kaffe et al. (1985) avaliaram 200 séries de radiografias periapicais de boca toda dos arquivos de uma universidade para estudar o número de canais radiculares em incisivos inferiores e caninos. O total de 400 incisivos centrais e 400 incisivos laterais foi visualizado em radiografia periapical ortorradial e em radiografia periapical de regiões adjacentes com angulação horizontal alterada. Os autores tinham informações adicionais sobre os pacientes, tais como idade e gênero. Como resultado, obtiveram que $32,5 \%$ dos incisivos centrais e $42,5 \%$ dos incisivos laterais apresentaram 2 canais radiculares. Não houve correlação significante entre o gênero do paciente e o número de canais radiculares, nem entre a idade do paciente e o número de canais radiculares. Os autores sugerem que a avaliação de dentes anteriores com uso de radiografias tomadas com diferentes ângulos horizontais deve ser realizada previamente ao tratamento endodôntico do dente em questão.

Pécora, Savioli e Murgel (1990) realizaram estudo in vitro para verificar a incidência de 2 canais radiculares em incisivos inferiores permanentes humanos, por meio de diafanização. Para isso, avaliaram 634 dentes extraídos de pacientes de uma universidade brasileira, sendo 300 incisivos centrais inferiores e 334 incisivos laterais inferiores. Como resultado, obtiveram que a prevalência de 2 canais foi de $29,7 \%$ nos incisivos centrais e de $39,9 \%$ nos incisivos laterais. A presença de 2 canais com 2 forames apicais foi muito baixa, sendo de $2,3 \%$ nos incisivos centrais e de $1,5 \%$ nos incisivos laterais. 
Kartal e Yanikoglu (1992) avaliaram 100 incisivos centrais e laterais inferiores, a fim de determinar o número de canais radiculares e seus tipos, as ramificações do canal principal, a localização do forame apical e a frequência de deltas apicais. Os dentes foram diafanizados e as análises basearam-se na classificação de Vertucci (1984). Os autores não diferenciaram incisivos centrais de laterais. Como resultado, encontraram 55\% de anatomia Tipo I (1 único canal); $16 \%$ de anatomia Tipo II (2 canais separados desde a câmara pulpar até o ápice); $20 \%$ de anatomia Tipo III (2 canais que terminam em 1 forame). Os demais tipos, terminando com 2 forames apicais (IV, V, VI, VII), tiveram prevalência de $9 \%$.

Caliskan et al. (1995) realizaram estudo in vitro a fim de determinar o número, o tipo de canais radiculares e suas ramificações, bem como localização de forame apical e frequência de deltas apicais em uma população da Turquia. Para isso, 1.400 dentes humanos permanentes foram diafanizados e o critério de Vertucci foi adotado para classificá-los. Considerando incisivos inferiores, os autores encontraram $68,6 \%$ de anatomia Tipo I (1 único canal); 13,7\% de anatomia Tipo II (2 canais separados desde a câmara pulpar até o ápice); $15,6 \%$ de anatomia Tipo III (2 canais que terminam em 1 forame) e 1,9\% de anatomia Tipo $\mathrm{V}$ (1 canal que se divide em 2 canais, que terminam em 2 forames). A imensa maioria (98\%) dos incisivos inferiores apresentou apenas 1 forame apical. Os demais tipos IV, VI, VII não foram observados em incisivos inferiores.

Miyashita et al. (1997) avaliaram 1.085 incisivos inferiores que foram diafanizados para estudo da configuração do canal radicular, presença de canal acessório e localização de forame apical. Constataram que $87,6 \%$ dos canais eram únicos. A prevalência de 2 canais nos dentes avaliados foi, portanto, de 12, 4\%.

Mauger, Schindler e Walker (1998) avaliaram incisivos inferiores para determinar a prevalência e localização de 2 canais radiculares e descrever a anatomia que pode ser encontrada durante a cirurgia apical. Para isso, realizaram secção da raiz de 100 dentes em $1 \mathrm{~mm}, 2 \mathrm{~mm}$ e $3 \mathrm{~mm}$ de distância do ápice. Os autores encontraram que a prevalência de 2 canais nesse nível foi de $2 \%$ a $1 \mathrm{~mm}$, de $0 \%$ a $2 \mathrm{~mm}$ e de $1 \%$ a $3 \mathrm{~mm}$. Concluíram, portanto, que no nível apical próximo ao ápice, é muito rara a presença de 2 canais. 
Sert e Bayirli (2004) realizaram estudo da anatomia de dentes superiores e inferiores extraídos de pacientes da Turquia. Diferentemente de outros estudos, os autores consideraram o gênero dos pacientes cujos dentes foram avaliados. $O$ total de 400 incisivos inferiores diafanizados foi avaliado, sendo 200 de homens e 200 de mulheres. A prevalência de segundo canal radicular foi de $65 \%$ em incisivos centrais inferiores de homens, $70 \%$ em incisivos centrais de mulheres, $62 \%$ em incisivos laterais de homens e $64 \%$ em incisivos laterais de mulheres. Os autores ressaltam que o profissional deve atentar para informações sobre o paciente, tais como gênero e etnia, ao fazer a avaliação prévia de dentes que serão submetidos a tratamento endodôntico.

Al-Qudah e Awawdeh (2006) avaliaram a morfologia do canal radicular de incisivos inferiores de uma população da Jordânia com uso de diafanização. Para isso, 450 incisivos inferiores extraídos foram avaliados de acordo com os critérios de: número e tipo de canal radicular, presença e localização de canais laterais, localização de forame apical e prevalência de deltas apicais. Os autores encontraram que a maioria dos incisivos inferiores apresentava 1 canal radicular (73, $8 \%$ ). A presença de 2 canais foi observada em $26,2 \%$ dos dentes.

Galafassi et al. (2007) realizaram estudo in vitro com o objetivo de analisar o número de canais radiculares nos terços cervical, médio e apical da raiz de incisivos inferiores permanentes, com uso da técnica de diafanização. Para isso, avaliaram 150 dentes extraídos de pacientes de uma universidade brasileira. Como resultado, obtiveram que a presença de 2 canais radiculares foi de $18 \%$ no terço cervical, $53 \%$ no terço médio e $28 \%$ no terço apical. Os autores concluíram que há maior incidência de 2 canais radiculares no terço médio da raiz em comparação aos outros 2 terços.

Boruah e Bhuyan (2011) avaliaram as características morfológicas dos canais radiculares de incisivos inferiores de uma população do nordeste da Índia. Para isso, 480 dentes extraídos foram diafanizados e avaliados, de acordo com número de tipo de canais radiculares, presença e localização de canais laterais, localização do forame apical e bifurcação dos canais. Como resultado, obtiveram que a maioria dos incisivos inferiores apresentava 1 canal radicular $(63,7 \%)$. A presença de 2 canais foi de $36,2 \%$. 
Leoni et al. (2013) realizaram estudo para descrever a anatomia de incisivos centrais e laterais inferiores com uso de imagens de micro-TC. Para tal, submeteram 100 dentes a escaneamento e estudaram a anatomia de cada um, observando comprimento das raízes, presença e localização de canais acessórios e deltas apicais e número de canais. Os resultados mostraram que não há diferença significante entre incisivos centrais e laterais no tocante a parâmetros morfológicos bidimensionais ou tridimensionais. Os autores verificaram que as configurações anatômicas de incisivos centrais e laterais mais prevalentes são do Tipo I (50\% e $62 \%$, respectivamente) e do Tipo III (28\%), sendo Tipo I com 1 único canal radicular e Tipo III com 2 canais radiculares e 1 forame apical.

Milanezi et al. (2013) também utilizaram imagens de micro-TC para avaliação da anatomia desse grupo dentário. Para tal, avaliaram 340 incisivos inferiores de acordo com parâmetros, tais como número de canais radiculares, diâmetros maior e menor da raiz e dos canais, presença de canais ovais e característica tridimensional do terço apical. Como resultado, obtiveram que 257 dentes apresentaram padrão anatômico Tipo I (1 único canal radicular) e 56 apresentaram padrão anatômico Tipo III (2 canais radiculares e 1 forame apical). Esses dois tipos representaram $92 \%$ da amostra de dentes. A presença de canais únicos com forma oval a $1 \mathrm{~mm}$ do nível apical foi de $16,7 \%$ e a $3 \mathrm{~mm}$ do nível apical aumentou para $32,4 \%$.

Lin et al. (2014) investigaram a morfologia do canal radicular de incisivos inferiores utilizando imagens de TCFC. Para isso, avaliaram exames de 353 pacientes de um banco de dados de uma universidade da China, sendo o total de incisivos inferiores de 1.412. Os autores também anotaram dados como idade e gênero dos pacientes cujos exames foram avaliados. Como resultado, obtiveram que a presença de 2 canais radiculares era de 10,9\% em incisivos centrais e de $25,5 \%$ em incisivos laterais. Considerando o total de incisivos inferiores, a prevalência foi de $18,2 \%$. A imensa maioria dos dentes que apresentavam 2 canais radiculares tinham apenas 1 forame apical $(97,6 \%)$. A diferença entre os gêneros foi estatisticamente significante para a presença de 2 canais radiculares, sendo a relação homem/mulher de 1,37:1. Entretanto, não houve diferença significante entre os grupos etários.

Liu et al. (2014) avaliaram a morfologia dos canais radiculares de incisivos 
inferiores de pacientes chineses, usando imagens de TCFC. Para isso, avaliaram exames de TCFC do banco de dados de clínica de Estomatologia de uma universidade, contendo 1.553 dentes, no total. As análises eram feitas para determinar número e morfologia dos canais radiculares. Os autores consideraram o gênero dos pacientes para fins comparativos. Como resultado, obtiveram que 86,8\% dos dentes avaliados tinham uma única raiz com apenas 1 canal radicular. $A$ prevalência de 2 canais radiculares foi de 8,9\% para incisivos centrais e de 17,5\% para incisivos laterais. A diferença na presença de 2 canais em dentes de homens e de mulheres não foi significante (homens=14,6\%; mulheres=11,9\%).

\subsection{Variações anatômicas internas e implicações clínicas}

A importância do reconhecimento de variações anatômicas nos incisivos inferiores foi ressaltada por relatos de caso clínico publicados na literatura.

Loushine, Jurcak e Jeffalone (1993) relataram o caso de um paciente estadunidense que apresentava o incisivo lateral inferior direito com 2 raízes. Por motivos protéticos, foram extraídos os dentes anteriores do paciente, que estavam fragilizados. Os autores chamam a atenção para o fato de que a anomalia não estava visível em radiografia periapical ortorradial. A constatação da raiz supranumerária só foi possível após a extração do dente. Diante do fato, os autores solicitaram radiografias anteriores do paciente e constataram que, em uma radiografia periapical de região de canino inferior direito tomada havia 15 anos (portanto, com diferente angulação horizontal do que a ortorradial), era possível visualizar os 2 forames apicais distintos. Os autores reforçam a importância de que radiografias periapicais adicionais sejam tomadas, com variação de ângulo horizontal (mésio ou distorradial), a fim de visualizar possíveis variações anatômicas em incisivos inferiores.

Funato, Funato e Matsumoto (1998) relataram o caso de um incisivo central inferior de um paciente japonês que apresentava 2 canais radiculares e 2 forames apicais separados. O dente havia sido previamente tratado endodonticamente, porém uma imagem radiolúcida persistia na região periapical. Ao realizarem o retratamento, observaram a presença de um segundo canal, que não havia sido 
detectado anteriormente. Os demais incisivos inferiores do paciente apresentavam 1 único canal. Após a limpeza, modelagem e obturação de ambos os canais do dente afetado, observou-se ausência de sintomatologia do paciente e reparo ósseo constatado radiograficamente. Os autores concluíram que os resultados endodônticos satisfatórios dependem do conhecimento das variações anatômicas dos canais radiculares.

Tiku, Kalaskar e Damle (2005) relataram o caso raro de um paciente indiano que apresentava todos os incisivos e caninos inferiores com 2 canais radiculares. A variação anatômica foi observada em radiografias periapicais tomadas na ocasião em que o paciente necessitou de retratamento dos dentes 41 e 42 . Os autores verificaram que havia lesões apicais associadas aos dentes e o paciente queixavase de dor moderada. As obturações não estavam adequadas, indicando insucesso do tratamento endodôntico, associado à não-detecção das variações anatômicas.

Kabak e Abbott (2007) relataram casos de 2 pacientes bielorrussos que apresentavam 2 canais radiculares em cada um de seus 4 incisivos inferiores. Os autores afirmam que a presença de 2 canais radiculares em todos os incisivos inferiores de um mesmo paciente é rara. Nos casos relatados, a descoberta casual da variação anatômica foi possível devido a tomadas radiográficas bem executadas, com distintos ângulos horizontais de incidência. Na radiografia panorâmica e na radiografia periapical ortorradial para região de incisivos inferiores não se detectou claramente a alteração. Os autores reafirmam a importância do conhecimento das possíveis variações anatômicas que possam ser encontradas durante a prática clínica.

Autores têm demonstrado preocupação com a efetividade do tratamento endodôntico para limpeza e desinfecção de canais com anatomia complexa, tais como os ovais. De acordo com Wu et al. (2000), a conformação oval do canal radicular em incisivos inferiores dificulta as etapas do tratamento endodôntico.

Weiger, EIAyouti e Löst (2002) fizeram estudo com 75 canais radiculares ovais, sendo 30 de dentes incisivos inferiores, com a finalidade de determinar a eficiência de instrumentos manuais e rotatórios na modelagem de canais com essa 
conformação. Concluíram que nenhuma técnica de instrumentação foi capaz de preparar completamente as paredes de dentina de canais ovais.

Canais achatados de incisivos inferiores foram também objeto de estudo de Barbizam et al. (2002). Os autores testaram a capacidade de limpeza de técnicas de instrumentação manual e rotatória com uso de análise morfométrica. Os resultados confirmaram que a quantidade remanescente de resíduos no interior dos canais radiculares, após a instrumentação, está diretamente relacionada à anatomia interna complexa, ressaltando a dificuldade de instrumentar esse tipo de canal.

Jou et al. (2004) publicaram um artigo de revisão sobre a determinação do diâmetro de trabalho durante o tratamento endodôntico, considerando diferentes configurações anatômicas do canal principal. Os autores classificaram tipos de anatomia do canal radicular em sentido axial, tais como redondo, oval, achatado ou irregular. Essas classificações foram feitas de acordo com a proporção entre os diâmetros máximo e mínimo. O canal principal considerado oval apresenta essa proporção de $2: 1$. Os autores ressaltam que o conhecimento da anatomia é fundamental para o êxito da terapia endodôntica convencional e cirúrgica, e definem conceitos atuais para prover melhor qualidade dos tratamentos de canais radiculares.

A obturação de canais radiculares ovais de incisivos inferiores com condensação lateral e técnicas termoplastificadas foi avaliada por De Deus et al. (2008). Os autores instrumentaram e obturaram 87 canais ovais, com 4 técnicas de obturação diferentes. Em seguida, cortaram os dentes a $5 \mathrm{~mm}$ do ápice e avaliaram microscopicamente. Concluíram que a qualidade da obturação de canais radiculares ovais fica comprometida até mesmo com o uso de técnicas termoplastificadas modernas.

Alves et al. (2011) compararam a capacidade de diferentes protocolos endodônticos de aumentar os efeitos antibacterianos da preparação químicomecânica em canais com forma oval. Os autores utilizaram 54 dentes extraídos, sendo incisivos inferiores e segundos pré-molares superiores, com canais de conformação oval. Na discussão do trabalho, apontam que os procedimentos químico-mecânicos desempenham papel fundamental na eliminação ou na redução 
de populações bacterianas do canal principal, porém os efeitos de desinfecção dos instrumentos endodônticos e das soluções irrigadoras podem ser dificultados em casos com anatomia complexa. Os autores sugerem o uso de irrigação passiva ultrassônica seguido por irrigação com clorexidina, para reduzir a contagem bacteriana e a incidência de culturas positivas em canais com essa variação anatômica.

\subsection{Considerações sobre tomadas radiográficas periapicais}

A radiografia periapical é utilizada em todas as etapas do tratamento endodôntico, sendo essencial para o diagnóstico de patologia dentária e óssea, verificação de aspectos anatômicos do dente, determinação do comprimento do canal radicular e avaliação da qualidade da obturação (FAVA; DUMMER, 1997). No entanto, por ser um exame bidimensional, há sobreposição de estruturas nas imagens e falta de informação no plano vestíbulo-lingual. A interpretação da radiografia depende de vários fatores, incluindo experiência do examinador e condições de visualização (GOLDMAN; PEARSON; DARZENTA, 1972). Segundo Jou et al. (2004), a radiografia pode levar o clínico a confundir-se no momento de fazer o planejamento do acesso ao sistema de canais radiculares. A fim de minimizar esse problema e obter o máximo de informação, autores sugerem que sejam feitas, pelo menos, 2 tomadas radiográficas de um dente, sendo: uma tomada padrão para a região de interesse (radiografia ortorradial) e outra tomada com angulação horizontal alterada (radiografia mésio ou distorradial). Segundo Fava e Dummer (1997), a variação de angulação é útil para: determinar o número, localização, forma, tamanho e direção da curvatura de raízes e de canais radiculares; identificar raízes e canais sobrepostos; localizar a posição do ápice radicular em relação a reparos anatômicos adjacentes, entre outros.

Clark (1910) descreveu uma técnica para determinação da posição relativa de dentes não-irrompidos com uso de múltiplas radiografias. De acordo com o princípio da paralaxe, se há 2 objetos alinhados, um à frente do outro, o que está localizado atrás fica ocultado pelo objeto que está na frente. Porém, se for obtida uma vista de ambos os lados, os objetos podem ser visualizados. Na técnica batizada com seu 
nome, o autor sugere a tomada radiográfica central do dente a ser avaliado, seguida por outra tomada em sentido mesial àquela primeira e por uma terceira tomada, em sentido distal à primeira. Cada uma das 3 radiografias deve ser identificada imediatamente após o processamento radiográfico, para que não haja confusão. Com as 3 radiografias posicionadas em ordem, de acordo com a angulação horizontal adotada, a posição de cada dente deve ser avaliada, comparando com pontos de referência que apareçam nas 3 imagens. O autor diz que, com a prática, é possível determinar se o dente está localizado pelo lado palatino / lingual ou pelo lado vestibular. A técnica de Clark, portanto, utiliza-se de tomadas radiográficas em diferentes ângulos horizontais e é amplamente utilizada até os dias de hoje.

Nattress e Martin (1991) realizaram estudo in vitro com 455 incisivos inferiores extraídos para verificar a existência de canais duplos com uso de radiografias. Para isso, realizaram tomadas radiográficas convencionais em sentido mésio-distal (ortorradial) e em sentido vestíbulo-lingual. Como resultado, obtiveram que a porcentagem de canais duplos identificados foi de 13\%, sendo 57 dentes. De 398 dentes com 1 canal radicular, a avaliação correta ao visualizar a segunda radiografia (em sentido vestíbulo-lingual) foi feita em 95\% dos casos. Considerando os 57 dentes com 2 canais radiculares, houve acerto no reconhecimento da variação anatômica em $70 \%$ dos casos. Os autores concluem que a avaliação de apenas 1 radiografia resultou em falha no diagnóstico de 1 terço dos dentes com canais duplos.

Klein et al. (1997) realizaram estudo in vitro para determinar a angulação horizontal do feixe de radiação mais efetiva para diagnóstico de canais duplos em incisivos inferiores permanentes. Para isso, avaliaram 200 dentes extraídos, que foram divididos em grupos de 4 e posicionados em fantoma de silicone, de forma a simular o alinhamento do arco dentário. Em seguida, os grupos foram radiografados com diversas angulações horizontais, variando entre 0 e 50 graus, com intervalos de 10 graus de ambos lados direito e esquerdo. Cinco observadores avaliaram o número de canais radiculares em cada grupo de 4 dentes. Uma radiografia de controle de cada dente, individualmente, foi tomada a 90 graus com o plano mésiodistal a fim de identificar o número de canais duplos presentes. Uma amostra representativa de $10 \%$ do total de dentes foi vista pela segunda vez, 3 meses após, para determinar a concordância intraexaminador. Como resultado, os autores 
obtiveram que as angulações horizontais de 20 graus à direita e 30 graus à esquerda apresentaram maior acurácia no diagnóstico da presença de 2 canais radiculares do que a vista ortorradial.

Martínez-Lozano, Forner-Navarro e Sánchez-Cortés (1999) fizeram estudo com o propósito de avaliar o efeito da angulação da fonte de radiação $X$ para visualização do sistema de canais radiculares de pré-molares. Para isso, dividiram 100 pré-molares superiores e inferiores extraídos de pacientes de uma universidade da Espanha em 4 grupos de 25 dentes cada. O total de 10 radiografias convencionais foi feito para cada dente, em sentido horizontal (ângulos de 0, 20 e 40 graus) e vertical (0, 15 e 30 graus). Como resultado, os autores observaram que variando o ângulo horizontal em 20 e 40 graus, o número de canais radiculares observados em primeiros pré-molares superiores, segundos pré-molares superiores e primeiros pré-molar inferiores segundos coincidiu com o número real de canais presentes. No caso de segundos pré-molares inferiores, apenas a variação horizontal em 40 graus permitiu a correta identificação do número de canais. Como conclusão, os autores afirmam que a variação do ângulo horizontal melhora a visualização de canais adicionais sobrepostos em pré-molares. A alteração do ângulo vertical não influenciou significantemente, exceto para os primeiros prémolares inferiores.

Willershausen et al. (2008) e Zheng et al. (2009) utilizaram a radiografia como recurso na pesquisa da curvatura de canais radiculares de incisivos inferiores. Os autores utilizaram o paralelismo entre a fonte de radiação e o filme / sensor, e tomadas radiográficas com diferentes angulações horizontais, variando em 20 graus para mesial ou para distal. As observações feitas pelos autores foram possíveis graças às múltiplas tomadas radiográficas realizadas com diferentes angulações horizontais.

De Oliveira et al. (2009) verificaram a prevalência de bifurcação do canal radicular em incisivos inferiores com uso de radiografia digital direta. Para isso, 400 dentes de pacientes foram analisados e tomadas radiográficas digitais foram feitas em direção ortorradial da região de incisivos inferiores e caninos inferiores. As radiografias da região de canino permitiram a visualização dos incisivos em sentido distorradial, com 20 graus de variação do ângulo horizontal. Para o estudo in vitro, 
200 incisivos inferiores extraídos foram posicionados em um modelo, simulando o arco dentário inferior. Radiografias digitais foram tomadas em sentidos mésio-distal e vestíbulo-lingual. Como resultado, os autores obtiveram que a presença de bifurcação foi vista em $20 \%$ dos dentes extraídos, na direção mésio-distal. Em sentido vestíbulo-lingual, $17,5 \%$ dos dentes avaliados em pacientes e $15 \%$ dos avaliados dentes extraídos apresentaram bifurcação ou características indicando bifurcação. Os autores concluem que a radiografia digital realizada com diferentes angulações horizontais permite a detecção de maior número de casos de canais bifurcados.

\subsection{Considerações sobre tomografia computadorizada de feixe cônico (TCFC)}

A tomografia computadorizada (TC) foi idealizada por Hounsfield e Comack, que receberam o prêmio Nobel de Medicina em 1979 pelo feito (PATEL et al., 2007; GARIB et al., 2007; HOWERTON; MORA, 2008). A TC utiliza a radiação X e permite a avaliação da região de interesse por meio de cortes ou fatias em planos distintos: sagital, axial e coronal (SCARFE; FARMAN, 2008; SHERRARD et al., 2010). Desde a sua invenção, várias gerações de tomógrafos foram sendo desenvolvidas (KAU et al., 2009). A TCFC, desenvolvida para uso odontológico, é uma tecnologia recente, tendo sido apresentada pela primeira vez na literatura em 1998 (MOZZO et al., 1998), com o objetivo de superar algumas desvantagens da TC convencional para avaliação de dentes e estruturas maxilo e crânio-faciais. Essa tecnologia causou uma revolução na área de diagnóstico por imagem (SCARFE; FARMAN, 2008; PATEL et al., 2009). Vários autores preocuparam-se em apresentar os conceitos básicos a respeito dessa nova tecnologia, destacando suas vantagens, desvantagens, aplicações, princípios de obtenção da imagem, entre outros aspectos.

Scarfe, Farman e Sukovic (2006) publicaram artigo com o objetivo de apresentar visão geral a respeito da TCFC e de revisar aplicações específicas dos vários modelos de tomógrafos disponíveis e cada vez mais utilizados na prática odontológica. Os autores apontam as vantagens desta nova tecnologia, tais como acurácia das imagens, menor produção de artefatos, rapidez do exame e menor 
dose de radiação utilizada em comparação a outros tipos de TC. Concluem que é uma tecnologia de grande benefício para a prática odontológica e que será cada vez mais utilizada e solicitada pelos cirurgiões-dentistas.

Cotton et al. (2007) afirmaram que a capacidade da TCFC em permitir a avaliação de uma determinada região de interesse em 3 dimensões pode beneficiar tanto profissionais recém-graduados quanto profissionais experientes. Os autores realizaram uma breve revisão a respeito da TCFC e citaram suas vantagens em relação a radiografias convencionais e à TC médica, tais como aumento da acurácia, maior resolução de imagens, redução do tempo de escaneamento e menor dose de radiação. Em relação às aplicações desta tecnologia em Endodontia, destacaram avaliação de morfologia do canal radicular, diagnóstico de patologia endodôntica, detecção de fraturas e reabsorções radiculares externas/internas e planejamento pré-cirúrgico. Ao final, concluem que a TCFC apresenta potencial para tornar-se ferramenta válida na prática endodôntica atual e futura.

Tyndall e Rathore (2008) publicaram revisão sobre o uso da TCFC para diagnóstico de cáries, doenças periodontais e problemas endodônticos. Destacam que dentes com restaurações metálicas ou de qualquer outro material radiopaco não devem ser considerados para avaliação por TCFC, por conta de artefatos. Já para avaliação de problemas endodônticos, a TCFC apresenta-se como ferramenta importante, podendo ser usada para identificação de canais radiculares, estudo de lesões periapicais, fraturas radiculares e caracterização de reabsorção externa ou interna. Concluem que essa tecnologia é útil e, para alguns casos, indispensável.

Patel (2009) publicou revisão de literatura a respeito das aplicações da TCFC na prática endodôntica. O autor também destaca que a TCFC é uma tecnologia que utiliza radiação ionizante e, portanto, somente se deve realizar o exame quando os benefícios por ele proporcionados forem superiores aos potenciais riscos à saúde do paciente. Cada caso endodôntico precisa ser julgado individualmente e a indicação de exame de TCFC deve ser considerada em situações nas quais as informações oferecidas por radiografias convencionais não sejam suficientes para diagnóstico e manejo do problema endodôntico. O autor também prevê diminuição do preço dos equipamentos de TCFC no futuro e consequente aumento da procura pelo exame. Afirma também que os profissionais que utilizam TCFC devem receber treinamento 
adequado em interpretação de imagens tomográficas, uma vez que são totalmente diferentes das imagens dos sistemas radiográficos.

As imagens tomográficas revolucionaram a forma como os profissionais visualizam os dentes e suas complexidades anatômicas. As imagens radiográficas, muitas vezes, davam a falsa impressão de que todos os canais radiculares tinham forma arredondada (JOU et al., 2004). No entanto, a tomografia permitiu avaliação mais detalhada da anatomia dentária, na medida em que a morfologia pôde ser estudada em 3 dimensões. De acordo com Wang et al. (2010), a TCFC permite que o clínico compreenda melhor a real conformação do sistema de canais radiculares.

Tachibana e Matsumoto (1990) publicaram um artigo pioneiro sobre o uso da TC para observação da anatomia de dentes superiores e inferiores. Os autores afirmaram que as configurações anatômicas dos dentes foram claramente observadas nas imagens tomográficas, bem como a relação dos dentes com os tecidos periodontais. Além disso, foi possível determinar os comprimentos vestíbulolingual e mésio-distal dos dentes e a presença de materiais obturadores ou núcleos intrarradiculares. Concluíram que a análise das imagens em três planos é muito interessante.

Robinson et al. (2002) avaliaram 120 exames de TC médica de um banco de dados para descrever as configurações anatômicas e variações do canal radicular de primeiros pré-molares inferiores. Os exames haviam sido feitos para avaliação de cistos e tumores em diferentes regiões, cujas imagens foram primeiramente vistas em radiografias panorâmicas. Os autores apresentaram dados obtidos acerca da forma da raiz e do canal radicular desses dentes, bem como incidência de canais múltiplos e graus de bifurcação. Concluíram que a tomografia traz mais informações do que as radiografias panorâmicas, uma vez que a sobreposição de canais radiculares no plano vestíbulo-lingual dificulta a avaliação desses dentes em exames radiográficos convencionais. Os autores também chamam a atenção para que, ao ser realizado exame de TC do paciente, o radiologista avalie a anatomia dos dentes e relate possíveis variações anatômicas encontradas. Essas informações valorizam o exame de TC feito para outros propósitos, além de serem muito importantes para o cirurgião-dentista que for atender o paciente. 
Matherne et al. (2008) realizaram pesquisa in vitro com o objetivo de comparar a eficácia de diferentes modalidades de exames por imagem para a identificação do número de canais radiculares de 72 dentes extraídos. Para isso, expuseram 24 molares superiores, 24 pré-molares inferiores e 24 incisivos inferiores a exames de TCFC, radiografia digital direta (sensor-CCD) e indireta (placa de fósforo-PSP). As imagens de TCFC foram consideradas o padrão ouro e acusaram uma média de 3,6 canais por molar superior, 1,2 por pré-molar inferior e 1,5 por incisivo inferior. Endodontistas avaliaram as imagens radiográficas e falharam na identificação de 1 ou mais canais radiculares em 41\% dos dentes com CCD e em $40 \%$ dos dentes com PSP. Os autores concluíram, portanto, que as imagens obtidas com TCFC sempre resultam em maior número de canais radiculares identificados do que as avaliações com radiografia digital direta e indireta.

Blattner et al. (2010) avaliaram a capacidade da TCFC (tomógrafo i-CAT) para identificação acurada da presença ou ausência de segundo canal mésio-vestibular em primeiros e segundos molares superiores extraídos. Para isso, submeteram 20 molares extraídos a radiografia periapical digital, a TCFC e a secção dos dentes (padrão ouro). Como resultado, obtiveram que a TCFC permitiu a identificação correta da presença ou ausência desse canal em $79 \%$ da amostra. Não houve diferença significante entre a análise feita com uso de TCFC e o corte clínico dos dentes, demonstrando que a TCFC é um método confiável para a identificação de canais radiculares de difícil detecção em radiografias.

La et al. (2010) relataram um caso em que a imagem de TCFC foi fundamental para a detecção de configuração interna aberrante de um primeiro molar inferior de uma paciente sul-coreana. Após a abertura do dente e durante a exploração do orifício do canal mésio-lingual, o operador decidiu submeter o paciente ao escaneamento em tomógrafo, uma vez que desconfiou estar diante de uma variação anatômica. Nas imagens tomográficas, foi possível identificar 3 canais radiculares distintos, no interior da raiz mesial. Os autores concluem que a imagem de TCFC é de grande utilidade para o diagnóstico preciso e para o tratamento de dentes com morfologia interna incomum.

Michetti et al. (2010) fizeram estudo in vitro para avaliar o desempenho da TCFC como ferramenta para estudo da anatomia dos canais radiculares. Para isso, 
reconstruções dos canais radiculares de 9 dentes extraídos foram obtidas após escaneamento com o tomógrafo Kodak 9000 3D (0,076 mm de tamanho de voxel). Posteriormente, os dentes foram submetidos a cortes histológicos para fins comparativos. No total, 233 cortes foram comparados. Os autores encontraram correlação de forte a muito forte entre a informação adquirida com uso de TCFC e os cortes histológicos. Concluíram que a TCFC é uma ferramenta confiável e nãoinvasiva, que pode ser aplicada para avaliação em todos os planos.

Neelakantan, Subbarao e Subbarao (2010) avaliaram a acurácia de vários métodos de imagem, incluindo radiografia digital e TCFC, para o estudo da morfologia de canais radiculares. Para isso, utilizaram 95 dentes extraídos (sendo 8 incisivos inferiores com 1 canal radicular) de pacientes de uma universidade da Índia. O padrão ouro adotado para comparação entre métodos foi a diafanização modificada, que não causa destruição do dente. Cinco avaliadores, sendo 3 endodontistas e 2 radiologistas visualizaram todas as imagens. Como resultado, obtiveram índice de acerto de $82 \%$ para radiografia digital e $99 \%$ para TCFC. Os avaliadores falharam na identificação de um ou mais canais radiculares em $23,8 \%$ dos dentes com radiografia periapical e em $0,29 \%$ com TCFC. Os autores concluíram que a TCFC teve acurácia semelhante ao padrão ouro para identificação do sistema de canais radiculares de diversos grupos dentários.

Wang et al. (2010) realizaram pesquisa para avaliar a morfologia do canal radicular de primeiros molares permanentes de uma população chinesa usando imagens de TCFC. Para isso, avaliaram 558 dentes vistos em exames de TCFC, anotando informações como gênero do paciente, posição do dente, número de raízes e de canais radiculares e configuração do canal, de acordo com o critério de Vertucci (1984). Os autores não encontraram relação significante entre o gênero e a morfologia dentária.

Lee et al. (2011) utilizaram imagens de TCFC para avaliação do tipo de configuração de canais radiculares e a incidência de um segundo canal mésiovestibular do interior de raízes mesio-vestibulares de molares superiores de pacientes sul-coreanos. Os autores avaliaram 276 exames de TCFC desses pacientes, anotando também informações como idade e gênero disponíveis. Como resultado, verificaram que a frequência desse canal diminuiu com a idade. Em 
relação ao gênero, os resultados não foram significantes. Os autores reforçam os benefícios da imagem de TCFC para avaliação detalhada da morfologia dos canais radiculares.

Hassan et al. (2012) pesquisaram a influência do protocolo de escaneamento, incluindo FOV (de localizado a grande) e número de projeções, na visibilidade do canal radicular com uso de TCFC. Para isso, submeteram uma mandíbula humana dentada a escaneamento no tomógrafo Accuitomo, selecionando 6 FOVs diferentes $(4 \times 4 \mathrm{~cm}, 6 \times 6 \mathrm{~cm}, 8 \times 8 \mathrm{~cm}, 10 \times 10 \mathrm{~cm}, 14 \times 10 \mathrm{~cm}$ e $17 \times 12 \mathrm{~cm})$ com projeções de 360 ou 180 graus, em resolução padrão ou alta. O dente canino direito foi escolhido para ser avaliado. Dez observadores julgaram a visibilidade do canal radicular e a qualidade da imagem com uso de uma escala de 0 a 5 . Os resultados indicaram que o tamanho do FOV escolhido e o número de projeções influenciaram significantemente a visibilidade do canal radicular. A resolução não teve influência significante. Os autores concluem que o menor FOV disponível no tomógrafo a ser utilizado deve ser sempre escolhido para aplicações em Endodontia e não se recomenda reduzir o número de projeções a 180.

Domark et al. (2013) realizaram estudo in vitro com o propósito de comparar imagens de radiografia periapical digital, de TCFC e de micro-TC (padrão ouro) para determinar o número de canais radiculares em raízes mésio-vestibulares de molares superiores permanentes. Para isso, realizaram tomadas radiográficas e escaneamentos em tomógrafo Kodak 9000 3D de 18 hemi-maxilas contendo 27 molares, no total. Três tomadas radiográficas com variações de ângulo horizontal de 20 graus foram feitas para cada dente. Em seguida, os dentes foram extraídos e escaneados separadamente no microtomógrafo. Dois examinadores avaliaram as imagens para determinar o número de canais em cada dente. Foram feitas 2 análises, com intervalo de 2 semanas entre elas. Como resultado, os autores observaram que houve um número significantemente maior de canais identificados nas imagens de micro-TC (padrão ouro) do que nas radiografias periapicais. No entanto, a diferença entre contagem de canais com micro-TC e TCFC não foi estatisticamente significante.

Junqueira et al. (2013) realizaram pesquisa in vitro para comparar imagens de TCFC de diferentes tamanhos de voxel com radiografia periapical digital direta para 
a detecção de fraturas radiculares verticais em dentes com e sem núcleo metálico intracanal. Para isso, submeteram 18 dentes anteriores inferiores (incisivos e caninos) tratados endodonticamente $e$ fraturados experimentalmente a escaneamento no tomógrafo i-CAT Next Generation com tamanhos de voxel de 0,125 e $0,25 \mathrm{~mm}$. Radiografias periapicais digitais foram tomadas com 3 angulações horizontais distintas. Como resultado, obtiveram que não houve diferença estatisticamente significante entre as imagens de TCFC e radiografia periapical. $\mathrm{O}$ tamanho de voxel não influenciou significantemente no diagnóstico de fraturas verticais. Os autores sugerem que a radiografia periapical com variação de ângulo horizontal deve ser a primeira opção para a detecção de fraturas verticais.

Yang et al. (2013) utilizaram a TCFC como ferramenta para avaliar a morfologia do sistema de canais radiculares de primeiros pré-molares inferiores em pacientes da China. Para isso, avaliaram imagens de exames de 238 pacientes. As imagens tomográficas permitiram a análise da posição dentária, da morfologia dos canais radiculares, bem como da distância entre o forame apical e o ápice anatômico. Os autores destacam as vantagens da utilização de TCFC para avaliação de anatomia dentária em comparação a técnicas empregadas em outras pesquisas, como secção dentária ou diafanização, que danificam os dentes e não permitem análise in vivo.

\subsection{Considerações sobre microtomografia computadorizada}

A microtomografia computadorizada (micro-TC) é uma ferramenta avançada para a pesquisa científica in vitro, que permite a análise detalhada qualitativa e quantitativa da anatomia dentária (LEONI et al., 2013). Ao contrário de outros métodos utilizados por vários autores em pesquisas anteriores, tais como diafanização ou secção macroscópica dos dentes, a micro-TC não causa dano ou destruição ao objeto de estudo, o que é considerado uma vantagem. As imagens de micro-TC podem ser utilizadas como padrão ouro para estudos da anatomia dentária.

Peters et al. (2000) avaliaram o potencial e a acurácia de um método para estudo da geometria do canal radicular com uso da micro-TC. Para isso, 
escanearam 12 molares superiores extraídos, com resolução de 0,034 mm, e calcularam a área de superfície e o volume de cada canal radicular. Os autores observaram que a geometria do canal radicular pôde ser estudada de forma acurada pela micro-TC. Concluíram que as variáveis e índices apresentados podem servir como base para análises futuras com essa técnica inovadora, no campo da pesquisa endodôntica.

Guillaume et al. (2006) utilizaram a micro-TC para avaliar a anatomia de terceiros molares extraídos. Os autores apresentam as vantagens do uso dessa nova técnica para estudo da anatomia dentária, na medida em que permite reconstruir e observar com riqueza de detalhes o dente, a câmara pulpar e o sistema de canais radiculares.

Somma et al. (2009) realizaram estudo de primeiros molares superiores usando a micro-TC. Para isso, utilizaram 30 dentes extraídos, que foram submetidos a escaneamento. Os autores afirmam que essa nova tecnologia permitiu a avaliação detalhada de canais radiculares mésio-vestibulares, istmos, canais acessórios e deltas apicais. Relatam que a microtomografia permite avaliação precisa da anatomia dentária sem a necessidade de cortar o dente. No entanto, é um método de imagem que requer muito tempo de reconstrução e não pode ser aplicado clinicamente.

Someda et al. (2009) publicaram estudo feito para investigar o método de estimativa de idade na área forense, baseado em medidas tridimensionais de incisivos centrais inferiores em japoneses. Para isso, submeteram 155 dentes a escaneamento em micro-TC. Os autores puderam avaliar as estruturas dentárias tridimensionalmente, bem como obter os volumes de esmalte, da dentina e da cavidade pulpar.

Swain e Xue (2009) publicaram uma revisão de literatura na qual destacaram os recentes avanços da micro-TC aplicada à pesquisa, ressaltando suas aplicações na mensuração da espessura do esmalte, na morfologia do canal radicular, na avaliação de preparo do canal radicular, na engenharia de tecidos dentários, na avaliação de densidade mineral de tecidos duros e de implantes dentários. Os autores destacaram que essa técnica de produção de imagens de alta resolução é 
uma poderosa ferramenta para análises qualitativas e quantitativas em pesquisas. As vantagens da micro-TC são apresentadas e futuras aplicações dessa tecnologia na pesquisa odontológica são comentadas.

Villas-Bôas et al. (2011) realizaram estudo com micro-TC para estudar características de canais radiculares mesiais de molares inferiores, tais como diâmetro mésio-distal e vestíbulo-lingual, volume apical e presença de istmos no nível apical. Para isso, escanearam 60 molares inferiores extraídos, utilizando 0,018 $\mathrm{mm}$ de tamanho de voxel. Os autores apresentam vários dados obtidos a respeito da anatomia desse grupo dentário, concluindo que o padrão anatômico é muito variável.

Yamada et al. (2011) observaram características morfológicas tridimensionais de canais radiculares mésio-vestibulares de primeiros molares superiores com uso da micro-TC. Esse avançado método de estudo in vitro permitiu a detecção de ramificações apicais microscópicas, difíceis de serem observadas em métodos convencionais para análise de anatomia dentária.

Grande et al. (2012) publicaram artigo no qual ilustram as aplicações e o potencial da micro-TC na análise da anatomia dentária e da morfologia do canal radicular. Os autores escanearam diversos dentes com anatomia complexa, tais como primeiros molares superiores com segundo canal mésio-vestibular, primeiros molares inferiores com variações na raiz mesial e pré-molares com uma ou mais raízes, com configuração complexa na região apical. Os autores afirmam que foi possível visualizar com precisão a anatomia externa e interna dos dentes, com visualização dos mínimos detalhes. Concluem que a micro-TC é uma técnica reprodutível de simples execução, que permite a análise em 3D não-invasiva para estudo do sistema de canais radiculares.

Marca et al. (2013) fizeram pesquisa para analisar as variações do canal radicular em pré-molares superiores com 3 raízes utilizando micro-TC e TCFC. Para isso, utilizaram 16 dentes extraídos, que foram escaneados nos 2 aparelhos e tiveram suas imagens medidas e comparadas. Os autores apontam que as imagens de TCFC ofereciam menos detalhe em relação às microtomográficas. Concluem que, apesar da TCFC ser uma ferramenta muito útil, melhoramentos ainda são necessários a fim de prover mais detalhe do sistema de canais radiculares. 
Ordinola-Zapata et al. (2013) realizaram estudo com o propósito de descrever a anatomia de pré-molares inferiores com 3 canais radiculares usando micro-TC. Para isso, avaliaram 105 dentes extraídos, verificando número de localização dos canais, distância entre referências anatômicas, ocorrência de deltas apicais e de fusão de canais. As imagens microtomográficas permitiram análise bidimensional (área, perímetro, circunferência, diâmetros maior e menor) e tridimensional (volume).

Considerando a importância do reconhecimento de variações anatômicas de dentes incisivos inferiores para o sucesso do tratamento endodôntico, destacada pela literatura científica, a presente pesquisa foi proposta. A intenção foi verificar in vitro qual recurso de imagem permite maior reconhecimento do número e da forma do canal radicular nesse grupo dentário, a fim de auxiliar o cirurgião-dentista no momento de optar por um tipo de imagem para diagnóstico (radiografia periapical com mais de uma tomada ou TCFC). Como padrão ouro, considerou-se a micro-TC, cujas vantagens foram apontadas por vários autores. Sabendo-se que a prevalência de dois canais radiculares em incisivos inferiores é variável de acordo com grupos étnicos, a avaliação de imagens de TCFC de pacientes brasileiros para essa observação fez-se necessária e, assim, estabeleceu-se a segunda etapa da pesquisa. 



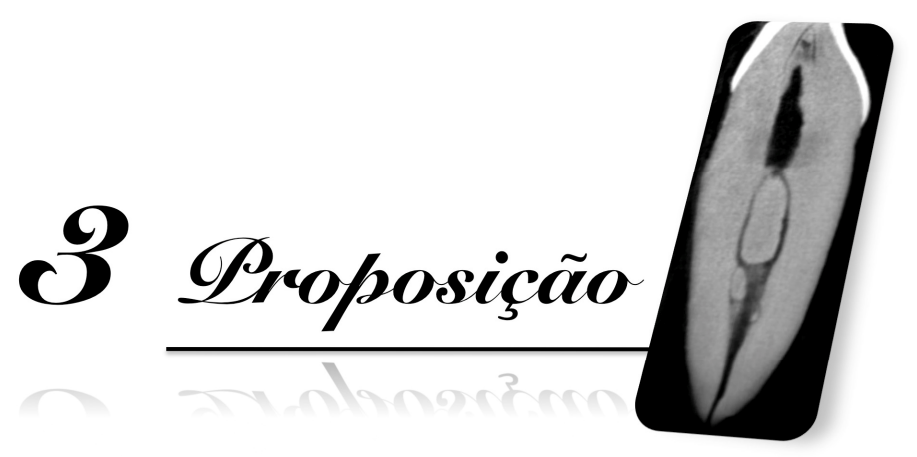





\section{PROPOSIÇÃO}

O presente trabalho foi realizado com os seguintes objetivos:

1) Avaliar a capacidade de identificação de distintos padrões anatômicos internos de dentes incisivos inferiores permanentes extraídos, em imagens obtidas por radiografia periapical digital e tomografia computadorizada de feixe cônico, utilizando a microtomografia computadorizada como padrão ouro;

2) Determinar a prevalência de 2 canais radiculares em dentes incisivos inferiores permanentes de pacientes da FOB-USP com uso de imagens de tomografia computadorizada de feixe cônico de um banco de dados, relacionando-a com localização do dente, gênero e idade do paciente. 



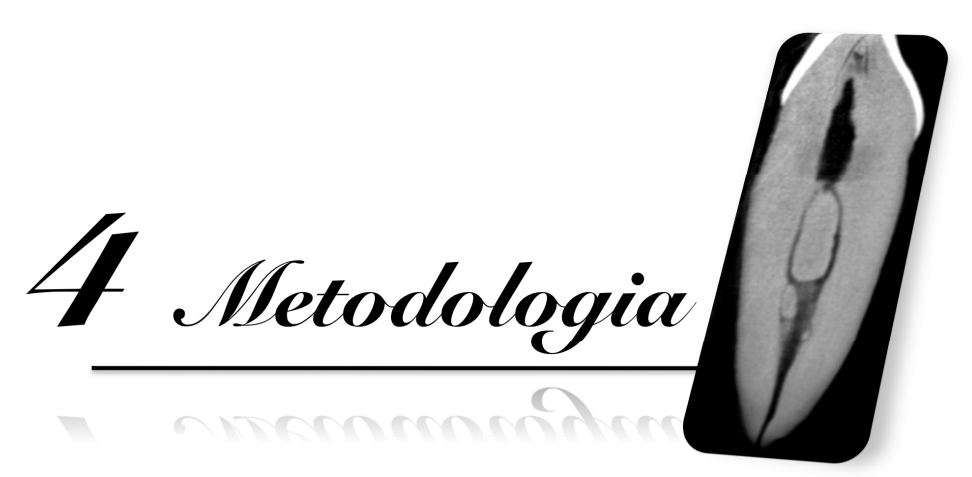





\section{METODOLOGIA}

O presente estudo foi dividido em 2 etapas e aprovado pelo Comitê de Ética em Pesquisa (CEP) da FOB-USP, sob o protocolo CAAE 01229812.0.0000.5417 (Anexo A) e pelo IRB (Institutional Review Board) da Faculdade de Odontologia da Universidade de Loma Linda, California, Estados Unidos, onde parte da primeira etapa do trabalho foi desenvolvida, sob o protocolo \#5120178 (Anexo B).

\subsection{PRIMEIRA ETAPA DA PESQUISA: Identificação de padrões da anatomia} interna de incisivos inferiores extraídos utilizando imagem radiográfica periapical digital e imagem obtida por tomografia computadorizada de feixe cônico

\subsubsection{Seleção da amostra / estabelecimento do padrão ouro (micro-TC)}

Primeiramente, $\mathbf{4 0}$ dentes incisivos inferiores permanentes extraídos foram obtidos, por meio de doação proveniente de consultório odontológico. A estrutura radicular de todos os dentes apresentava-se íntegra, com ápices fechados e sem tratamento endodôntico prévio, fratura ou outras alterações que pudessem comprometer a avaliação da anatomia radicular interna ou do sistema de canais radiculares.

Em seguida, cada dente foi identificado com o propósito de facilitar a associação com imagens que seriam obtidas posteriormente. A marcação foi feita com caneta permanente na coroa dentária e era composta por uma letra e um número, conforme exemplo mostrado na Figura 1.

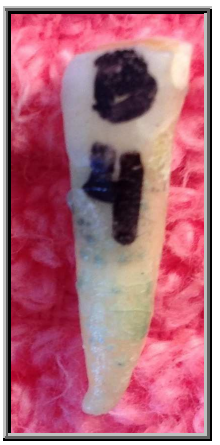

Figura 1: Exemplo de marcação feita em incisivo inferior da amostra. 
Para o estabelecimento do padrão ouro da anatomia interna dos dentes, utilizou-se a microtomografia computadorizada (micro-TC). Para isso, cada dente foi submetido a escaneamento no aparelho Skyscan 1074 (Bruker-microCT, Kontich, Bélgica) da FOB-USP (Figura 2), com protocolo de 0,018 mm de tamanho de voxel; $800 \mathrm{~mA}$ e $50 \mathrm{kVp}$. Os processos de binarização e de reconstrução em 3D foram feitos com uso dos softwares CTan/ CTvol (Bruker-microCT, Kontich, Bélgica).

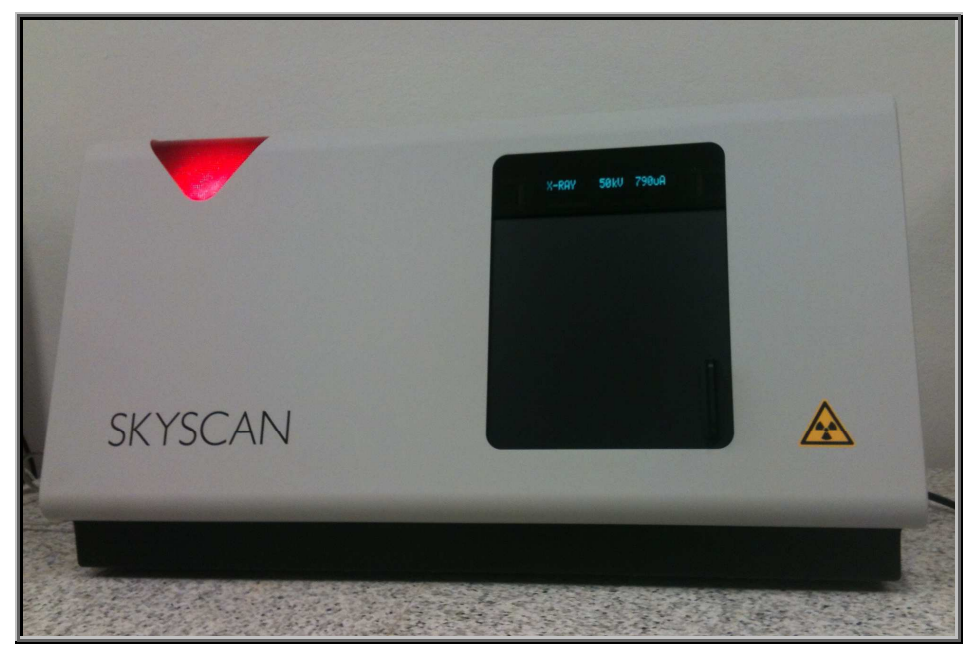

Figura 2: Microtomógrafo Skyscan 1074.

As imagens microtomográficas de cada dente foram avaliadas por uma radiologista odontológica experiente, com a finalidade de estabeler-se o padrão ouro de anatomia interna para cada incisivo da amostra. Três padrões anatômicos foram determinados na presente pesquisa e serviram de parâmetro para a classificação dos dentes, baseados nos critérios de Vertucci (1984), ilustrados na Figura 3, e de Jou et al. (2004).

Os tipos anatômicos (Figura 4) foram definidos de acordo com o aspecto do sistema de canais radiculares no terço médio (de 3 a $5 \mathrm{~mm}$ do nível apical), em vista axial, sendo:

-Tipo I (1 canal radicular regular): esse padrão corresponde ao tipo I da classificação de Vertucci, sendo que a proporção entre o diâmetro mésiodistal e o diâmetro vestíbulo-lingual era igual ou $<2$;

-Tipo la (1 canal radicular oval): esse padrão corresponde a uma subdivisão do tipo I da classificação de Vertucci, sendo que a proporção entre o diâmetro diâmetro mésio-distal e o diâmetro vestíbulo-lingual era > 2;

-Tipo III ( 2 canais radiculares com 1 forame apical): esse padrão corresponde ao tipo III da classificação de Vertucci. 


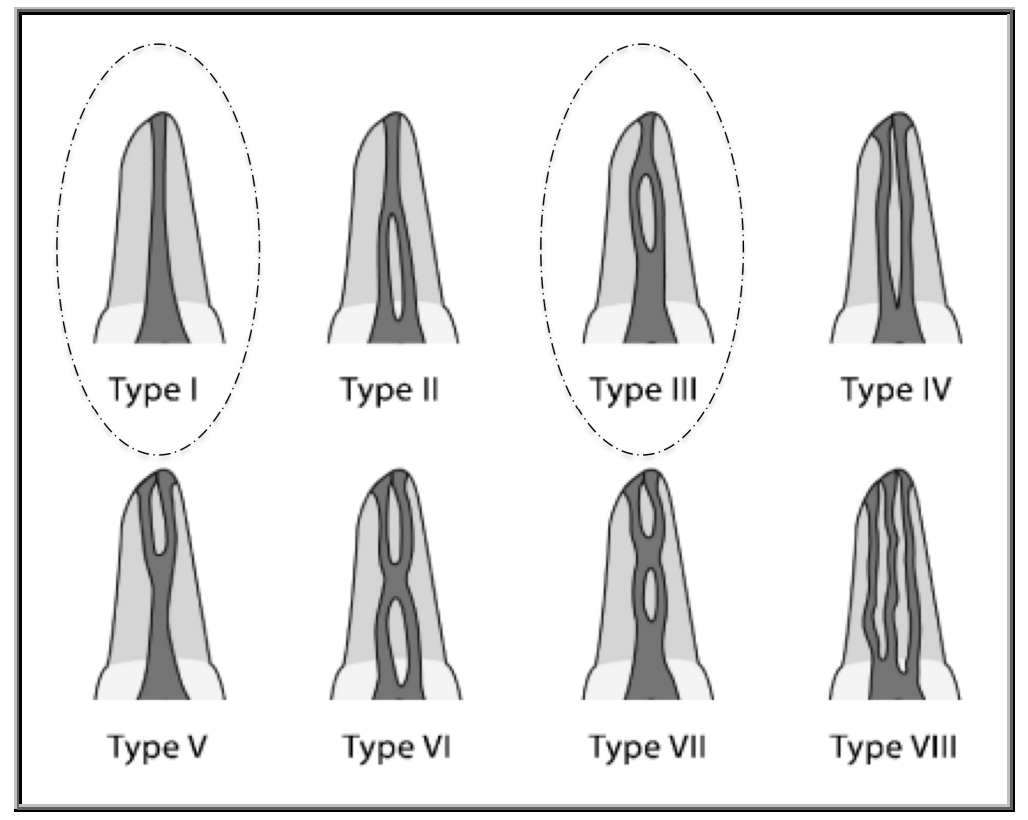

Figura 3: Esquema representativo das configurações do sistema de canais radiculares propostas por Vertucci, com destaque para os padrões encontrados em incisivos inferiores. (Extraído do artigo: Vertucci FJ. Root canal morphology and its relationship to endodontic procedures. Endod Top. 2005;10(1):3-29).

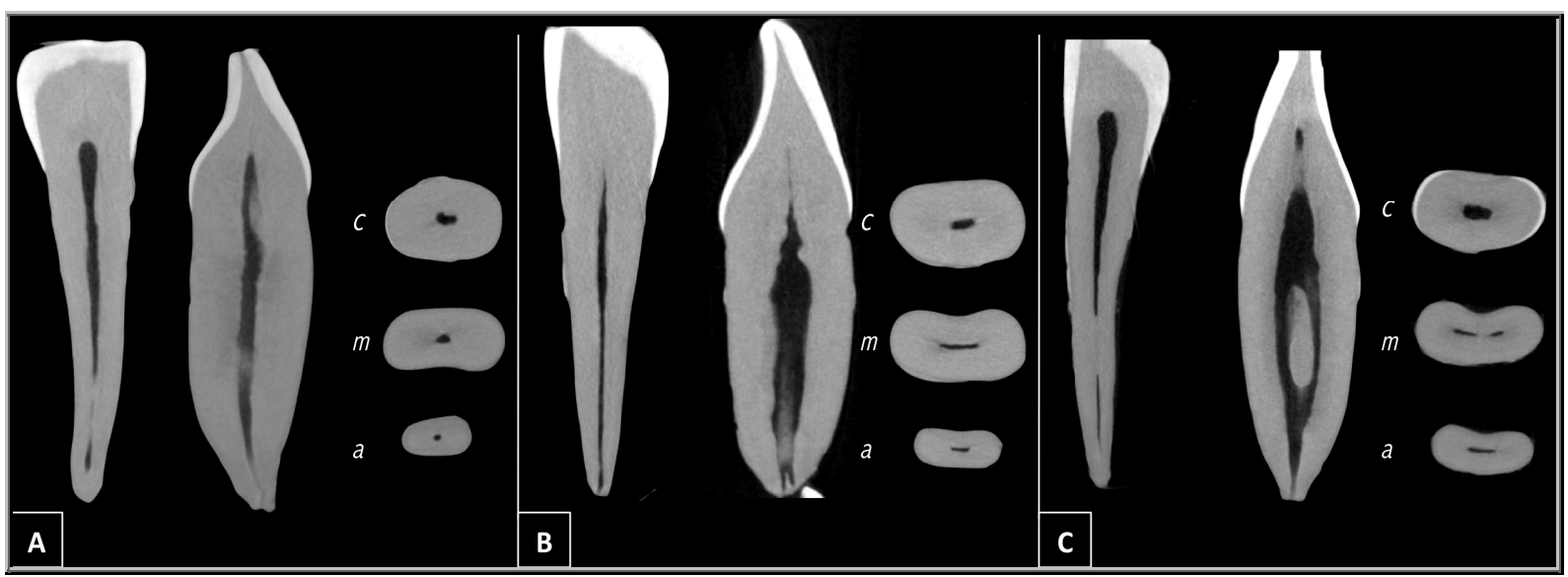

Figura 4: Imagens de micro-TC de vistas em sentido coronal, sagital e axial, respectivamente, de 3 incisivos inferiores da amostra, ilustrativos do critério adotado para determinação dos 3 padrões anatômicos. As imagens axiais são dos terços cervical (c), médio (m) e apical (a). (A) Tipo I corresponde a um dente com 1 canal radicular regular, (B) Tipo la corresponde a um dente com 1 canal radicular oval, e (C) Tipo III corresponde a um dente com 2 canais radiculares. 


\subsubsection{Divisão dos grupos de dentes da amostra}

Após o estabelecimento do padrão ouro, com uso de imagens de micro-TC, encontrou-se o seguinte total de dentes: 12 dentes do tipo I; 12 dentes do tipo la e 16 dentes do tipo III. Criou-se uma tabela utilizando o programa Microsoft Office Excel (Microsoft Corporation, Redmond, EUA), na qual a identificação de cada dente e de seu respectivo padrão anatômico ouro foi inserida.

Em seguida, os 40 dentes da amostra foram divididos em 10 grupos de 4 incisivos cada (Figura 5). Essa divisão teve como objetivo orientar a colocação dos dentes em mandíbula humana, desdentada na região de incisivos inferiores, para as tomadas radiográficas e escaneamentos em aparelhos de TCFC. Os dentes foram posicionados nos alvéolos dentários da mandíbula de forma a simular o alinhamento natural de incisivos inferiores no arco dentário, sendo, portanto, 4 dentes por vez.

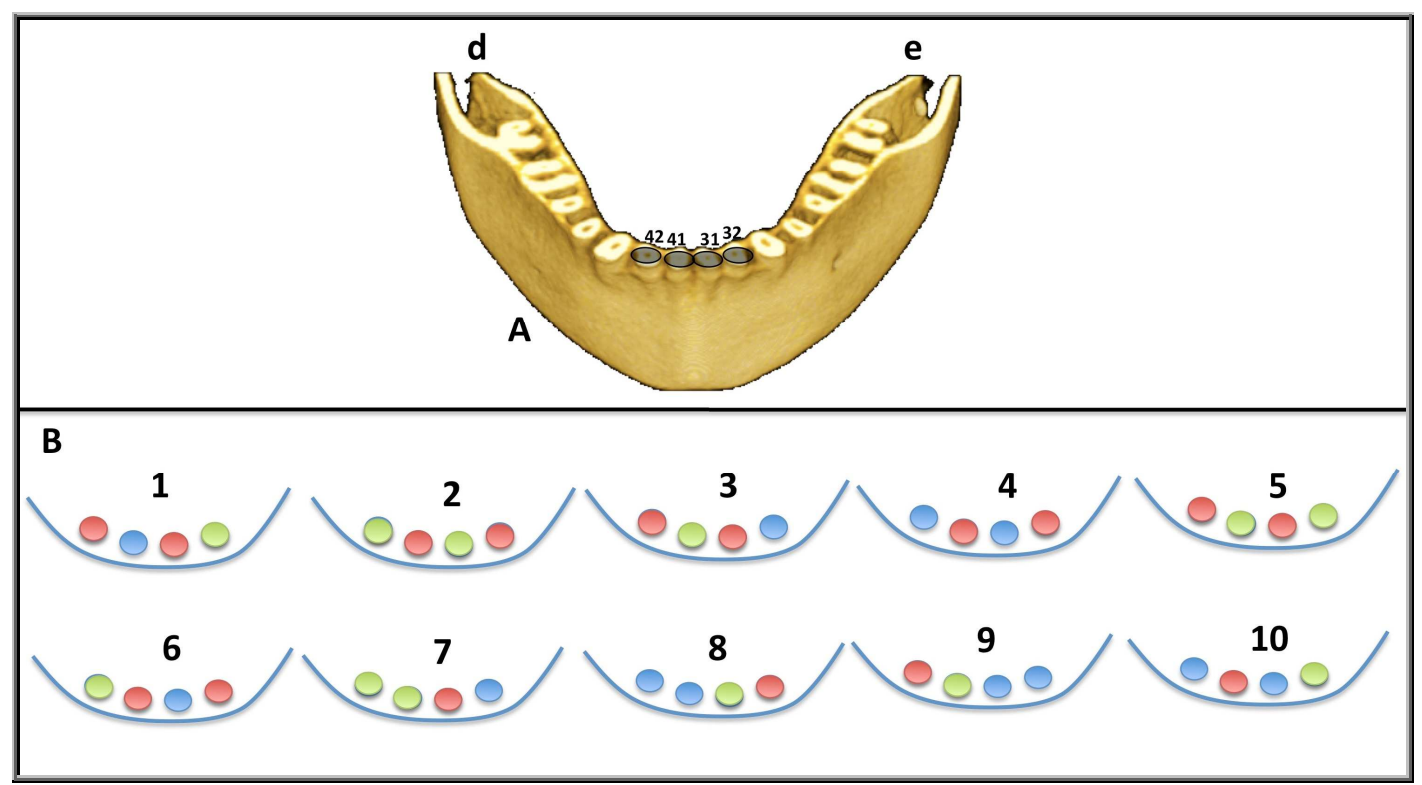

Figura 5: (A) Representação da mandíbula e dos alvéolos correspondentes ao dentes 42, 41, 31 e 32, nos quais os incisivos da pesquisa foram posicionados para obtenção de imagens ( $d=l a d o$ direito; $\mathrm{e}=$ esquerdo). (B) Esquema representativo dos 10 grupos de 4 dentes, indicando a posição prédeterminada de cada dente: círculos verdes (dentes tipo I); círculos azuis (dentes tipo la); círculos vermelhos (dentes tipo III). 


\subsubsection{Tomadas radiográficas periapicais digitais}

Os incisivos da amostra foram posicionados nos alvéolos da mandíbula, de acordo com os grupos pré-determinados, sendo 4 dentes por vez. As tomadas radiográficas periapicais diretas foram realizadas, utilizando o sistema digital Schick CDR (Schick Technologies, Inc, Long Island, EUA) e o aparelho de raios $X$ Gendex GX-700 (Kavo/Gendex Division, Biberach an der Riss, Alemanha), com 70 kVp, 7 $\mathrm{mA}$ e 6 pulsos por ciclo, da Faculdade de Odontologia da Universidade de Loma Linda, California, EUA. Cada dente foi exposto por duas vezes, com variação do ângulo horizontal entre as tomadas de 20 graus. Para estabilidade do sensor durante a tomada radiográfica, utilizou-se cera utilidade (Figura 6).

As imagens periapicais foram identificadas, salvas em formato JPG e inseridas em um arquivo de apresentação do programa Microsoft Office Power Point (Microsoft Corporation, Redmond, EUA), para posterior análise por avaliadores.

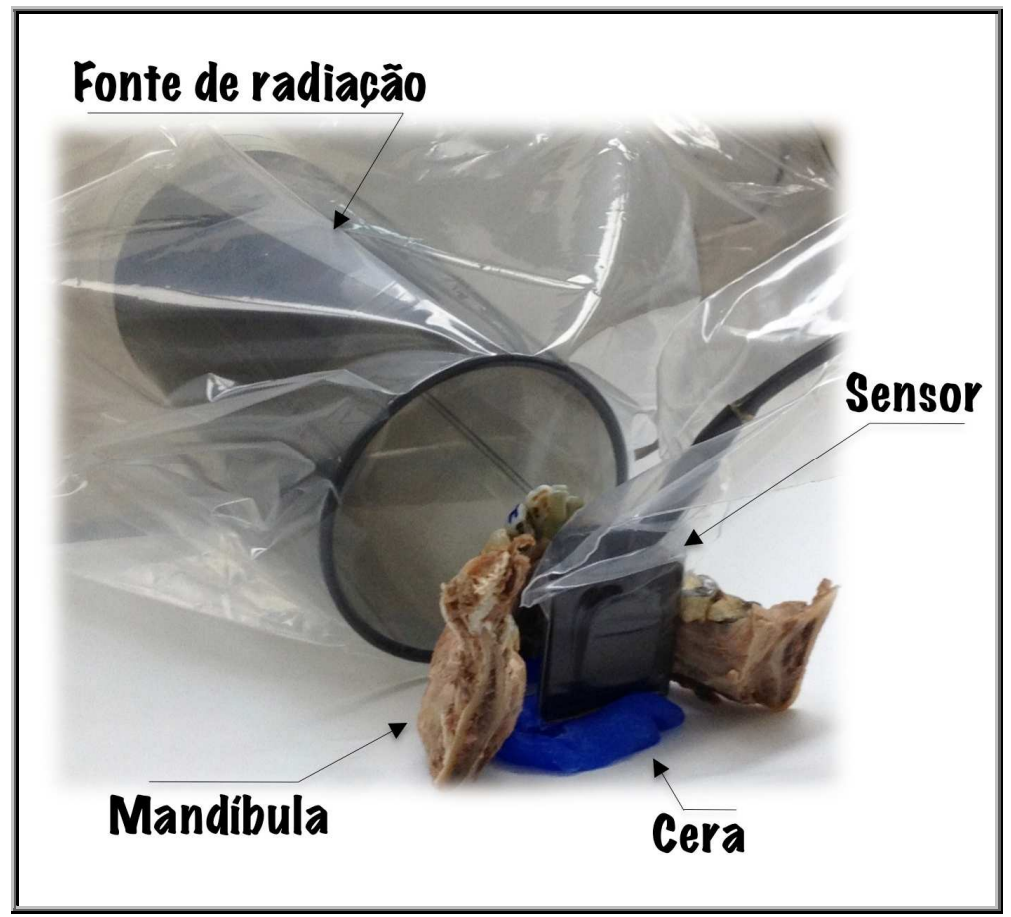

Figura 6: Posicionamento da mandíbula com os incisivos para tomada radiográfica periapical digital direta. 


\subsubsection{Escaneamentos em aparelhos de tomografia computadorizada de feixe cônico (TCFC)}

De modo idêntico ao das tomadas radiográficas periapicais, os incisivos da amostra foram posicionados nos alvéolos da mandíbula, de acordo com os grupos pré-determinados, sendo 4 dentes por vez, para cada escaneamento. A mandíbula com os dentes em posição foi colocada em recipiente plástico contendo água em seu interior, a fim de simular a presença de tecido mole. Em seguida, foi posicionada nos aparelhos de TCFC (Figura 7).

Três aparelhos de TCFC foram utilizados nessa etapa da pesquisa, sendo todos pertencentes à Faculdade de Odontologia da Universidade de Loma Linda, California, EUA. Os menores tamanhos de FOV e de voxel disponíveis em cada aparelho foram selecionados, sendo:

- Kodak 9000 3D (Carestream Health, Rochester, EUA), com 90 kVp, 10 mA, FOV de $5 \times 3,75 \mathrm{~cm}$ e tamanho de voxel de 0,076 mm;

- Veraviewepocs 3De (J Morita Mfg Corp, Kyoto, Japão), com 80 kVp, 10 mA, FOV de $4 \times 4 \mathrm{~cm}$ e tamanho de voxel de 0,125 mm;

- NewTom 5G (QR Srl, Verona, Itália), com 110 kVp, 12,74 mA, FOV de 6 X 6 $\mathrm{cm}$ e tamanho de voxel de $0,075 \mathrm{~mm}$.

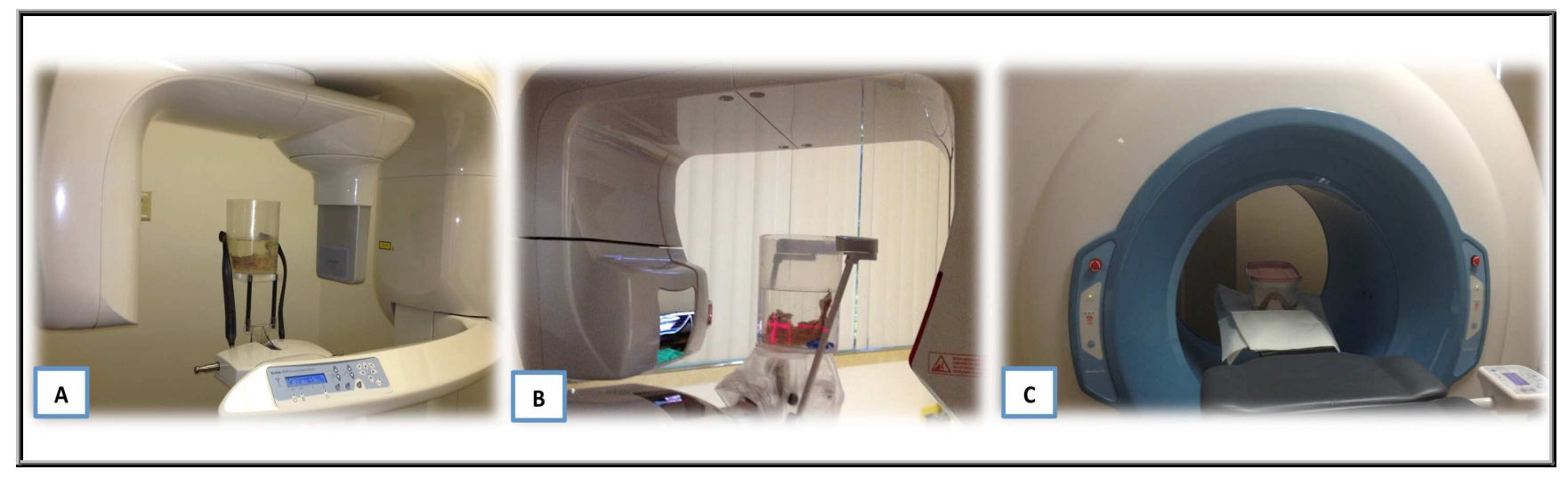

Figura 7: Posicionamento da mandíbula com os incisivos para escaneamento nos aparelhos de TCFC: (A) Kodak 9000 3D; (B) Veraviewepocs 3De; (C) NewTom 5 G.

Nos 3 tomógrafos, o paciente é posicionado de formas distintas, sendo em pé no Kodak 9000 3D e no Veraviewepocs 3De, e deitado no NewTom 5G. O recipiente 
contendo a mandíbula e os incisivos foi posicionado de forma a simular a cabeça do paciente ao ser escaneado em cada aparelho.

Os escaneamentos obtidos foram armazenados em um pen drive, devidamente identificados, para posterior avaliação nos softwares específicos de cada aparelho.

\subsubsection{Avaliação das imagens por examinadores}

Todas as imagens obtidas foram organizadas para posterior análise por examinadores. A fim de não haver memorização da sequência de dentes analisados por parte dos examinadores, cada dente foi apresentado com código diferente para cada tipo de imagem. Por exemplo: o dente "A1", que fazia parte do grupo "1", recebeu o código "1r" nas imagens radiográficas; "25K" nas imagens do tomógrafo Kodak; "37V" nas imagens do tomógrafo Veraviewepocs; "1N" nas imagens do tomógrafo NewTom (Figura 8). Esses números indicam a ordem de visualização, ou seja, o dente $A 1$ foi $\circ 25^{\circ}$ a ser visto nas imagens do tomógrafo Kodak e $\circ 1^{\circ}$ a ser visto nas imagens do tomógrafo NewTom, por exemplo. Portanto, a ordem com a qual o mesmo dente foi apresentado nas mais variadas imagens não foi a mesma, propositalmente. Um "gabarito" foi criado na planilha Excel, contendo: a identificação original do dente, seu tipo anatômico estabelecido por micro-TC e seus códigos nos 4 tipos de imagens obtidas. Apenas a responsável pela pesquisa tinha acesso a essa planilha.

\begin{tabular}{|c|c|c|c|c|c|c|}
\hline Dente & $\begin{array}{c}\text { Tipo } \\
\text { (padrão ouro) }\end{array}$ & Grupo & Periapical & TCFC Kodak & TCFC Veraviewepocs & TCFC NewTom \\
\hline A1 & III & 1 & $1 \mathrm{r}$ & $25 K$ & $37 \mathrm{~V}$ & $\mathbf{1 N}$ \\
\hline M4 & la & 8 & $29 \mathrm{r}$ & $13 \mathrm{~K}$ & $9 \mathrm{~V}$ & $\mathbf{2 9 N}$ \\
\hline
\end{tabular}

Figura 8: Exemplo de parte da planilha Excel com o "gabarito", ilustrando que os dentes da amostra receberam identificações diferentes em cada imagem e a ordem de análise foi variada para não haver memorização.

Previamente à análise de todas as imagens, 2 examinadores endodontistas receberam explicação, com uso da Figura 4, sobre quais tipos anatômicos deviam ser considerados (tipo I, tipo la e tipo III). Os examinadores também receberam 
treinamento para utilizar os softwares específicos de cada tomógrafo, como será explicado mais adiante. Cada examinador avaliou cada imagem por 2 vezes, com intervalo de 1 semana entre as avaliações, para estabelecer a concordância inter e intraexaminador. As avaliações foram realizadas em um computador de mesa com sistema Microsoft Windows Vista instalado (Microsoft Corporation, Redmond, EUA) e com monitor LCD Samsung SyncMaster 2220WM de 22 polegadas (Samsung, Seul, Coréia do Sul). As análises foram feitas em ambiente com pouca luminosidade e ausência de ruídos, proporcionando condições ideais para concentração dos observadores.

\subsubsection{Análise de imagens radiográficas:}

As imagens radiográficas estavam inseridas em um arquivo de apresentação do Microsoft Power Point, de fundo preto, com cada dente identificado por sua respectiva sigla "r" (Figura 9A). Como foi feita a técnica com duas tomadas com variação do ângulo horizontal, cada dente tinha 2 imagens radiográficas com diferentes angulações horizontais. As imagens já apresentavam brilho e contraste ideais para a avaliação. O examinador deveria olhar para ambas as imagens de cada dente e definir o padrão anatômico que julgava correto, anotando em uma folha de respostas (Figura 9B).

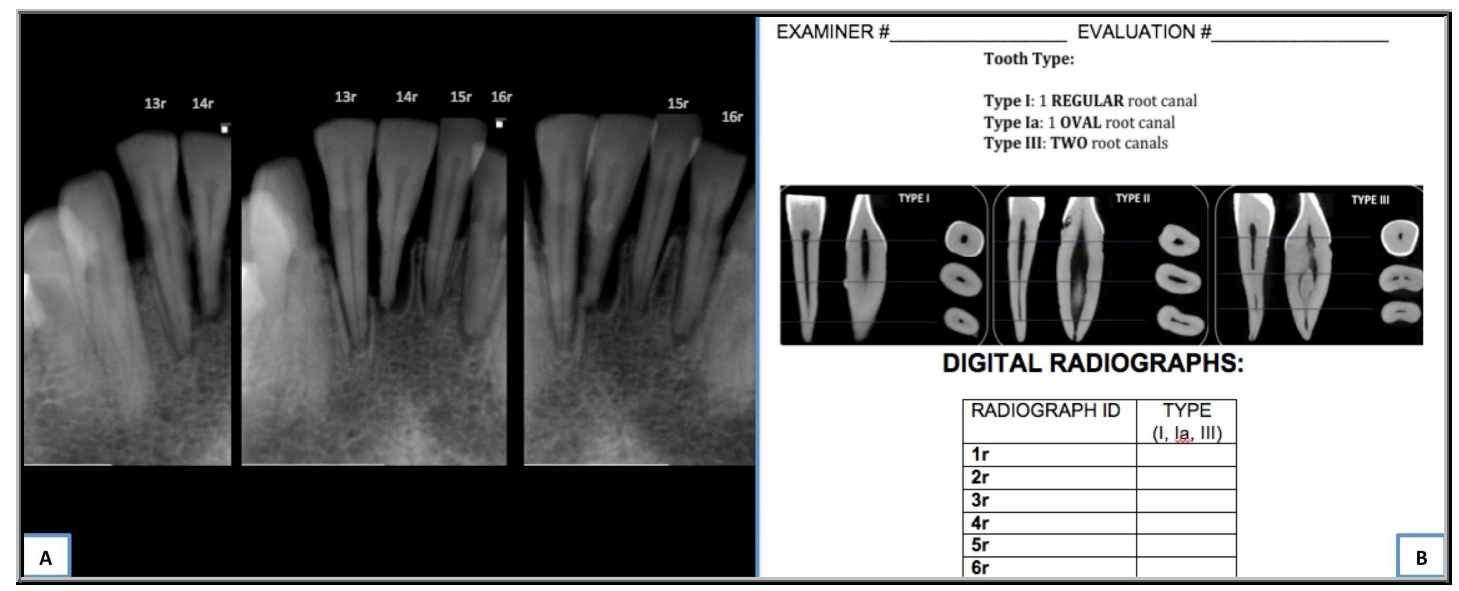

Figura 9: (A) Imagens radiográficas com identificação da ordem de análise; (B) Folha de respostas distribuída aos examinadores para que apontassem o tipo anatômico que julgavam correto ao ver imagens radiográficas de cada dente. 


\subsubsection{Análise de imagens tomográficas:}

Previamente à análise das imagens tomográficas, os examinadores receberam treinamento para cada software que iriam utilizar. Os programas de cada aparelho de TCFC foram, respectivamente:

-CS 3D Imaging Software, versão 3.1.9 (Carestream Health, Rochester, EUA);

-One Volume Viewer, versão 2.5.3.2864 (J Morita Mfg Corp, Kyoto, Japão);

-NNT Viewer, versão 3.00 (QR Srl, Verona, Itália).

Na Figura 10, observam-se capturas de tela representativas de cada software mencionado, respectivamente (Figuras 10A, 10B e 10C). Cada examinador aprendeu a utilizar as ferramentas dos softwares, após ter contato com tutoriais montados especificamente para essa pesquisa. Os dentes a serem avaliados estavam apontados em cada tutorial, de acordo com as siglas pré-determinadas, conforme explicado anteriormente (Figura 8). O avaliador podia ajustar contraste, brilho e angulações das imagens, de acordo com a preferência individual. Os programas eram bem semelhantes entre si, permitindo a visualização da região de interesse nas reformatações axial, coronal e sagital (Figura 10). O examinador deveria explorar as imagens tomográficas ao máximo e definir o padrão anatômico que julgava correto para cada dente, anotando em folha de respostas. 



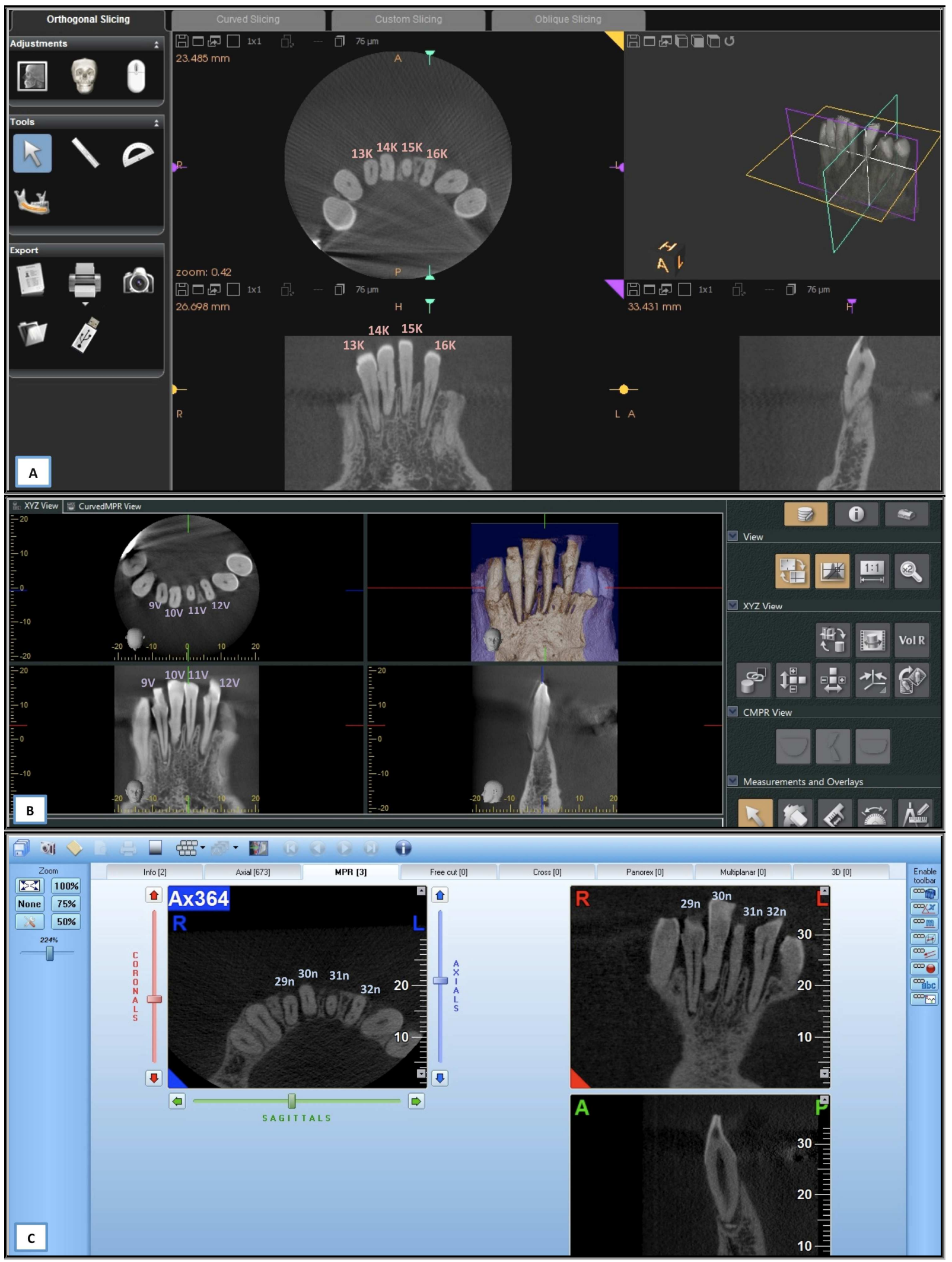

Figura 10: Exemplo de telas dos programas de cada aparelho de TCFC: (A) software CS 3D (Kodak); (B) software One Volume Viewer (Veraviewepocs); (C) software NNT Viewer (NewTom). 



\subsubsection{Comparação ao padrão ouro e análise dos resultados}

Após a obtenção das respostas dos 2 examinadores para cada dente e em cada avaliação, criou-se uma planilha Excel contendo todos os dados. As respostas dadas pelos examinadores foram confrontadas com o padrão ouro e foi feita uma identificação na tabela, podendo ser "C" (resposta certa) ou "E" (resposta errada) (Figura 11).

\begin{tabular}{|c|c|c|c|c|c|}
\hline \multicolumn{6}{|c|}{$\begin{array}{l}\text { MÉTODO 1- Radiografia Periapical Digital } \\
\text { Examinador 1: }\end{array}$} \\
\hline MET & $\begin{array}{l}\text { TIPO } \\
1^{\mathrm{a}}\end{array}$ & $\begin{array}{l}\mathrm{C} / \mathrm{E} \\
1^{\mathrm{a}}\end{array}$ & $\begin{array}{l}\text { TIPO } \\
2^{\mathrm{a}}\end{array}$ & $\begin{array}{l}\mathrm{C} / \mathrm{E} \\
2^{\mathrm{a}}\end{array}$ & Padrão Ouro \\
\hline $1 \mathbf{r}$ & III & C & III & C & Tipo III \\
\hline $2 r$ & I & E & I & E & Tipo Ia \\
\hline $3 r$ & III & C & I & E & Tipo III \\
\hline \multicolumn{6}{|c|}{ MÉTODO 2-TCFC Kodak } \\
\hline MET & $\begin{array}{l}\text { TIPO } \\
1^{\mathrm{a}}\end{array}$ & $\begin{array}{l}\mathrm{C} / \mathrm{E} \\
1^{\mathrm{a}}\end{array}$ & $\begin{array}{l}\text { TIPO } \\
2^{a}\end{array}$ & $\begin{array}{l}\mathrm{C} / \mathrm{E} \\
2^{\mathrm{a}}\end{array}$ & Padrão Ouro \\
\hline $1 \mathrm{~K}$ & I & E & III & C & Tipo III \\
\hline $2 \mathrm{~K}$ & I & C & I & C & Tipo I \\
\hline 3K & III & C & III & C & Tipo III \\
\hline
\end{tabular}

Figura 11: Exemplo de parte da tabela Excel criada para avaliação de resultados: "MET": identificação do dente no referido método; "TIPO 1"a": resposta do avaliador na primeira avaliação de imagens daquele método; "C/E $1^{\text {a": }}$ resposta do examinador na primeira avaliação de acordo com o padrão ouro ("C"- certa) ou não correspondente ao padrão ouro ("E"- errada); "TIPO 2": resposta do avaliador na segunda avaliação de imagens daquele método; "C/E $2^{\text {a". }}$ resposta do examinador na segunda avaliação de acordo com o padrão ouro ("C"- certa) ou não correspondente ao padrão ouro ("E"- errada); "PADRÃO OURO": classificação anatômica determinada nas imagens de micro-TC.

Para descrição dos resultados, utilizou-se a porcentagem (\%) de respostas certas / erradas. Aplicou-se o teste do qui-quadrado $\left(\chi^{2}\right)$, com nível de significância estatística estabelecido em $5 \%$, para verificação da associação entre variáveis. A concordância inter e intraexaminador para a primeira e a segunda avaliações foi determinada por teste de kappa. 
4.2 SEGUNDA ETAPA DA PESQUISA: Determinação da prevalência de 2 canais radiculares em incisivos inferiores de pacientes da FOB-USP no banco de imagens de tomografia computadorizada de feixe cônico

\subsubsection{Seleção da amostra / critérios de inclusão}

Nessa etapa da pesquisa, realizou-se interpretação de imagens de exames de TCFC armazenados em banco de dados do tomógrafo i-CAT (Imaging Sciences International, Hatfield, PA, EUA), modelo Classic, pertencente ao Departamento de Estomatologia da Faculdade de Odontologia de Bauru da Universidade de São Paulo (FOB-USP). Nenhum paciente foi submetido ao exame de TCFC exclusivamente para este estudo.

Como critérios de inclusão na amostra, apontam-se:

\subsubsection{Protocolo de escaneamento}

Foram selecionados exames cujos protocolos utilizaram FOV de 6 X $16 \mathrm{~cm}$ ou de $8 \times 16 \mathrm{~cm}$; voxel de 0,25 ou de $0,3 \mathrm{~mm}$ e tempo de $40 \mathrm{~s}$ ou $20 \mathrm{~s}$, para visualização da mandíbula.

\subsubsection{Condição dos incisivos inferiores}

Foram selecionados exames nos quais a mandíbula era dentada total ou desdentada parcial, apresentando no mínimo 1 incisivo inferior. O dente deveria estar com sua estrutura radicular íntegra, sem obturação endodôntica, brackets ortodônticos, fraturas ou outras alterações que pudessem comprometer a avaliação de sua anatomia interna radicular.

O total de 100 exames de TCFC que atendiam os critérios de inclusão foi selecionado para composição da amostra. 


\subsubsection{Registro dos dados e interpretação das imagens}

Previamente ao início da avaliação dos incisivos inferiores nos exames de TCFC, foram coletados dados armazenados no software i-CAT Vision (Imaging Sciences International, Hatfield, PA, EUA) e inseridos em uma planilha Excel. Anotavam-se então os seguintes dados: a identificação do exame, que consistia em numeração ordinal, a partir do primeiro exame a ser analisado, com a finalidade de organizar e localizar o exame sempre que necessário; a idade e o gênero do paciente, com finalidade comparativa. Tais informações estavam disponíveis na tela inicial do programa, denominada "preview screen".

A interpretação das imagens foi feita rigorosamente da mesma maneira, utilizando-se um computador de mesa com sistema operacional Microsoft Windows XP Professional versão 2002 (Microsoft Corporation, Redmond, WA, EUA) e monitor da marca EIZO (Eizo Nanao Corporation, Ishiwaka, Japão), modelo FlexScan S2000 de 20 polegadas, com resolução de 1600 por 1200 pixels, com o software i-CAT Vision instalado.

Na primeira etapa de avaliação das imagens, a reformatação panorâmica da mandíbula foi utilizada para realizar a contagem dos incisivos inferiores e verificar se os mesmos obedeciam aos critérios de inclusão. Utilizou-se ferramenta específica para definir a reformatação panorâmica na tela inicial ("preview screen") (Figura 12).

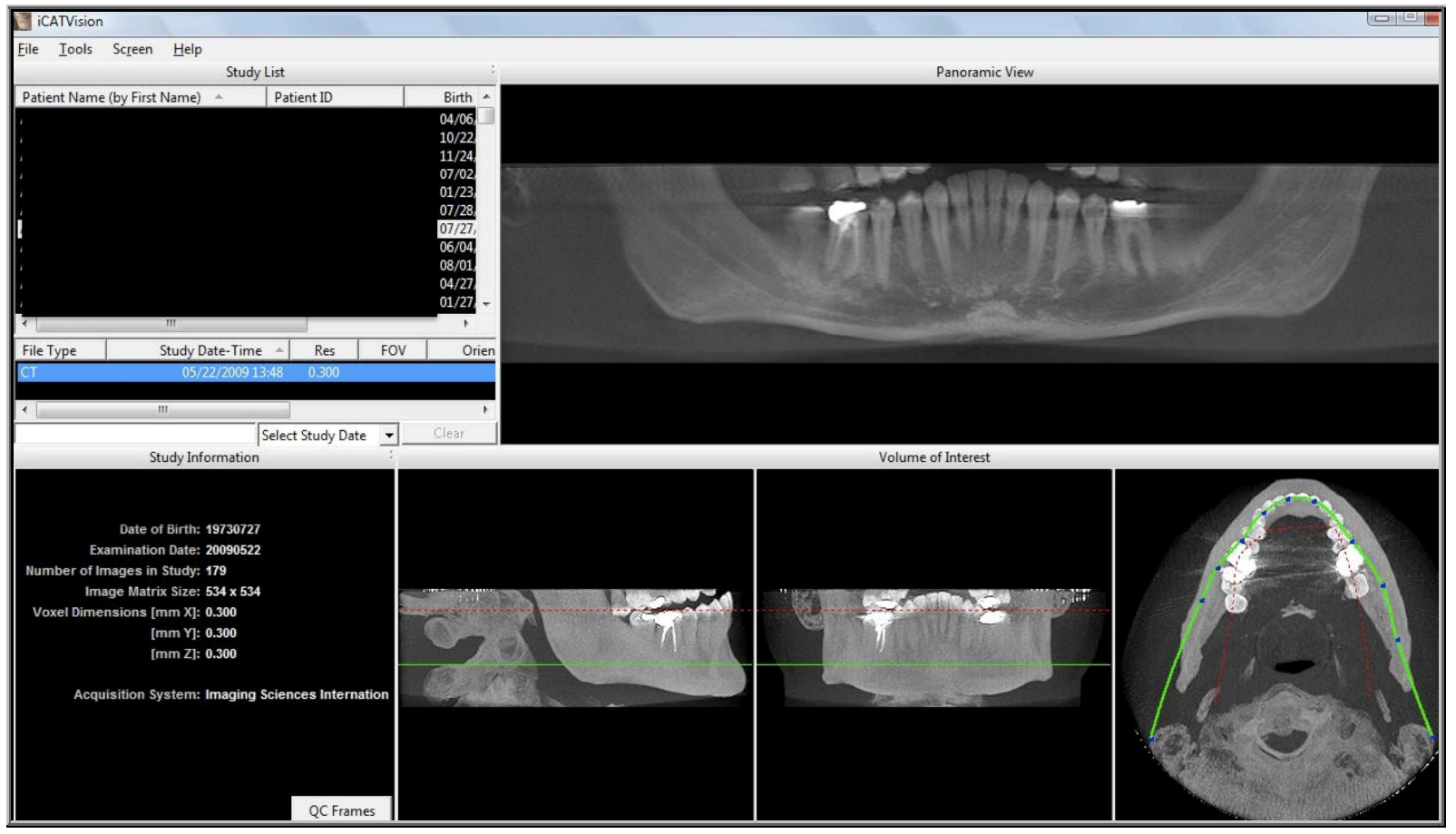

Figura 12: Tela "preview screen" do programa i-CAT Vision. 
Em seguida, a anatomia dos incisivos inferiores era avaliada na tela "MPR screen" do software, que permitia a avaliação nas reformatações sagital, axial e coronal (Figura 13). O filtro utilizado para as imagens era o "normal" e a espessura e o intervalo (step) entre as reformatações era ajustado para os menores valores possíveis $(0,3 \mathrm{~mm}$ em caso de tamanho de voxel 0,3 ou $0,25 \mathrm{~mm}$ em caso de tamanho de voxel 0,25 ).

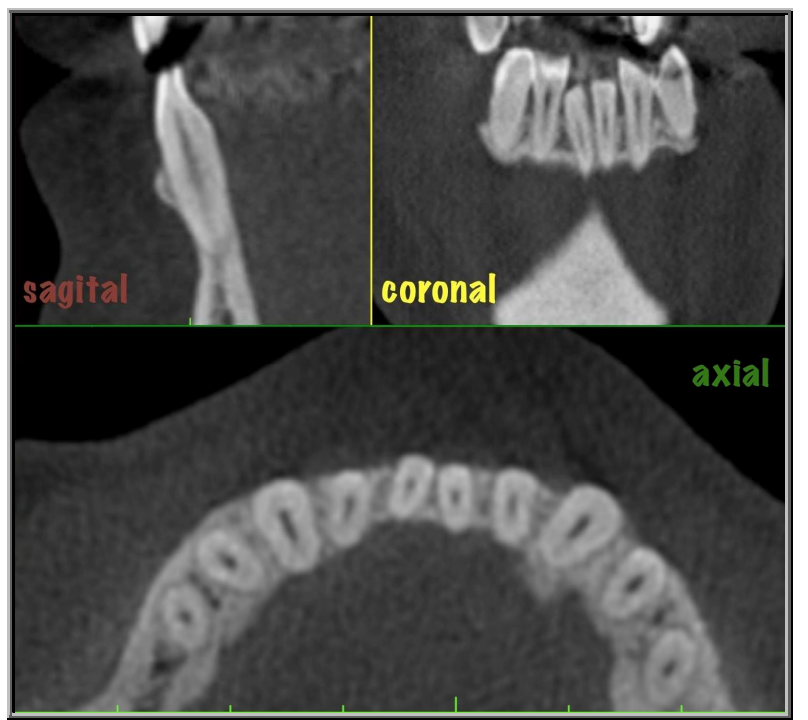

Figura 13: Imagens representativas das reformatações nas quais os dentes foram avaliados.

O padrão anatômico de cada dente foi anotado na planilha Excel, que continha as informações computadas inicialmente, bem como os dados da contagem de incisivos inferiores de cada paciente. Para essa etapa da pesquisa foram considerados 2 tipos apenas (Figura 14):

\section{-Tipo anatômico com 1 canal radicular;}

-Tipo anatômico com 2 canais radiculares.

Cada incisivo era observado individualmente, nas 3 reformatações e nos 3 terços (apical, médio e cervical). Se em algum ponto fosse observada a divisão de um canal radicular em 2 canais principais, o dente era classificado como sendo de tipo anatômico com 2 canais radiculares. Dois examinadores realizaram a interpretação das imagens, sendo um radiologista e outro endodontista. $O$ avaliador radiologista realizou 2 avaliações, com intervalo de 1 semana entre elas, para estabelecer a concordância intraexaminador. 


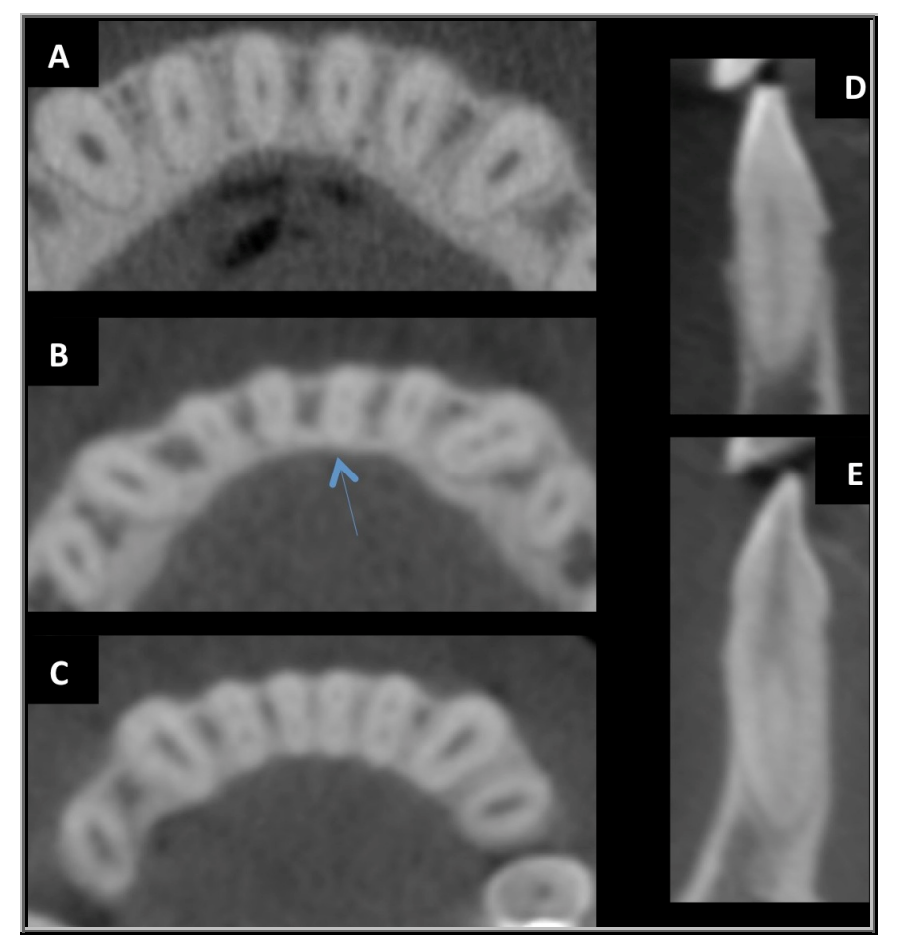

Figura 14: Imagens representativas dos tipos anatômicos considerados nessa etapa da pesquisa. Vista axial: (A) 4 incisivos com 1 canal radicular; (B) 3 incisivos com 1 canal radicular e 1 incisivo com 2 canais (apontado pela seta); (C) 4 incisivos com 2 canais radiculares. Vista sagital: (D) incisivo com 1 canal radicular; $(\mathbf{E})$ incisivo com 2 canais radiculares.

\subsubsection{Análise dos resultados}

Após a avaliação dos incisivos inferiores presentes em 100 exames de TCFC, os dados foram inseridos na planilha Excel. Para descrição dos dados coletados e constatação da prevalência de 2 canais radiculares em incisivos da amostra, utilizouse a porcentagem (\%). Para verificar a associação entre prevalência de 2 canais radiculares e localização do dente, gênero e idade do paciente, utilizou-se o teste do qui-quadrado $\left(\chi^{2}\right)$, com nível de significância estatística estabelecido em $5 \%$. Para a concordância intra e interexaminador, utilizou-se o teste de kappa. 

5 Resultados 



\section{RESULTADOS}

\subsection{PRIMEIRA ETAPA DA PESQUISA:}

Após a tabulação dos dados obtidos na planilha Excel, observou-se o número de respostas dos avaliadores que correspondiam ao padrão ouro (ou seja, o total de dentes corretamente identificados), para cada método, para cada tipo anatômico e para cada avaliador.

Somaram-se as respostas dadas nas 2 avaliações pelos 2 examinadores, o que justifica o " $\mathrm{n}$ " duplicado para cada tipo (por exemplo: a amostra continha 12 dentes de padrão ouro do Tipo I. No entanto, cada avaliador examinou essa amostra 2 vezes, sendo, portanto, o total de 24 dentes de Tipo I avaliados por examinador). A significância estatística entre os métodos foi calculada e está representada por letras sobrescritas ao número de respostas corretas.

\subsubsection{Tipo I}

A quantidade de respostas certas para o Tipo I está apresentada na Tabela 1. O Gráfico 1 indica as porcentagens de respostas certas e de respostas erradas, apontando quais foram os erros.

Tabela 1- Comparação entre os métodos para identificação do Tipo I: total de respostas corretas por avaliador.

\begin{tabular}{|c|c|c|}
\hline & AVALIADOR A & AVALIADOR B \\
\hline MÉTODO & $\begin{array}{l}\text { Tipo I } \\
(n=24)\end{array}$ & $\begin{array}{l}\text { Tipo } I \\
(n=24)\end{array}$ \\
\hline Radiografia periapical & $16^{\mathrm{a}}$ & $16^{\mathrm{a}}$ \\
\hline TCFC-Kodak & $23^{b}$ & $24^{b}$ \\
\hline TCFC-Veraviewepocs & $24^{b}$ & $24^{b}$ \\
\hline TCFC-NewTom & $23^{b}$ & $24^{b}$ \\
\hline
\end{tabular}




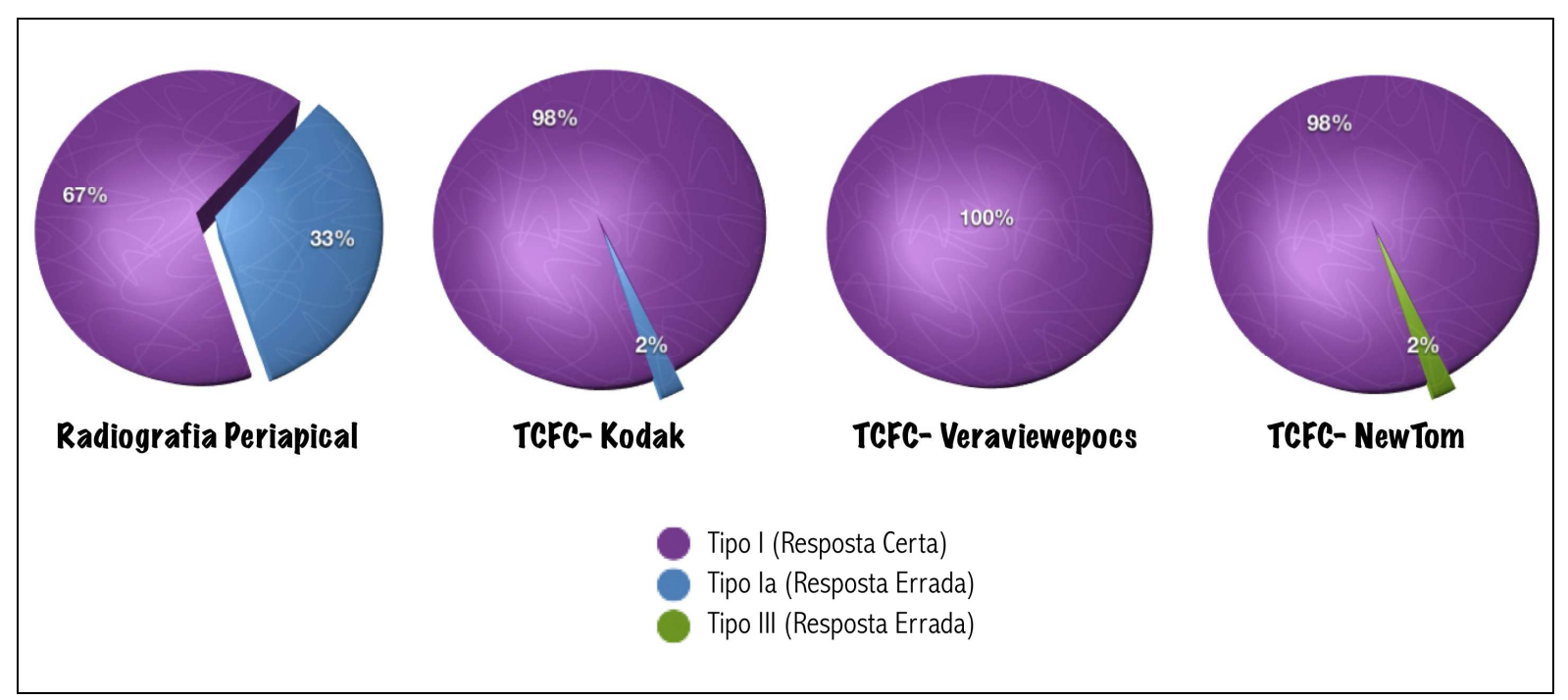

Gráfico 1- Respostas certas e erradas em relação ao Tipo I.

Ao observar a Tabela 1, constata-se que, para a identificação do Tipo I, as imagens de TCFC foram superiores em comparação à radiografia periapical digital com duas tomadas e variação do ângulo horizontal $(\mathrm{RP}=67 \%$ de acerto; TCFC= $98 \%$ de acerto, $p<0,05)$. Considerando os 3 aparelhos de TCFC, não houve diferença estatística significante entre eles para a identificação do Tipo I.

Analisando a totalidade das respostas obtidas (Gráfico 1), verificou-se que, quando os examinadores deram uma resposta errada em relação ao padrão ouro Tipo I, na grande maioria das vezes, a confusão foi com o Tipo la. Com o método de radiografia periapical, por exemplo, 33\% das respostas dadas estavam erradas, sendo todas Tipo la. O Tipo I foi confundido com Tipo III (2 canais) somente em $2 \%$ das respostas, com o tomógrafo NewTom. 


\subsubsection{Tipo la}

A quantidade de respostas certas para o Tipo la está apresentada na Tabela 2. O Gráfico 2 indica as porcentagens de respostas certas e de respostas erradas, apontando quais foram os erros.

Tabela 2- Comparação entre os métodos para identificação do Tipo la: total de respostas corretas por avaliador.

\begin{tabular}{|c|c|c|}
\hline & AVALIADOR A & AVALIADOR B \\
\hline MÉTODO & $\begin{array}{c}\text { Tipo Ia } \\
(n=24)\end{array}$ & $\begin{array}{c}\text { Tipo Ia } \\
(n=24)\end{array}$ \\
\hline Radiografia periapical & $10^{\mathrm{a}}$ & $11^{\mathrm{a}}$ \\
\hline TCFC-Kodak & $16^{\mathrm{a}, \mathrm{b}}$ & $18^{\mathrm{a}, \mathrm{b}}$ \\
\hline TCFC-Veraviewepocs & $17^{\mathrm{a}, \mathrm{b}}$ & $17^{\mathrm{a}, \mathrm{b}}$ \\
\hline TCFC-NewTom & $22^{b}$ & $20^{b}$ \\
\hline
\end{tabular}

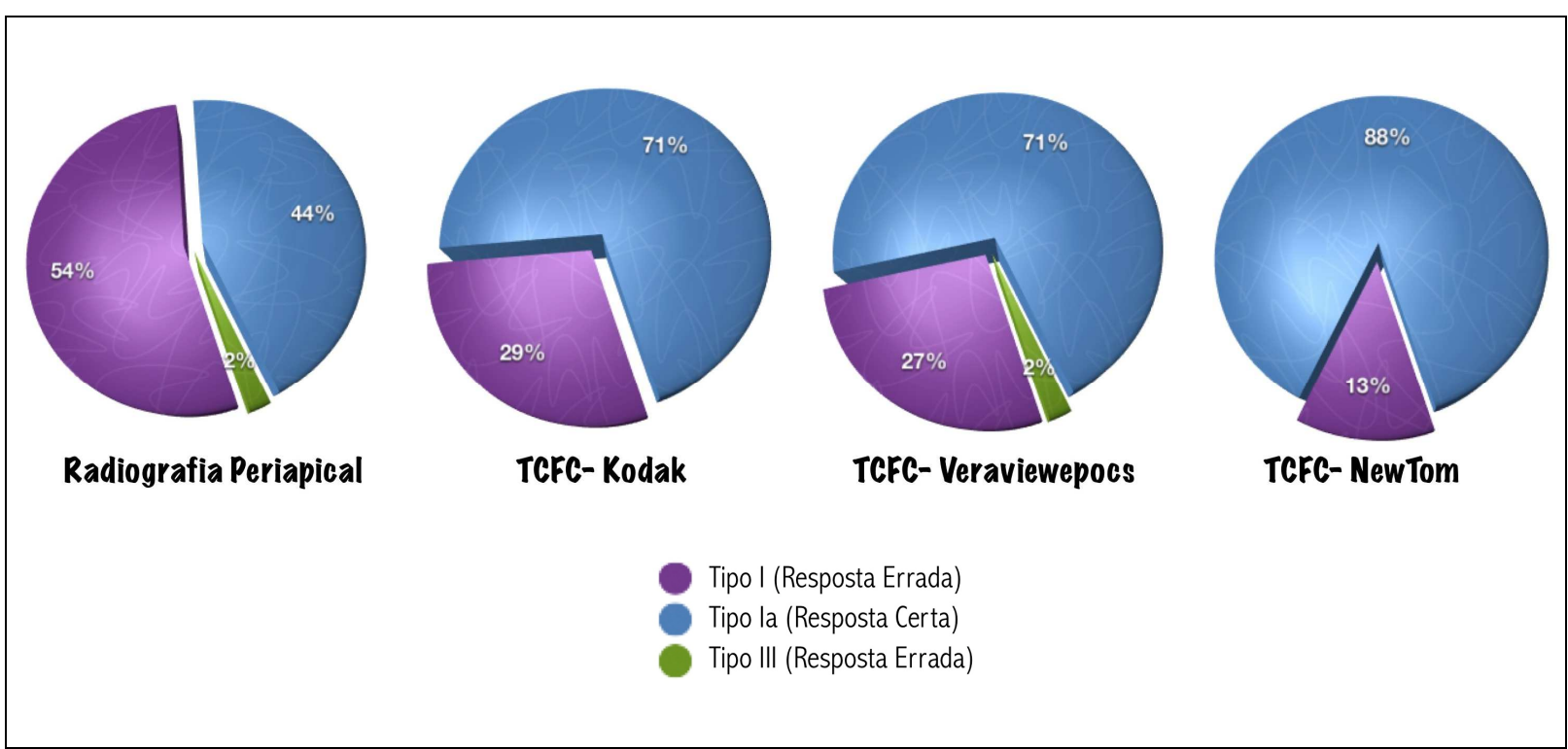

Gráfico 2- Respostas certas e erradas em relação ao Tipo la.

Considerando a identificação do Tipo la, houve diferença estatística significante entre radiografia periapical digital com duas tomadas e variação do ângulo horizontal e o tomógrafo NewTom (RP=44\% de acerto; TCFC NewTom= $88 \%$ de acerto). Não houve diferença significante entre os outros 2 tomógrafos e radiografia periapical ou entre os 3 tomógrafos. 
Analisando a totalidade das respostas obtidas (Gráfico 2), verificou-se que, quando os examinadores deram uma resposta errada em relação ao padrão ouro Tipo la, na grande maioria das vezes, a confusão foi com o Tipo I. Com o método de radiografia periapical, por exemplo, 54\% das respostas dadas estavam erradas, sendo todas Tipo I. O Tipo la foi confundido com Tipo III (2 canais) somente em 4\% das respostas, no total.

\subsubsection{Tipo III}

A quantidade de respostas certas para o Tipo III está apresentada na Tabela 3. O Gráfico 3 indica as porcentagens de respostas certas e de respostas erradas, apontando quais foram os erros.

Tabela 3- Comparação entre os métodos para identificação do Tipo III: total de respostas corretas por avaliador.

\begin{tabular}{|c|c|c|}
\hline & AVALIADOR A & AVALIADOR B \\
\hline MÉTODO & $\begin{array}{c}\text { Tipo III } \\
(n=32)\end{array}$ & $\begin{array}{c}\text { Tipo III } \\
(n=32)\end{array}$ \\
\hline Radiografia periapical & $23^{a}$ & $24^{a}$ \\
\hline TCFC-Kodak & $25^{\mathrm{a}}$ & $27^{\mathrm{a}}$ \\
\hline TCFC-Veraviewepocs & $27^{\mathrm{a}}$ & $27^{\mathrm{a}}$ \\
\hline TCFC-NewTom & $27^{\mathrm{a}}$ & $28^{a}$ \\
\hline
\end{tabular}

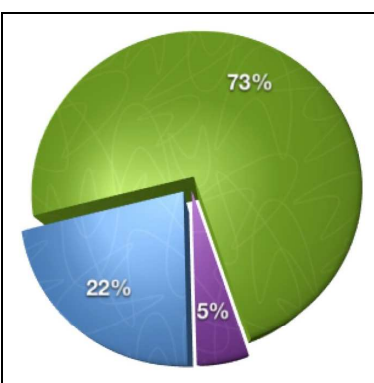

Radiografia Periapical

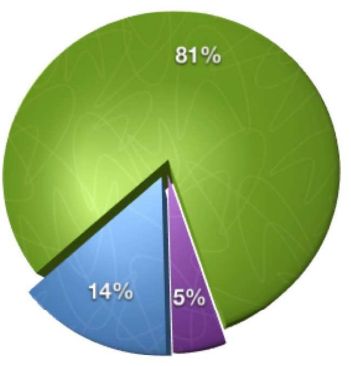

TCFC- Kodak

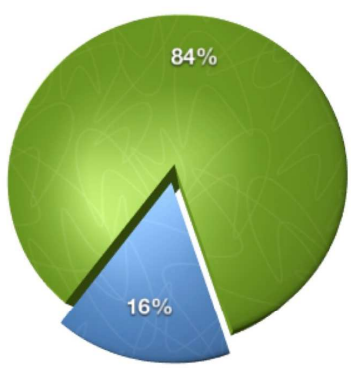

TCFC- Veraviewepocs

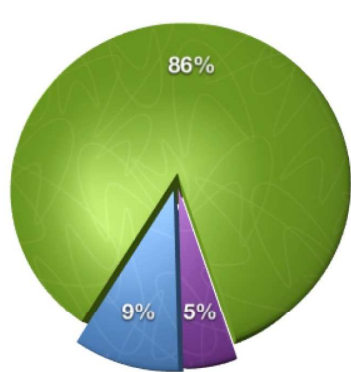

TCFC- NewTom

Gráfico 3- Respostas certas e erradas em relação ao Tipo III. 
Considerando a identificação do Tipo III, não houve diferença estatística significante entre nenhum dos métodos. Todos os métodos apresentaram quantidades de respostas certas semelhantes.

Em relação à totalidade das respostas obtidas (Gráfico 3), verificou-se que, quando os examinadores deram uma resposta errada em relação ao padrão ouro Tipo III, na maioria das vezes, a confusão foi com o Tipo la.

\subsubsection{Concordância entre avaliações}

Considerando a concordância intraexaminador, os valores de kappa estão apresentados na Tabela 4. Esses valores indicam concordância regular para radiografia periapical e concordância de boa a excelente para os aparelhos de TCFC.

Tabela 4- Concordância intraexaminador.

\begin{tabular}{l|c|c|}
\hline \multicolumn{1}{|c|}{ Método } & Avaliador A & Avaliador B \\
\hline Radiografia periapical & 0,40 & 0,66 \\
\hline TCFC-Kodak & 0,62 & 0,85 \\
\hline TCFC-Veraviewepocs & 0,63 & 0,77 \\
\hline TCFC-NewTom & 0,74 & 0,85 \\
\hline
\end{tabular}

Em relação à concordância interexaminador, os valores de kappa estão apresentados na Tabela 5. Esses valores indicam concordância de ruim a regular para radiografia periapical e concordância de boa a excelente para os aparelhos de TCFC.

Tabela 5- Concordância interexaminador.

\begin{tabular}{|l|c|c|}
\hline \multicolumn{1}{|c|}{ Método } & $\mathbf{1}^{\text {a }}$ avaliação & $\mathbf{2}^{\text {a }}$ avaliação \\
\hline Radiografia periapical & 0,32 & 0,25 \\
\hline TCFC-Kodak & 0,62 & 0,85 \\
\hline TCFC-Veraviewepocs & 0,81 & 0,85 \\
\hline TCFC-NewTom & 0,74 & 0,92 \\
\hline
\end{tabular}




\subsection{SEGUNDA ETAPA DA PESQUISA:}

\subsubsection{Amostra}

Foram avaliadas imagens de TCFC de 100 indivíduos, em cujos exames a mandíbula era visível, atendendo os critérios de inclusão. O total de 386 incisivos inferiores foi avaliado, sendo 192 incisivos centrais e 194 incisivos laterais. A prevalência de 2 canais radiculares constatada nas imagens de TCFC dos indíviduos foi de $16,5 \%$.

\subsubsection{Prevalência de incisivos inferiores com 1 ou 2 canais radiculares} em relação à localização do dente

As Tabelas 6 e 7 e os gráficos 4 e 5 apontam a prevalência dos padrões anatômicos para incisivos centrais e laterais inferiores.

Tabela 6- Distribuição numérica e percentual de incisivos centrais inferiores, em relação a tipos anatômicos $(p>0,05)$.

\begin{tabular}{lcc}
\hline Tipos anatômicos & $\mathbf{n}$ & $\mathbf{\%}$ \\
& & \\
\hline 1 canal & 167 & $87 \%$ \\
\hline 2 canais & 25 & $13 \%$ \\
TOTAL & 192 & $100 \%$ \\
\hline
\end{tabular}

Tabela 7- Distribuição numérica e percentual de incisivos laterais inferiores, em relação a tipos anatômicos $(p>0,05)$.

\begin{tabular}{lcc}
\hline Tipos anatômicos & $\mathbf{n}$ & $\mathbf{\%}$ \\
& & \\
\hline 1 canal & 155 & $80 \%$ \\
2 canais & 39 & $\mathbf{2 0 \%}$ \\
TOTAL & 194 & $100 \%$ \\
\hline
\end{tabular}




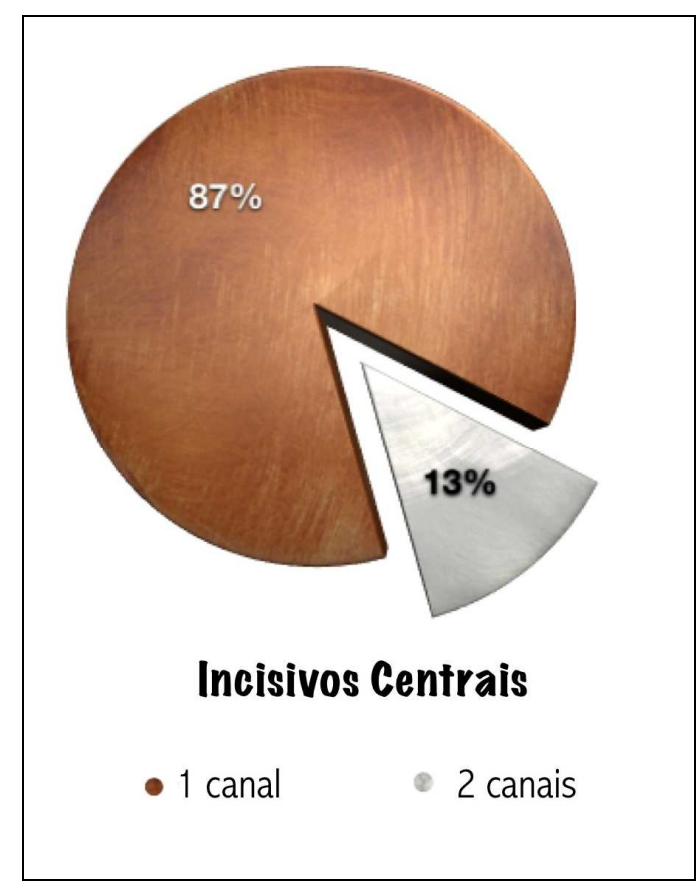

Gráfico 4- Prevalência de 1 ou 2 canais em incisivos centrais inferiores da amostra.

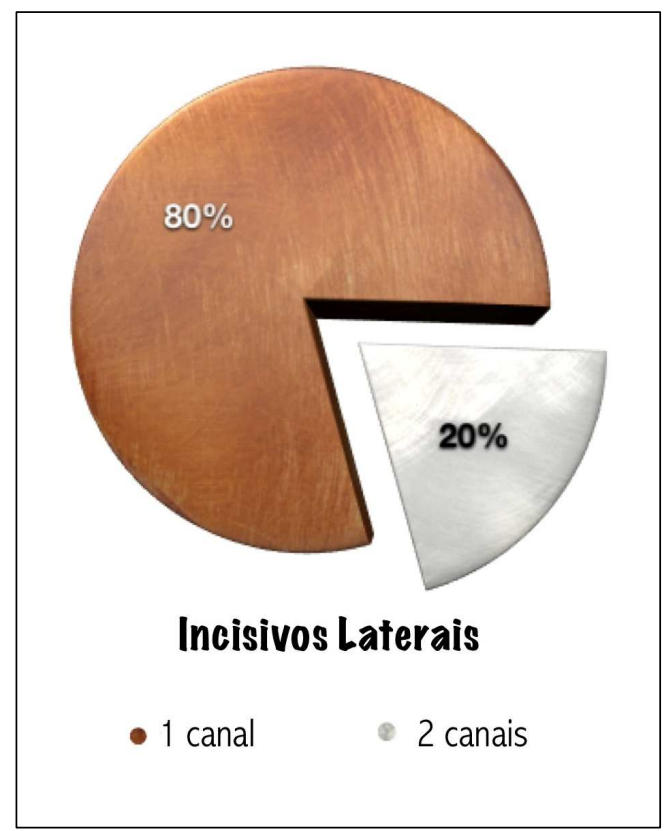

Gráfico 5- Prevalência de 1 ou 2 canais em incisivos laterais inferiores da amostra.

Não houve diferença estatisticamente significante quanto à presença de 2 canais radiculares entre incisivos centrais inferiores e incisivos laterais inferiores $(p>0,05)$. 


\subsubsection{Prevalência de incisivos inferiores com 1 ou 2 canais radiculares} em relação a gênero

Ao observar as informações sobre os pacientes que haviam realizado os exames de TCFC, contabilizaram-se 42 homens e 58 mulheres. A Tabela 8 apresenta a prevalência dos tipos anatômicos em relação ao gênero dos pacientes.

Tabela 8- Distribuição percentual de incisivos centrais e laterais inferiores em relação a tipos anatômicos e gênero dos pacientes $(p>0,05)$.

\begin{tabular}{l|cccc}
\hline & \multicolumn{3}{c}{ Prevalência / gênero } \\
\cline { 2 - 5 } Tipos anatômicos & centrais & centrais & laterais & laterais \\
HOMENS & MULHERES & HOMENS & MULHERES \\
\hline 1 canal & $84 \%$ & $86 \%$ & $79 \%$ & $73 \%$ \\
\hline 2 canais & $\mathbf{1 6 \%}$ & $\mathbf{1 4 \%}$ & $\mathbf{2 1 \%}$ & $\mathbf{2 7 \%}$ \\
\hline TOTAL & $100 \%$ & $100 \%$ & $100 \%$ & $100 \%$ \\
\hline
\end{tabular}

Observou-se pequena diferença entre os gêneros, e ambos apresentaram maior prevalência de 2 canais radiculares em incisivos laterais inferiores do que em centrais. No entanto, os resultados não foram estatisticamente significantes ( $p>$ $0,05)$.

\subsubsection{Prevalência de incisivos inferiores com 1 ou 2 canais radiculares} em relação à idade

Os 100 pacientes que realizaram exames de TCFC foram divididos em grupos etários, sendo:
a) 15 - 29 anos: 20 pacientes;
b) 30 - 49 anos: 39 pacientes;
c) 50 ou mais: 41 pacientes.

Dos 100 pacientes, a presença de 2 canais radiculares em incisivos centrais inferiores foi observada em 15 pacientes e em incisivos laterais inferiores em 25 pacientes. A idade média dos pacientes foi de 45 anos, sendo a idade mínima de 15 
e a máxima de 79 anos. As tabelas 9 e 10 apresentam a prevalência dos tipos anatômicos em relação à idade dos pacientes.

Tabela 9- Distribuição percentual de incisivos centrais inferiores em relação a tipos anatômicos e idade dos pacientes $(p>0,05)$

\begin{tabular}{lccc}
\hline & \multicolumn{3}{c}{ Prevalência / idade } \\
\cline { 2 - 4 } Tipos anatômicos & $\begin{array}{c}15-29 \\
\text { anos }\end{array}$ & $\begin{array}{c}30-49 \\
\text { anos }\end{array}$ & $\begin{array}{c}50 \text { ou }+ \\
\text { anos }\end{array}$ \\
\hline 1 canal & $70 \%$ & $89,8 \%$ & $87,8 \%$ \\
\hline 2 canais & $30 \%$ & $\mathbf{1 0 , 2} \%$ & $\mathbf{1 2 , 2 \%}$ \\
\hline TOTAL & $100 \%$ & $100 \%$ & $100 \%$ \\
\hline
\end{tabular}

Tabela 10- Distribuição percentual de incisivos laterais inferiores em relação a tipos anatômicos e idade dos pacientes $(p>0,05)$

\begin{tabular}{lccc}
\hline & \multicolumn{3}{c}{ Prevalência / idade } \\
\cline { 2 - 4 } Tipos anatômicos & $\begin{array}{c}15-29 \\
\text { anos }\end{array}$ & $\begin{array}{c}30-49 \\
\text { anos }\end{array}$ & $\begin{array}{c}50 \text { ou }+ \\
\text { anos }\end{array}$ \\
\hline 1 canal & $70 \%$ & $84,6 \%$ & $68,3 \%$ \\
\hline 2 canais & $30 \%$ & $\mathbf{1 5 , 4 \%}$ & $\mathbf{3 1 , 7 \%}$ \\
\hline TOTAL & $100 \%$ & $100 \%$ & $100 \%$ \\
\hline
\end{tabular}

Observou-se diferença entre os grupos etários, com a maior porcentagem de incisivos centrais inferiores com 2 canais radiculares em pacientes na faixa dos 15 29 anos de idade. Em relação aos incisivos laterais inferiores, a maior prevalência de 2 canais radiculares foi constatada no grupo de pacientes na faixa dos 50 ou mais anos de idade. No entanto, as diferenças não foram estatisticamente significantes $(p>0,05)$. 


\subsubsection{Concordância entre avaliações}

A Tabela 11 apresenta a concordância intraexaminador (radiologista antes e depois) e interexaminador (radiologista e endodontista).

Tabela 11- Concordâncias intra e interexaminador.

\begin{tabular}{|l|c|}
\hline \multicolumn{1}{|c|}{ Concordância } & kappa \\
\hline Intraexaminador & 0,60 \\
\hline Interexaminador & 0,57 \\
\hline
\end{tabular}

Esses valores indicam concordâncias intra e interexaminador regulares. 


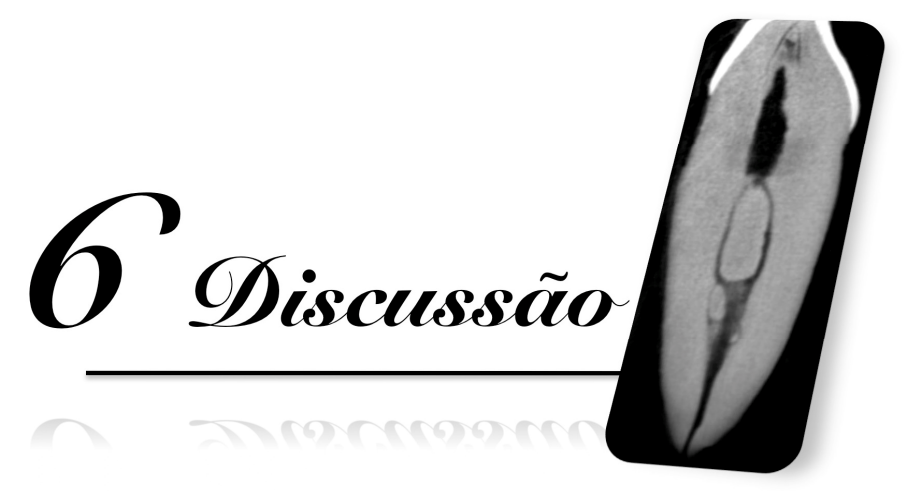





\section{DISCUSSÃO}

\subsection{PRIMEIRA ETAPA DA PESQUISA:}

\subsubsection{Anatomia interna dos incisivos inferiores e suas implicações} clínicas

O conhecimento da anatomia interna dos dentes é fundamental para o sucesso do tratamento de canais radiculares. Os incisivos inferiores frequentemente são tratados endodonticamente por profissionais clínicos gerais, que consideram que esses dentes não oferecem dificuldade por serem monorradiculados, possuírem anatomia relativamente simples e estarem localizados na região anterior da mandíbula, onde o acesso é mais fácil. No entanto, variações anatômicas internas relevantes podem estar presentes e, caso não sejam detectadas pelo profissional, o resultado do tratamento endodôntico estará comprometido (CARROTTE, 2004b). Na presente pesquisa, optou-se por estudar incisivos inferiores permanentes, após verificar na literatura que, em média, $30 \%$ de dentes desse grupo podem apresentar 2 canais radiculares (HESS, 1925; PINEDA; KUTTLER, 1972; GREEN, 1973; MADEIRA; HETEM, 1973; BENJAMIN; DOWSON, 1974; WARREN; LAWS, 1981; VERTUCCI, 1984; KAFFE et al., 1985; PÉCORA; SAVIOLI; MURGEL, 1990; KARTAL; YANIKOGLU, 1992; CALISKAN et al., 1995; MIYASHITA et al., 1997; ALQUDAH; AWAWDEH, 2006; BORUAH; BHUYAN, 2011; LIN et al., 2014; LIU et al. 2014).

Autores constataram que não há diferença morfológica significante entre incisivo central inferior e incisivo lateral inferior (MADEIRA; HETEM, 1973; VERTUCCI, 1984; LEONI et al., 2013). Nessa etapa da pesquisa, portanto, não foi feita essa diferenciação nos 40 dentes extraídos, assim como nos estudos de Hess (1925), Green (1973), Kartal e Yanikoglu (1992) e Boruah e Bhuyan (2011).

Os padrões anatômicos internos considerados nessa etapa da pesquisa foram baseados na classificação proposta por Vertucci (1984), sendo: Tipo I (1 canal radicular regular), Tipo la (1 canal radicular oval) e Tipo III ( 2 canais radiculares 
terminando em 1 forame apical). De modo geral, pode-se dizer que esses tipos anatômicos diferenciam-se entre si pelo número de canais radiculares e/ou forma de canais radiculares. No caso, Tipo I e Tipo la apresentam o mesmo número de canais (1), porém com conformações diferentes. Já o Tipo III apresenta 1 canal radicular a mais que os Tipos I e la, sendo, portanto, diferente em relação ao número de canais. Essas diferenças entre os tipos têm implicações clínicas e por isso foram assim consideradas.

Os canais radiculares nem sempre seguem o mesmo padrão em toda a extensão da raiz, ou seja, nos terços cervical, médio e apical (WU et al., 2000). Nessa pesquisa, durante a determinação do padrão ouro com as imagens microtomográficas, considerou-se 0 aspecto apresentado pelo canal radicular no terço médio (de 3 a $5 \mathrm{~mm}$ distante do ápice). No terço apical, a imensa maioria dos incisivos inferiores apresenta somente 1 canal radicular, que culmina em um forame apical único (MAUGER; SCHINDLER; WALKER, 1998).

O Tipo I (1 canal radicular regular) é o padrão anatômico de menor complexidade, pois apresenta aspecto semelhante nos terços cervical, médio e apical. O canal radicular único apresenta-se arredondado, de maneira uniforme, ao longo da raiz do incisivo inferior. Já o Tipo la (1 canal radicular oval), subtipo considerado nessa pesquisa, apresenta uma secção transversal oval do único canal no terço médio. A limpeza, a desinfecção e a obturação desse tipo de canal radicular são dificultadas pela configuração interna apresentada (WU, WESSELINK, 2001; BARBIZAM et al., 2002; WEIGER, ELAYOUTI, LÖST, 2002; DE-DEUS et al., 2008; ALVES et al., 2011). O preparo das paredes de dentina no terço médio e apical de canais ovais nem sempre é eficiente, devido a diferenças entre o desenho do instrumento e a geometria do canal. Tentativas de estender o preparo desse tipo de canal em determinada direção para abranger toda a anatomia pode levar a complicações como perfurações e zips. Como nem sempre há remoção total de resíduos orgânicos e inorgânicos do interior de um canal oval, a desinfecção e limpeza ficam comprometidas (NAIR, 2004). Assim, novas técnicas de instrumentação e de irrigação têm sido propostas, a fim de melhorar o tratamento endodôntico em dentes com essa variação anatômica (ALVES et al., 2011). Se o cirurgião-dentista souber previamente à abertura coronária qual é a característica do dente que irá tratar, por meio de sua visualização em imagens, será possível optar 
por instrumentos específicos e por técnicas de irrigação que garantam melhor desempenho e sucesso do tratamento endodôntico.

Considerando o Tipo III (2 canais radiculares que se unem no terço apical e desembocam em 1 forame apical), se apenas 1 canal for instrumentado e preenchido, a probabilidade de obter uma interface adequada entre o material obturador e as paredes do canal diminuirão, pela presença de tecido orgânico no interior do canal deixado sem tratamento. Dessa forma, o prognóstico a longo prazo pode ser comprometido. Frequentemente, há necessidade de retratamento em incisivos inferiores de Tipo III, em virtude da não-detecção do segundo canal (BENJAMIN; DOWSON, 1974; FUNATO; FUNATO; MATSUMOTO, 1998; NAIR, 2004; TIKU; KALASKAR; DAMLE, 2005). Procedimentos endodônticos cirúrgicos em incisivos inferiores também requerem uma avaliação prévia eficiente. $A$ ressecção apical pode transformar a configuração do dente, tornando 1 forame apical em 2 saídas separadas no caso do Tipo III, ou em 1 canal oval maior no caso do Tipo la (KARTAL; YANIKOGLU, 1992; MAUGER; SCHINDLER; WALKER, 1998).

Existem outras configurações anatômicas estabelecidas por Vertucci (1984), cuja presença em incisivos inferiores é muito rara. A configuração Tipo IV (2 canais radiculares que desembocam em 2 forames separados), por exemplo, tem prevalência menor que $3 \%$ nesse grupo dentário (MADEIRA; HETEM, 1973; BENJAMIN; DOWSON, 1974; VERTUCCI, 1984; PÉCORA; SAVIOLI; MURGEL, 1990; CALISCAN et al., 1995; MIYASHITA et al., 1997; MAUGER; SCHINDLER; WALKER, 1998; LIN et al., 2014). Essas configurações menos prevalentes não foram consideradas na presente pesquisa, e tampouco foram encontradas nos 40 dentes da amostra.

\subsubsection{Estabelecimento do padrão ouro: micro-TC}

A microtomografia computadorizada (micro-TC) foi utilizada como padrão ouro do tipo anatômico dos dentes avaliados nessa etapa da pesquisa. Trata-se de um recurso moderno que vem sendo empregado na avaliação tridimensional da morfologia radicular (SWAIN; XUE, 2009; VILLAS-BÔAS et al., 2011; LEONI et al., 2013; MILANEZI DE ALMEIDA et al., 2013; ORDINOLA-ZAPATA et al., 2013). A micro-TC permite avaliação in vitro muito vantajosa, na medida em que não há 
necessidade de danificar os dentes para análise. Após o escaneamento em microtomógrafo dos 40 incisivos inferiores dessa pesquisa, os mesmos continuaram em boas condições e mantiveram a sua integridade estrutural, permitindo posteriores tomadas radiográficas e escaneamentos tomográficos.

O aparelho de micro-TC utilizado na pesquisa permite a obtenção de imagens com tamanho de voxel de $0,018 \mathrm{~mm}$. Os tamanhos de voxel das imagens dos aparelhos de TCFC são muito maiores (Kodak: 0,076 mm; Veraviewepocs: 0,125 $\mathrm{mm}$; NewTom: 0,075 mm). Quanto menor é o tamanho do voxel, melhor é a qualidade da imagem e a visualização de detalhes (HASSAN et al., 2012). O microtomógrafo consegue oferecer imagens com tamanho de voxel muito reduzido, porque utiliza maior dose de radiação e tempo de exposição do que os aparelhos de TCFC, o que é inviável para pacientes.

A eficácia da TCFC para avaliação da morfologia de canais radiculares foi estudada em diferentes trabalhos. O padrão ouro adotado por Blattner et al. (2010) e Michetti et al. (2010) foi a secção dos dentes avaliados, enquanto Matherne et al. (2008) e Neelakantan, Subbarao e Subbarao (2010) utilizaram a própria TCFC em comparação à radiografia digital, e diafanização dos dentes avaliados, respectivamente. No caso da presente pesquisa, como havia disponibilidade de uso de imagens de altíssima qualidade e muito mais detalhadas, optou-se por estabelecer o padrão ouro com micro-TC, assim como Domark et al. (2013).

Estabelecer o padrão ouro com micro-TC para cada um dos 40 dentes, antes das tomadas radiográficas e dos escaneamentos tomográficos, permitiu 0 planejamento da posição dos dentes para os procedimentos posteriores, o que é uma vantagem. Já em estudos nos quais o padrão ouro causa dano estrutural aos dentes (tais como secção e diafanização), isso não é possível. Nesses casos, a determinação do padrão ouro é a última etapa a ser realizada.

\subsubsection{Posicionamento dos dentes para tomadas radiográficas e} escaneamentos tomográficos

Os 40 dentes da amostra, devidamente identificados, foram divididos em 10 grupos de 4 incisivos cada, com o objetivo de orientar o posicionamento de cada um 
para tomadas radiográficas e escaneamentos tomográficos. A posição predeterminada foi estabelecida com a finalidade de que dentes com cada tipo anatômico (I, la ou III) estivessem nas mais variadas posições na mandíbula. O nãoposicionamento aleatório evitou um viés na etapa de análise das imagens, que poderia ser causado pelo fato de o tipo anatômico estar na mesma posição ou com a mesma angulação.

Klein et al. (1997), em seu estudo sobre angulação horizontal ideal para visualização de 2 canais em incisivos inferiores, dividiram os dentes de sua amostra em grupos de 4 e posicionou-os em uma moldeira contendo silicone, servindo como fantoma. No caso da presente pesquisa, o posicionamento dos dentes simulando o arco dentário foi semelhante, porém uma mandíbula com alvéolos correspondentes aos dentes $31,32,41$ e 42 devidamente preparados foi utilizada como fantoma.

\subsubsection{Tomadas radiográficas digitais com diferentes angulações horizontais}

Para essa pesquisa, utilizou-se a tecnologia digital direta, com sensor conectado diretamente a um computador via cabo. Realizaram-se duas tomadas radiográficas para cada dente, com variação do ângulo horizontal de cerca de 20 graus. Klein et al. (1997) observaram que essa angulação promove melhor visualização de 2 canais em incisivos inferiores. Kaffe et al. (1985) afirmaram que a decisão final sobre o número de canais em dentes anteriores inferiores deve ser feita somente após a tomada de 2 radiografias periapicais com diferentes angulações. $A$ observação de apenas uma radiografia periapical não é vantajosa, pois a sobreposição de estruturas pode impedir a visualização adequada da anatomia do dente. Kabak e Abbott (2007), ao publicarem relato de casos clínicos com presença de 2 canais radiculares, afirmaram que a detecção da variação só foi possível após a realização de tomadas radiográficas com ângulos horizontais variados. Com uma radiografia apenas, não foi possível diagnosticar a variação anatômica, em virtude da sobreposição dos canais. Considerando esse fato, no presente estudo, não foi realizada a tomada radiográfica periapical única para cada dente, pois não seria o ideal. Já se partiu do princípio que uma avaliação radiográfica ideal para os incisivos 
inferiores deve ser feita com, pelo menos, 2 radiografias obtidas com diferentes angulações horizontais.

\subsubsection{Escaneamentos em tomógrafos computadorizados de feixe cônico}

A mandíbula com os dentes devidamente posicionados foi colocada em recipiente plástico contendo água em seu interior, de maneira a simular tecido mole, de acordo com o método adotado por Katsumata et al. (2006), Noujeim et al. (2009) e Junqueira et al. (2013). Um estudo que avaliou diferentes materiais, tais como resina acrílica autopolimerizável, cera utilidade e recipiente plástico contendo água para substituir tecido mole constatou que todos poderiam ser utilizados para esse fim em Radiologia Odontológica (CALDAS et al., 2010). Para facilitar o posicionamento nos tomógrafos simulando a cabeça do paciente, optou-se pelo recipiente plástico contendo água.

É importante mencionar que nesse estudo in vitro, a mandíbula e os dentes estiveram estáticos durante a exposição radiográfica e os escaneamentos em tomógrafos. A possível movimentação do paciente durante os exames não foi simulada, assim como em vários estudos com metodologia semelhante (NOUJEIM et al., 2009; BLATTNER et al., 2010; DOMARK et al., 2013). No escaneamento de pacientes, as imagens podem apresentar artefatos e redução da resolução espacial devido à micromovimentação da mandíbula ou da maxila (HASSAN et al., 2012). A TCFC requer maior tempo de exposição do que a radiografia periapical, e a movimentação do paciente pode afetar a precisão do método, principalmente para aqueles tomógrafos nos quais o paciente não está deitado (por exemplo, Kodak e Veraviewepocs).

De acordo com Hassan et al. (2012), a visibilidade dos canais radiculares é significantemente melhorada quanto menor for o FOV do aparelho. No momento de selecionar o protocolo de escaneamento, o menor FOV possível de cada aparelho foi escolhido, bem como o menor tamanho de voxel. Dessa forma, o tempo de exposição também foi reduzido ao mínimo. Dessa forma, os FOVs e tamanhos de voxel adotados foram: 5 X 3,75 cm e 0,076 mm (Kodak 9000 3D); 4 X $4 \mathrm{~cm}$ e 0,125 $\mathrm{mm}$ (Veraviewepocs 3De) e 6 X $6 \mathrm{~cm}$ e 0,075 mm (NewTom 5G), respectivamente. 


\subsubsection{Examinadores e avaliações}

Para determinação do padrão ouro com uso das imagens de micro-TC, uma examinadora radiologista com experiência nesse tipo de imagem determinou o padrão anatômico. Não houve necessidade de outro examinador nessa etapa, uma vez que as imagens são de altíssima qualidade e não geram dúvidas quanto à visualização dos canais radiculares.

Já para interpretação das imagens radiográficas e tomográficas, 2 examinadores endodontistas foram recrutados. Neelakantan, Subbarao e Subbarao (2010) observaram que diferenças nos resultados obtidos por avaliadores endodontistas e radiologistas não são significantes em relação à avaliação de morfologia do canal radicular. Como os endodontistas trabalham diariamente com imagens desse tipo para observação da anatomia dentária, sua experiência é tão vasta quanto a de especialistas em Radiologia.

Os examinadores foram devidamente calibrados antes das análises e receberam instrução para utilizarem os programas dos tomógrafos. Dessa maneira, tinham total liberdade para visualizar cada dente nas 3 reconstruções (axial, sagital e coronal) com uso de recursos tais como aumento ou diminuição da imagem (zoom) e ajuste de brilho e contraste. O tipo anatômico só era determinado pelos examinadores após interpretação minuciosa das imagens de TCFC, com utilização de todos os recursos, simulando uma situação real.

Os examinadores avaliaram cada imagem por 2 vezes, com intervalo de 1 semana entre as avaliações, de forma independente e cega, semelhantemente à metodologia dos estudos com TCFC de Domark et al. (2013) e de Liang et al. (2013). O intervalo é importante para não haver memorização da sequência de imagens e para descanso visual.

\subsubsection{Detecção dos padrões anatômicos internos}

Observando-se os resultados para identificação de 1 canal radicular regular (Tipo I), as imagens obtidas nos aparelhos de TCFC permitiram quase $100 \%$ de identificação correta do padrão anatômico, sendo superior à radiografia periapical 
com dupla exposição ( $R P=67 \%$ de acerto; TCFC $=98 \%$ de acerto, $p<0,05)$. Considerando apenas as imagens dos 3 tomógrafos entre si, os desempenhos foram muito similares, não havendo diferença estatisticamente significante.

Já para identificação de 1 canal radicular oval (Tipo la), a radiografia periapical e os tomógrafos Veraviewepocs e Kodak foram menos efetivos (RP=44\% de acerto; TCFC $=71 \%$ de acerto, $p>0,05)$. Apesar de os tomógrafos apresentarem maior porcentagem de acerto em relação à radiografia periapical, a diferença não foi significante. Apenas o tomógrafo NewTom obteve melhor desempenho em relação à radiografia periapical $(\mathrm{RP}=44 \%$ de acerto; TCFC NewTom $=88 \%$ de acerto, $p<0,05)$. Entre os 3 tomógrafos, não houve diferença significante.

Esses resultados sugerem que o Tipo la é mais difícil de ser detectado e mais propenso a ser confundido com Tipo I. Essa confusão pode ser atribuída a diferenças no tamanho de voxel entre os tomógrafos (Kodak: 0,076 mm; Veraviewepocs: 0,125 mm; NewTom: 0,075 mm) e o padrão ouro, estabelecido por microtomografia (SkyScan: 0,018 mm). A resolução da imagem microtomográfica é muito superior à da imagem tomográfica, uma vez que seu voxel é muito menor. As reentrâncias dentinárias estreitas dos incisivos inferiores não puderam ser identificadas em 100\% dos casos, mesmo com uso de TCFC. Algumas reentrâncias só podem ser observadas em imagens de alta resolução obtidas in vitro, sendo, portanto, inviável a visualização em dentes na boca de pacientes. Apesar de não haver diferença estatisticamente significante entre os tomógrafos, NewTom apresentou a maior porcentagem de respostas corretas, provavelmente por utilizar maior kVp e mA. Pode-se concluir, com base nessas observações, que a detecção da forma do canal radicular de incisivos inferiores é limitada, mesmo com uso de TCFC.

Para detecção do Tipo III (2 canais radiculares separados que terminam em um único forame), não houve diferença significante entre os 4 métodos, pois a porcentagem de respostas corretas foi similar entre eles. Esse resultado indica que a técnica periapical com duas tomadas e variação do ângulo horizontal é tão efetiva quanto a TCFC para detecção de canais adicionais em incisivos inferiores. As poucas respostas erradas que os examinadores deram para o Tipo III foram, na maioria das vezes, relacionadas ao Tipo la. Isso indica que os examinadores, 
nesses casos, tiveram dificuldade de visualizar a estreita barreira de dentina entre os canais vestibular e lingual.

A diferença entre Tipo I / Tipo la e Tipo III está no número de canais radiculares, sendo, 1 e 2, respectivamente. Esse estudo mostrou que o número de canais radiculares é mais facilmente identificável do que a forma, tanto na radiografia periapical com duas tomadas e variação do ângulo horizontal quanto na TCFC.

Estudos anteriores mostraram que as imagens de TCFC são superiores às de radiografia periapical para identificação do número de canais radiculares. Matherne et al. (2008) observaram que incisivos inferiores extraídos tinham 1,5 canais radiculares por dente com uso de TCFC como padrão ouro de sua identificação. Usando radiografia periapical, os examinadores encontraram 1 canal por dente na mesma amostra. Os examinadores falharam na identificação de pelo menos 1 canal em $40 \%$ dos dentes avaliados. Os resultados do presente estudo também mostraram que a imagem de TCFC é superior à de radiografia periapical para detecção de diferentes padrões anatômicos Tipo I e Tipo la. No entanto, para Tipo III, a diferença não foi significante. É importante ressaltar que, diferentemente de Matherne et al. (2008), o presente estudo adotou como padrão ouro a imagem de micro-TC, que é muito superior à imagem de TCFC.

\subsubsection{Concordância entre avaliações}

Observou-se que a TCFC apresentou maiores valores de kappa do que a radiografia periapical digital, tanto para a concordância interexaminador como para a concordância intraexaminador. Tewary, Luzzo e Hartwell (2011) fizeram estudo para avaliar a interpretação radiográfica em Endodontia, em relação à observação de alteração periapical com tecnologia digital. $\mathrm{Na}$ primeira avaliação que 6 examinadores fizeram, a concordância interexaminador foi de 0,34 e na segunda avaliação, o valor de kappa foi de 0,35. No caso do presente estudo, os valores de kappa para as avaliações com radiografia periapical foram semelhantes. Por outro lado, considerando as imagens de TCFC dos 3 tomógrafos, os valores de kappa foram superiores e aumentaram na segunda avaliação em relação à primeira (por exemplo, com o tomógrafo NewTom os valores foram 0,74 e 0,92, respectivamente). Blattner et al. (2010) e Neelakantan, Subbarao e Subbarao (2010), que compararam 
radiografia digital e TCFC para avaliação da morfologia do canal radicular também observaram maior concordância interexaminador para TCFC, sendo concordância em $90 \%$ dos casos no estudo de Blattner et al. (2010) e de $98 \%$ no estudo de Neelakantan, Subbarao e Subbarao (2010).

Considerando a concordância intraexaminador, Tewary, Luzzo e Hartwell (2011) obtiveram valor de kappa de 0,50, em média, semelhantemente aos valores encontrados no presente estudo para radiografia periapical digital $(0,40$ e 0,66$)$. Os autores afirmam que a interpretação radiográfica é subjetiva e que fatores como anos de experiência e familiaridade do observador com determinado sistema digital exercem impacto significativo. No caso do presente estudo, pôde-se observar que a TCFC gerou menos discordância entre os examinadores, justificada pela melhor qualidade da imagem.

\subsection{SEGUNDA ETAPA DA PESQUISA:}

\subsubsection{Seleção da amostra de exames / critérios de inclusão}

Nessa etapa do estudo, foram selecionados 100 exames de TCFC de pacientes da FOB-USP, realizados com o tomógrafo i-CAT Classic. Esses exames atenderam os critérios de inclusão na amostra, quanto ao protocolo de escaneamento com que haviam sido realizados (com menores FOVs e tamanhos de voxel disponíveis no aparelho) e quanto à condição dos incisivos inferiores observáveis (estavam com sua estrutura radicular íntegra, sem obturação endodôntica, brackets ortodônticos, fraturas ou outras alterações que pudessem comprometer a avaliação de sua anatomia interna radicular).

É sabido que para avaliação do sistema de canais radiculares com uso de TCFC, o menor FOV é o ideal (HASSAN et al., 2012). Apesar de o i-CAT Classic ser um tomógrafo que oferece imagens de boa qualidade, não é um aparelho que tenha FOV para região limitada e, sim, de FOV médio (para um arco dentário ou para ambos) a grande (para a cabeça inteira) (SCARFE; FARMAN, 2008). O i-CAT Classic também apresenta diferentes tamanhos de voxel, sendo o menor valor de $0,2 \mathrm{~mm}$. Dessa forma, apenas exames realizados com os menores FOVs do 
aparelho e com os menores tamanhos de voxel foram selecionados, para que a visualização dos canais radiculares dos incisivos inferiores fosse a melhor possível.

Em relação aos incisivos inferiores, dentes com alterações que pudessem dificultar ou inviabilizar a visualização dos canais radiculares não foram incluídos, semelhantemente ao estudo de Yang et al. (2013), que também utilizou TCFC para avaliação de morfologia do canal radicular.

Na primeira etapa da presente pesquisa, que utilizou dentes extraídos, não foi feita a diferenciação entre incisivos centrais inferiores ou laterais, em virtude da configuração anatômica ser semelhante (MADEIRA; HETEM, 1973; VERTUCCI, 1984; LEONI et al., 2013). Nessa segunda etapa, como a avaliação foi em exames de TCFC de pacientes, essa diferenciação era fácil de ser realizada e, portanto, os dentes foram devidamente identificados com seus respectivos números (31 e 41 para incisivos centrais inferiores e 32 e 42 para incisivos laterais inferiores). Autores que avaliaram morfologia radicular de dentes em exames de TCFC também fizeram essa diferenciação (LIN et al., 2014; LIU et al., 2014).

Em relação aos critérios para avaliar a configuração anatômica interna dos incisivos inferiores dos pacientes, considerou-se apenas o número de canais radiculares e não a forma. O subtipo la, considerado na primeira etapa da pesquisa, não foi utilizado na presente etapa. Os 386 dentes avaliados foram classificados como tendo apenas 1 canal radicular ou 2 canais radiculares. A classificação foi feita dessa maneira em virtude da limitação do tomógrafo i-CAT Classic em relação aos tomógrafos utilizados na primeira etapa da pesquisa, que tinham resolução de imagem melhor, por conta de oferecerem FOV e tamanho de voxel menores.

\subsubsection{Dados dos pacientes}

A intenção ao realizar-se essa etapa da pesquisa foi classificar os incisivos inferiores quanto ao número de canais radiculares de pacientes brasileiros, da região de Bauru, SP. A TCFC é uma ferramenta muito útil para avaliar morfologia dentária de pacientes de diferentes populações, como fizeram Wang et al. (2010), Lee et al. (2011), Yang et al. (2013), Lin et al. (2014) e Liu et al. (2014). Os pacientes desses estudos, bem como da presente pesquisa realizaram exames tomográficos para 
outros propósitos e suas informações ficaram armazenadas em banco de dados. De acordo com Robinson et al. (2002), exames de TC ou de TCFC realizados para outros propósitos devem ser analisados em sua totalidade, não apenas na região que tenha motivado a realização do escaneamento. O radiologista deve avaliar também a anatomia dos dentes, pois essas informações valorizam o exame e são úteis para o cirurgião-dentista que for tratar do paciente. Esses exames também contribuem para estudos populacionais dos mais diversos reparos anatômicos ou de variações dentárias.

Com o propósito de comparação com a anatomia interna de seus incisivos inferiores, o gênero e a idade dos pacientes foram anotados, uma vez que estavam disponíveis nos exames de TCFC. Lee et al. (2011), Lin et al. (2014) e Liu et al. (2014) também consideraram essas informações. Wang et al. (2010) considerou somente o gênero. Em alguns estudos in vitro, essas informações também foram consideradas, apesar da maior dificuldade em obtê-las quando se trata de dentes extraídos (PINEDA; KUTTLER, 1972; KAFFE et al., 1985; SERT; BAYIRLI, 2004).

\subsubsection{Prevalência de 2 canais radiculares em relação à localização do} dente

Considerando o total de 386 incisivos inferiores, a prevalência de 2 canais radiculares terminando em 1 forame apical (Tipo III) foi de 16,5\%. Essa porcentagem é semelhante aos achados em estudos anteriores que utilizaram TCFC de pacientes, tais como: 18,2\% (LIN et al., 2014) e 13,2\% (LIU et al., 2014). Em relação a estudos feitos com dentes extraídos, a porcentagem encontrada no presente estudo também é semelhante: $21 \%$ (GREEN, 1973), 11\% (MADEIRA; HETEM, 1973), 20\% (KARTAL; YANIKOGLU, 1992) e 12,4\% (MIYASHITA et al., 1997). Porém, alguns estudos in vitro observaram maior prevalência de 2 canais radiculares em incisivos inferiores, sendo: 37,6\% (HESS, 1925), 41,4\% (BENJAMIN; DOWSON, 1974), 40,2\% (WARREN; LAWS, 1981) 26,2\% (AL-QUDAH; AWAWDEH, 2006) e 36,2\% (BORUAH; BHUYAN, 2011).

Considerando os incisivos centrais inferiores e laterais inferiores separadamente, a prevalência de 2 canais radiculares terminando em 1 forame 
apical (Tipo III) foi de 13\% e 20\%, respectivamente. Observou-se maior incidência de 2 canais radiculares em incisivos laterais inferiores, porém essa diferença não foi significante. Em relação a estudos que utilizaram TCFC de pacientes, essas porcentagens foram semelhantes: $10,9 \%$ e $25,5 \%$ (LIN et al., 2014), e 8,9\% e $17,5 \%$ (LIU et al., 2014). Em relação a estudos feitos com dentes extraídos, algumas pesquisas encontraram maior prevalência de 2 canais radiculares em incisivos centrais inferiores: $27,6 \%$ e 23,8\% (PINEDA; KUTTLER, 1972); $43 \%$ e $35,9 \%$ (WARREN; LAWS, 1981). Outros, assim como no presente estudo, verificaram maior prevalência em incisivos laterais inferiores: $32,5 \%$ e $42,5 \%$ (KAFFE et al., 1985); 29,7\% e 39,9\% (PÉCORA; SAVIOLI; MURGEL, 1990); 13,7\% e 15,7\% (CALISKAN et al., 1995).

O fato de não haver diferença estatística significante entre a prevalência de 2 canais radiculares em incisivos centrais inferiores e laterais inferiores nessa pesquisa confirma o que autores disseram sobre a semelhança morfológica entre ambos (MADEIRA; HETEM, 1973; VERTUCCI, 1984; LEONI et al., 2013).

Não se observou nenhum dente com 2 canais terminando em 2 forames apicais (Tipo IV), o que está de acordo com a literatura, que demonstrou que esse tipo anatômico é muito raro nesse grupo dentário (MADEIRA; HETEM, 1973; BENJAMIN; DOWSON, 1974; VERTUCCI, 1984; PÉCORA; SAVIOLI; MURGEL, 1990; CALISCAN et al., 1995; MIYASHITA et al., 1997; MAUGER; SCHINDLER; WALKER, 1998; LIN et al., 2014). A ausência desse tipo anatômico na amostra dessa etapa da pesquisa pode dever-se ao número de dentes avaliados $(n=386) \mathrm{em}$ 100 pacientes. Talvez se a amostra fosse maior, esse tipo fosse detectado, ainda que em baixa porcentagem.

As diferenças entre as prevalências de um segundo canal em incisivos inferiores de cada estudo estão relacionadas ao desenho metodológico da pesquisa, técnica utilizada para identificação dos canais radiculares, tamanho da amostra de dentes e etnia dos pacientes cujos dentes foram analisados (AL-QUDAH; AWAWDEH, 2006; BORUAH; BHUYAN, 2011). Em relação à etnia, não se encontrou na literatura, até o presente momento, uma pesquisa utilizando imagens de TCFC de pacientes brasileiros para determinação da prevalência de 2 canais radiculares de incisivos inferiores. A presente pesquisa foi pioneira nesse aspecto. 


\subsubsection{Prevalência de 2 canais radiculares em relação a gênero}

Considerando os 100 pacientes da amostra, 42 eram homens e 58 eram mulheres. A prevalência de 2 canais radiculares em incisivos inferiores de homens foi de $18,5 \%$ e de mulheres foi de $20,5 \%$. Observou-se pequena diferença entre os gêneros, sendo que ambos apresentaram maior prevalência de 2 canais radiculares em incisivos laterais inferiores. No entanto, os resultados não foram estatisticamente significantes ( $p>0,05)$. Portanto, não houve correlação significante entre gênero e a variação anatômica em incisivos inferiores.

Kaffe et al. (1985) não encontraram correlação significante entre o gênero do paciente e o número de canais radiculares, o que é concorde com os resultados da presente pesquisa. Liu et al. (2014) também encontraram pequena diferença entre os gêneros, sendo não significante. Os autores verificaram maior prevalência de segundo canal em incisivos inferiores de homens $(14,6 \%)$ do que de mulheres (11,9\%). Já Lin et al. (2014) encontraram diferença estatística significante para a presença de 2 canais radiculares em incisivos inferiores, sendo a relação homem/mulher de 1,37:1.

\subsubsection{Prevalência de 2 canais radiculares em relação à idade}

As idades dos pacientes foram divididas em 3 grupos, sendo de 15 a 29 anos; de 30 a 49 anos e de 50 ou mais anos de idade. Essa divisão foi baseada no trabalho de Píneda e Kuttler (1972). Esses autores observaram que a idade influencia no aspecto do canal radicular, provocando redução de seu diâmetro pela deposição de dentina. Até a $3^{a}$ década de vida, os canais radiculares são mais amplos e, a partir dos 35 anos, passa a haver redução no diâmetro. Porém, os autores não estabeleceram relação clara entre a idade e o número de canais radiculares.

Na presente pesquisa, observou-se diferença entre os grupos etários, com a maior porcentagem de incisivos centrais inferiores com 2 canais radiculares em pacientes na faixa dos 15 a 29 anos de idade. Em relação aos incisivos laterais inferiores, a maior prevalência de 2 canais radiculares foi constatada no grupo de 
pacientes na faixa dos 50 ou mais anos de idade. No entanto, as diferenças não foram estatisticamente significantes $(p>0,05)$.

Kaffe et al. (1985), de semelhante forma, não encontraram correlação significante entre o número de canais radiculares dos incisivos inferiores e a idade do paciente, bem como Lin et al. (2014). Liu et al. (2014) optaram por não considerar a idade em sua pesquisa com TCFC, uma vez que vários fatores são responsáveis por alterar as configurações do endodonto ao longo da vida. Segundo Someda et al. (2009), após o crescimento e desenvolvimento do indivíduo, por volta dos 20 anos de idade, os dentes e os ossos são influenciados por mudanças fisiológicas, que, por sua vez, são afetadas diretamente por condições do interior da boca. Dessa forma, há muita variação entre os indivíduos, uma vez que cada um está submetido a condições diferentes. Portanto, não é possível fazer associação entre a idade do paciente e a maior ou menor probabilidade de que seus incisivos inferiores apresentem 2 canais radiculares.

\subsubsection{Concordância entre avaliações}

Nessa etapa da pesquisa, 2 examinadores avaliaram as imagens, sendo um radiologista e um endodontista. O valor de kappa para a concordância interexaminador foi de 0,57 , sendo considerada regular. Esse valor foi inferior em relação às concordâncias interexaminador da primeira etapa da pesquisa (de 0,62 a 0,92 ), que utilizou tomógrafos que oferecem imagem de melhor qualidade. Pode-se concluir que imagens de tomógrafos com FOV e tamanho de voxel menores geram menos dúvidas entre os avaliadores.

Para determinação da concordância intraexaminador, o radiologista fez 2 avaliações, com intervalo de 1 semana entre elas. $O$ valor de kappa foi de 0,60, sendo considerada concordância regular. Tal valor foi semelhante ao obtido na primeira etapa da pesquisa, para alguns tomógrafos. 



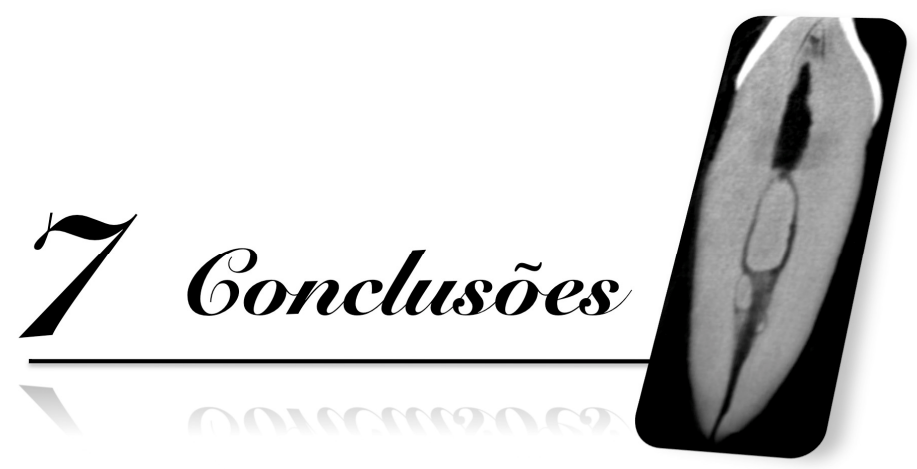





\section{CONCLUSÕES}

Com a análise dos resultados e após a discussão dos mesmos, é possível concluir que:

1) A radiografia periapical digital com duas tomadas e variação do ângulo horizontal e a tomografia computadorizada de feixe cônico foram efetivas para a identificação do número de canais radiculares de incisivos inferiores. No entanto, houve limitação de ambas para diferenciação da forma do canal radicular nesse grupo dentário;

2) A prevalência de 2 canais radiculares em incisivos inferiores com uso de imagens de tomografia computadorizada de feixe cônico de pacientes da FOB-USP foi de $16,5 \%$. Não houve correlação significante entre a presença de um segundo canal radicular e a localização do dente, o gênero e a idade do paciente. 



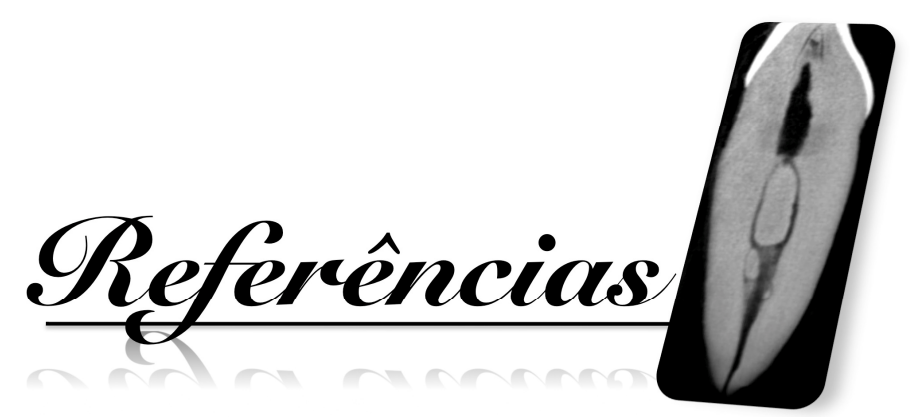





\section{REFERÊNCIAS}

Al-Qudah AA, Awawdeh LA. Root canal morphology of mandibular incisors in a Jordanian population. Int Endod J. 2006;39(11):873-7.

Alves FR, Almeida BM, Neves MA, Moreno JO, Rôças IN, Siqueira JF Jr. Disinfecting oval-shaped root canals: effectiveness of different supplementary approaches. J Endod. 2011;37(4):496-501.

Barbizam JV, Fariniuk LF, Marchesan MA, Pécora JD, Sousa-Neto MD. Effectiveness of manual and rotary instrumentation techniques for cleaning flattened root canals. J Endod. 2002;28(5):365-6.

Benjamin KA, Dowson J. Incidence of two root canals in human mandibular incisor teeth. Oral Surg Oral Med Oral Pathol. 1974;38(1):122-6.

Blattner TC, George N, Lee CC, Kumar V, Yelton CD. Efficacy of cone-beam computed tomography as a modality to accurately identify the presence of second mesiobuccal canals in maxillary first and second molars: a pilot study. J Endod. 2010;36(5):867-70.

Boruah LC, Bhuyan AC. Morphologic characteristics of root canal of mandibular incisors in North-East Indian population: an in vitro study. J Conserv Dent. $2011 ; 14(4): 346-50$.

Caldas M de P, Ramos-Perez FM, de Almeida SM, Haiter-Neto F. Comparative evaluation among different materials to replace soft tissue in oral radiology studies. $J$ Appl Oral Sci. 2010;18(3):264-7.

Caliskan MK, Pehlivan Y, Sepetçioglu F, Türkün M, Tuncer SS. Root canal morphology of human permanent teeth in a Turkish population. $J$ Endod. $1995 ; 21(4): 200-4$.

Carrotte P. Endodontics: Part 1. The modern concept of root canal treatment. $\mathrm{Br}$ Dent J. 2004a;197(4):181-3.

Carrotte P. Endodontics: Part 4. Morphology of the root canal system. Br Dent J. 2004b;197(7):379-83. 
Clark CA. A method of ascertaining the relative position of unerupted teeth by means of film radiographs. Proc R Soc Med. 1910;3(Odontol Sect):87-90.

Connert T, Hülber-JM, Godt A, Löst C, ElAyouti A. Accuracy of endodontic working length determination using cone beam computed tomography. Int Endod J. 2013; [in press].

Cotton TP, Geisler TM, Holden DT, Schwartz SA, Schindler WG. Endodontic applications of cone-beam volumetric tomography. J Endod. 2007;33(9):1121-32.

De-Deus G, Reis C, Beznos D, de Abranches AM, Coutinho-Filho T, Paciornik S. Limited ability of three commonly used thermoplasticized gutta-percha techniques in filling oval-shaped canals. J Endod. 2008;34(11):1401-5.

De Oliveira SH, de Moraes LC, Faig-Leite H, Camargo SE, Camargo $\mathrm{CH}$. In vitro incidence of root canal bifurcation in mandibular incisors by radiovisiography. J Appl Oral Sci. 2009;17(3):234-9.

De Vos W, Casselman J, Swennen GR. Cone-beam computerized tomography (CBCT) imaging of the oral and maxillofacial region: a systematic review of the literature. Int J Oral Maxillofac Surg. 2009;38(6):609-25.

Domark JD, Hatton JF, Benison RP, Hildebolt CF. An ex vivo comparison of digital radiography and cone-beam and micro computed tomography in the detection of the number of canals in the mesiobuccal roots of maxillary molars. $J$ Endod. 2013;39(7):901-5.

Fava LR, Dummer PM. Periapical radiographic techniques during endodontic diagnosis and treatment. Int Endod J. 1997;30(4):250-61.

Funato A, Funato $\mathrm{H}$, Matsumoto K. Mandibular central incisor with two root canals. Endod Dent Traumatol. 1998;14(6):285-6.

Galafassi D, Lazzaretti DN, Spazzin AO, Vanni JR, da Silva SO. Estudo da anatomia interna do canal radicular em incisivos inferiores pela técnica de diafanização. Rev Sulbras Odontol. 2007;4(1):7-11.

Garib DG, Raymundo Júnior R, Raymundo MV, Vasconcellos D, Ferreira SN. Tomografia computadorizada de feixe cônico (cone beam): entendendo este novo método de diagnóstico por imagem com promissora aplicabilidade na Ortodontia. Rev Dent Press Ortodon Ortoped Facial. 2007;12(2):139-56. 
Goldman M, Pearson AH, Darzenta N. Endodontic success-who's reading the radiograph? Oral Surg Oral Med Oral Pathol. 1972;33(3):432-7.

Grande NM, Plotino G, Gambarini G, Testarelli L, D'Ambrosio F, Pecci R, Bedini R. Present and future in the use of micro-CT scanner 3D analysis for the study of dental and root canal morphology. Ann Ist Super Sanita. 2012;48(1):26-34.

Green D. Double canals in single roots. Oral Surg Oral Med Oral Pathol. 1973;35(5):689-96.

Guillaume B, Lacoste JP, Gaborit N, Brossard G, Cruard A, Baslé MF, Chappard D. Microcomputed tomography used in the analysis of the morphology of root canals in extracted wisdom teeth. Br J Oral Maxillofac Surg. 2006;44(3):240-4.

Hans MG, Valiathan M, Palomo JM. Cone beam computed tomography: a link with the past, a promise for the future. Semin Orthod. 2011;17:81-87.

Hassan BA, Payam J, Juyanda B, van der Stelt P, Wesselink PR. Influence of scan setting selections on root canal visibility with cone beam CT. Dentomaxillofac Radiol. 2012;41(8):645-8.

Hess W. Anatomy of root canals of the teeth of the permanent dentition, Part I, Lower Incisors. William Wood \& Co. 1925:27-9.

Howerton WB, Mora MA. Advancements in digital imaging: what is new and on the horizon? J Am Dent Assoc.2008;139:20S-24S.

Jou YT, Karabucak B, Levin J, Liu D. Endodontic working width: current concepts and techniques. Dent Clin North Am. 2004;48(1):323-35.

Junqueira RB, Verner FS, Campos CN, Devito KL, do Carmo AM. Detection of vertical root fractures in the presence of intracanal metallic post: a comparison between periapical radiography and cone-beam computed tomography. J Endod. 2013;39(12):1620-4.

Kabak YS, Abbott PV. Endodontic treatment of mandibular incisors with two root canals: report of two cases. Aust Endod J. 2007;33(1):27-31.

Kaffe I, Kaufman A, Littner MM, Lazarson A. Radiographic study of the root canal system of mandibular anterior teeth. Int Endod J. 1985;18(4):253-9. 
Kartal N, Yanikoglu FC. Root canal morphology of mandibular incisors. J Endod. 1992;18(11):562-4.

Katsumata A, Hirukawa A, Noujeim M, Okumura S, Naitoh M, Fujishita M, Ariji E, Langlais RP. Image artifact in dental cone-beam CT. Oral Surg Oral Med Oral Pathol Oral Radiol Endod. 2006;101(5):652-7.

Kau $\mathrm{CH}$, Bozic M, English J, Lee R, Bussa H, Ellis RK. Cone-beam computed tomography of the maxillofacial region-an update. Int J Med Robot. 2009;5(4):366-80.

Klein RM, Blake SA, Nattress BR, Hirschmann PN. Evaluation of X-ray beam angulation for successful twin canal identification in mandibular incisors. Int Endod J. 1997;30(1):58-63.

La SH, Jung DH, Kim EC, Min KS. Identification of independent middle mesial canal in mandibular first molar using cone-beam computed tomography imaging. J Endod. 2010;36(3):542-5.

Lee JH, Kim KD, Lee JK, Park W, Jeong JS, Lee Y, Gu Y, Chang SW, Son WJ, Lee WC, Baek SH, Bae KS, Kum KY. Mesiobuccal root canal anatomy of Korean maxillary first and second molars by cone-beam computed tomography. Oral Surg Oral Med Oral Pathol Oral Radiol Endod. 2011;111(6):785-91.

Leoni GB, Versiani MA, Pécora JD, de Sousa-Neto MD. Micro-computed tomographic analysis of the root canal morphology of mandibular incisors. J Endod. 2013 [in press].

Li G. Patient radiation dose and protection from cone-beam computed tomography. Imaging Sci Dent. 2013;43(2):63-9.

Liang YH, Jiang L, Chen C, Gao XJ, Wesselink PR, Wu MK, Shemesh H. The validity of cone-beam computed tomography in measuring root canal length using a gold standard. J Endod. 2013;39(12):1607-10.

Lin Z, Hu Q, Wang T, Ge J, Liu S, Zhu M, Wen S. Use of CBCT to investigate the root canal morphology of mandibular incisors. Surg Radiol Anat. 2014; [in press].

Liu, Luo J, Dou L, Yang D. CBCT study of root and canal morphology of permanent mandibular incisors in a Chinese population. Acta Odontol Scand. 2014;72(1):26-30.

Loushine RJ, Jurcak JJ, Jeffalone DM. A two-rooted mandibular incisor. J Endod. 
$1993 ; 19(5): 250-1$.

Ludlow JB, Davies-Ludlow LE, Brooks SL, Howerton WB. Dosimetry of 3 CBCT devices for oral and maxillofacial radiology: CB Mercuray, NewTom 3G and i-CAT. Dentomaxillofac Radiol. 2006;35(4):219-26.

Madeira MC, Hetem S. Incidence of bifurcations in mandibular incisors. Oral Surg Oral Med Oral Pathol. 1973;36(4):589-91.

Maini A, Durning P, Drage N. Resorption: within or without? The benefit of conebeam computed tomography when diagnosing a case of an internal/external resorption defect. Br Dent J. 2008;204(3):135-7.

Marca C, Dummer PM, Bryant S, Vier-Pelisser FV, Só MV, Fontanella V, Dutra VD, de Figueiredo JA. Three-rooted premolar analyzed by high-resolution and cone beam CT. Clin Oral Investig. 2013;17(6):1535-40.

Martínez-Lozano MA, Forner-Navarro L. Sánchez-Cortés JL. Analysis of radiologic factors in determining premolar root canal systems. Oral Surg Oral Med Oral Pathol Oral Radiol Endod. 1999;88(6):719-22.

Matherne RP, Angelopoulos C, Kulild JC, Tira D. Use of cone-beam computed tomography to identify root canal systems in vitro. J Endod. 2008;34(1):87-9.

Mauger MJ, Schindler WG, Walker WA 3rd. An evaluation of canal morphology at different levels of root resection in mandibular incisors. J Endod. 1998;24(9):607-9.

Mauger MJ, Waite RM, Alexander JB, Schindler WG. Ideal endodontic access in mandibular incisors. J Endod. 1999;25(3):206-7.

Michetti J, Maret D, Mallet JP, Diemer F. Validation of cone beam computed tomography as a tool to explore root canal anatomy. J Endod. 2010;36(7):1187-90.

Milanezi de Almeida $M$, Bernardineli $N$, Ordinola-Zapata $R$, Villas-Bôas $M H$, Amoroso-Silva PA, Brandão CG, Guimarães BM, Gomes de Moraes I, HúngaroDuarte, MA. Micro-computed tomography analysis of the root canal anatomy and prevalence of oval canals in mandibular incisors. J Endod. 2013;39(12):1529-33.

Miyashita M, Kasahara E, Yasuda E, Yamamoto A, Sekizawa T. Root canal system of the mandibular incisor. J Endod. 1997;23(8):479-84. 
Mozzo P, Procacci C, Tacconi A, Martini PT, Andreis IA. A new volumetric CT machine for dental imaging based on the cone-beam technique: preliminary results. Eur Radiol. 1998;8(9):1558-64.

Nair PN. Pathogenesis of apical periodontitis and the causes of endodontic failures. Crit Rev Oral Biol Med. 2004;15(6):348-81.

Nair MK, Nair UP. Digital and advanced imaging in endodontics: a review. J Endod. 2007;33(1):1-6.

Nattress BR, Martin DM. Predictability of radiographic diagnosis of variations in root canal anatomy in mandibular incisor and premolar teeth. Int Endod J. 1991;24(2):5862.

Neelakantan P, Subbarao C, Subbarao CV. Comparative evaluation of modified canal staining and clearing technique, cone-beam computed tomography, peripheral quantitative computed tomography, spiral computed tomography, and plain and contrast medium-enhanced digital radiography in studying root canal morphology. $\mathrm{J}$ Endod. 2010;36(9):1547-51.

Noujeim M, Prihoda T, Langlais R, Nummikoski P. Evaluation of high-resolution cone beam computed tomography in the detection of simulated interradicular bone lesions. Dentomaxillofac Radiol. 2009;38(3):156-62.

Ordinola-Zapata $\mathrm{R}$, Bramante $\mathrm{CM}$, Villas-Boas $\mathrm{MH}$, Cavenago $\mathrm{BC}$, Duarte $\mathrm{MH}$, Versiani MA. Morphologic micro-computed tomography analysis of mandibular premolars with three root canals. J Endod. 2013;39(9):1130-5.

Özen T, Kamburoğlu K, Cebeci AR, Yüksel SP, Paksoy CS. Interpretation of chemically created periapical lesions using 2 different dental cone-beam computerized tomography units, an intraoral digital sensor, and conventional film. Oral Surg Oral Med Oral Pathol Oral Radiol Endod. 2009;107(3):426-32.

Paes da Silva Ramos Fernandes LM, Ordinola-Zapata R, Hungaro-Duarte MA, Alvares Capelozza AL. Prevalence of apical periodontitis detected in cone beam CT images of a Brazilian subpopulation. Dentomaxillofac Radiol. 2013;42(1):80179163.

Patel S, Dawood A, Ford TP, Whaites E. The potential applications of cone beam computed tomography in the management of endodontic problems. Int Endod J. 2007;40(10):818-30. 
Patel S, Dawood A, Whaites E, Pitt Ford T. New dimensions in endodontic imaging: part 1.Conventional and alternative radiographic systems. Int Endod J. 2009;42(6):447-62.

Patel S. New dimensions in endodontic imaging: part 2.Cone beam computed tomography. Int Endod J. 2009;42(6):463-75.

Pauwels R, Beinsberger J, Collaert B, Theodorakou C, Rogers J, Walker A, Cockmartin L, Bosmans H, Jacobs R, Bogaerts R, Horner K, SEDENTEXCT Project Consortium. Effective dose range for dental cone beam computed tomography scanners. Eur J Radiol. 2012;81(2):267-71.

Pécora JD, Savioli RN, Murgel CAF. Estudo da incidência de dois canais nos incisivos inferiores humanos. Rev Bras Odontol. 1990;47(4):44-7.

Pineda F, Kuttler Y. Mesiodistal and buccolingual roentgenographic investigation of 7,275 root canals. Oral Surg Oral Med Oral Pathol. 1972;33(1):101-10.

Peters OA, Laib A, Rüegsegger P, Barbakow F. Three-dimensional analysis of root canal geometry by high-resolution computed tomography. J Dent Res. 2000;79(6):1405-9.

Robinson S, Czerny C, Gahleitner A, Bernhart T, Kainberger FM. Dental CT evaluation of mandibular first premolar root configurations and canal variations. Oral Surg Oral Med Oral Pathol Radiol Endod. 2002;93(3):328-32.

Scarfe WC, Farman AG, Sukovic P. Clinical applications of cone-beam computed tomography in dental practice. J Can Dent Assoc. 2006;72(1):75-80.

Scarfe WC, Farman AG. What is cone-beam CT and how does it work?. Dent Clin North Am. 2008;52(4):707-30.

Sert S, Bayirli GS. Evaluation of the root canal configurations of the mandibular and maxillary permanent teeth by gender in the Turkish population. $J$ Endod. 2004;30(6):391-8.

Sherrard JF, Rossouw PE, Benson BW, Carrillo R, Buschang PH. Accuracy and reliability of tooth and root lengths measured on cone-beam computed tomographs. Am J Orthod Dentofacial Orthop. 2010;137(4):S100-8. 
Someda H, Saka H, Matsunaga S, Ide Y, Nakahara K, Hirata S, Hashimoto M. Age estimation based on three-dimensional measurements of mandibular central incisors in Japanese. Forensic Sci Int. 2009;185(1-3):110-4.

Somma F, Leoni D, Plotino G, Grande NM, Plasschaert A. Root canal morphology of the mesiobuccal root of maxillary first molars: a micro-computed tomographic analysis. Int Endod J. 2009;42(2):165-74.

Swain MV, Xue J. State of the art of Micro-CT applications in dental research. Int J Oral Sci. 2009;1(4):177-88.

Tachibana H, Matsumoto K. Applicability of X-ray computerized tomography in endodontics. Endod Dent Traumatol. 1990;6(1):16-20.

Tewary S, Luzzo J, Hartwell G. Endodontic radiography: who is reading the digital radiograph? J Endod. 2011;37(7):919-21.

Tiku AM, Kalaskar RR, Damle SG. An unusual presentation of all the mandibular anterior teeth with two root canals-a case report. J Indian Soc Pedod Prev Dent. 2005;23(4):204-6.

Tyndall DA, Rathore S. Cone-beam CT diagnostic applications: caries, periodontal bone assessment, and endodontic applications. Dent Clin North Am. 2008;52(4):82541.

Tyndall DA, Kohltfarber $\mathrm{H}$. Application of cone beam volumetric tomography in endodontics. Aust Dent J. 2012;57(1):72-81.

Vertucci FJ. Root canal morphology and its relationship to endodontic procedures. Endod Top. 2005;10(1):3-29.

Vertucci FJ. Root canal anatomy of the human permanent teeth. Oral Surg Oral Med Oral Pathol. 1984;58(5):589-99.

Villas-Bôas $\mathrm{MH}$, Bernardineli N, Cavenago BC, Marciano M, Del Carpio-Perochena A, de Moraes IG, Duarte MH, Bramante CM, Ordinola-Zapata R. Micro-computed tomography study of the internal anatomy of mesial root canals of mandibular molars. J Endod. 2011;37(12):1682-6. 
Wang Y, Zheng QH, Zhou XD, Tang L, Wang Q, Zheng GN, Huang DM. Evaluation of the root and canal morphology of mandibular first permanent molars in a western Chinese population by cone-beam computed tomography. $J$ Endod. 2010;36(11):1786-9.

Warren EM, Laws AJ. The relationship between crown size and the incidence of bifid root canals in mandibular incisor teeth. Oral Surg Oral Med Oral Pathol. $1981 ; 52(4): 425-9$.

Weiger R, EIAyouti A, Löst C. Efficiency of hand and rotary instruments in shaping oval root canals. J Endod. 2002;28(8):580-3.

Willershausen B, Kasaj A, Röhrig B, Marroquin BB. Radiographic investigation of frequency and location of root canal curvatures in human mandibular anterior incisors in vitro. J Endod. 2008;34(2):152-6.

Wu MK, R'oris A, Barkis D, Wesselink PR. Prevalence and extent of long oval canals in the apical third. Oral Surg Oral Med Oral Pathol Oral Radiol Endod. 2000;89(6):739-43.

Wu MK, Wesselink PR. A primary observation on the preparation and obturation of oval canals. Int Endod J. 2001;34(2):137-41.

Yamada M, Ide Y, Matsunaga S, Sato H, Nakagawa K. Three-dimensional analysis of mesiobuccal root canal of Japanese maxillary first molar using Micro-CT. Bull Tokyo Dent Coll. 2011;52(2):77-84.

Yang H, Tian C, Li G, Yang L, Han X, Wang Y. A cone-beam computed tomography study of the root canal morphology of mandibular first premolars and the location of root canal orifices and apical foramina in a Chinese subpopulation. $J$ Endod. 2013;39(4):435-8.

Yoshioka T, Kikuchi I, Adorno CG, Suda H. Periapical bone defects of root filled teeth with persistent lesions evaluated by cone-beam computed tomography. Int Endod J. 2011;44(3):245-52.

Zheng QH, Zhou XD, Jiang Y, Sun TQ, Liu CX, Xue H, Huang DM. Radiographic investigation of frequency and degree of canal curvatures in Chinese mandibular permanent incisors. J Endod. 2009;35(2):175-8. 



$$
\text { (1) }
$$





\section{ANEXO A - Parecer do Comitê de Ética em Pesquisa da FOB-USP}

Plataforma Brasil - Ministério da Saúde

Faculdade de Odontologia de Bauru-USP

\section{PROJETO DE PESQUISA}

Título: Identificação de dois canais radiculares em incisivos inferiores com imagens radiográficas e
tomográficas

Número da Parecer: 9355

Data da Relatoria: 28/03/2012

Apresentaçāo do Projeto:

Projeto inicialmente, bem elaborado e comparando recursos modernos, para ajudar no diagnóstico de tratamento endodôntico em incisivos inferiores.

Objetlvo da Pesqulsa:

Comparar exames radiográficos periapicais convencionais, radiográficos periapicais digitais e tomografia computadorizada de feixe cônico (TCFC).

Avaliação dos Riscos e Benefícios:

A pesquisa desenvolver-se-á com 40 dentes humanos já extraídos e doados, que serão radiografados e expostos à tomografia computadorizada (TCFC) e depois comparados sobre a prevalência de dois canais radiculares pesquisados em 100 tomografias computadorizadas de feixe cônico, pertencentes ao banco da Disciplina de Radiologia da FOB-USP.

Não serão recrutados sujeitos para esta pesquisa, portanto, sem riscos.

Comentários e Considerações sobre a Pesquisa:

No resumo apresentado, informa-se que de acondo com a literatura científica pesquisada, ocorre entre 11 a $40 \%$ dos casos, a presença de um segundo canal radicular nos incisivos inferiores, que não sendo visualizado acarreta insucesso do tratamento endodôntico realizado, pelo não tratamento deste segundo canal, permitindo que microorganismos se instalem ou permaneçam no sistema de canais radiculares, perpetuando o processo patológico no dente.

A autora recomenda a TCFC para casos mais complexos, sobretudo para retratamento, alertando que a dose de radiação é superior ao da radiografia periapical, o que limita a indicação deste exame somente para casos mais complexos.

A pesquisa será desenvolvida na Disciplina de Radiologia da FOB-USP, onde encontram-se instalados todos os aparelhos necessários.

Consideraçס̄es sobre os Termos de apresentação obrigatória:

Todos os documentos apresentados, estão anexados a este processo e corretamente preenchidos.

Este trabalho dispensa o TCLE, por tratar-se de pesquisa laboratorial em dentes humanos, extraidos e com termo de doação pela pesquisadora e consulta a arquivo.

A pesquisadora informa que "O total de 140 sujeitos foi incluído nos campos "Tamanho da amostra no Brasil" e "informe o número de individuos abordados pessoalmene, recrutados, ou que sofrerão algum tipo de intervenção neste centro de pesquisa", pois os mesmos são de preenchimento obrigatório, não aceitando o algarismo 0 como opção. Nenhuma intervenção será feita em nenhum paciente, bem como nenhuma abordagem pessoal será executada."

Recomendaçōes: nada a declarar

Conclusōes ou Pendênclas e Llsta de Inadequaçōes: projeto aprovado

Situação do Parecer: Aprovado

Necessita Apreciação da CONEP: Não

Considerações Finais a critério do CEP: 
ANEXO B - Parecer do "Institutional Review Board" da Faculdade de Odontologia da Universidade de Loma Linda, CA, EUA

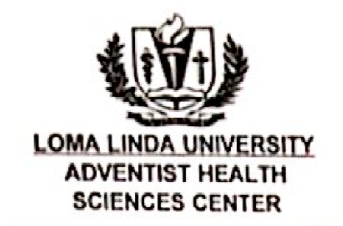

\section{INSTITUTIONAL REVIEW BOARD RESEARCH PROTECTION PROGRAMS \\ 24887 Taylor Street - Sutte 202 - Loma Linda, CA 92350 \\ (909) 558.4531 (voice) · (909) 558-0131 (fax)}

\section{Notice of Determination of Human Subject Research}

IRB\# 5120178

To: $\quad$ Rice, Dwight

Department: Oral Diagnosis, Radiology \& Pathology

Protocol: Identification of supplementary root canal systems in mandibular incisors using different diagnostic tools: An in vitro study

$\mathbb{X}$ The IRB has determined that this activity DOES NOT meet the definitions of human subject research (see below).

Reason(s):

$\Gamma$ Not a systematic investigation.

$\Gamma$ Not designed to develop or contribute to generalizable knowledge.

$\Gamma$ Not about living individuals)

$\nwarrow$ Not obtaining or receiving private individually identifiable information.

$\Gamma$ Data or specimens were not collected specifically for this study.

$\Gamma$ Coded data or specimens are used, but the researcher does not have access to the key to the code).

$\Gamma$ No direct intervention or interaction.

This study does not require IRB review or approval. If this activity is used in conjunction with any other human experimentation or if it is modified in any way, it must be re-reviewed by IRB staff. Your cooperation in LLU's shared responsibility for the ethical conduct of research is appreciated.

$\Gamma$ The IRB has determined that this activity DOES meet the definitions of human subject research and requires further review. Submit to:

$$
\begin{aligned}
& \Gamma \text { Exempt/Expedited Review } \\
& \Gamma \text { Convened Board }
\end{aligned}
$$

See http:/lwww.llu.edu/research-affairs/forms-and-online-tools. page? for further details.

Sincerely,

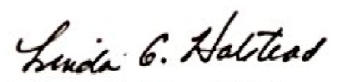

Linda G. Halstead, MA

IRB Administrator

Definitions (45 CFR 46.102):

Research: a systematic investigation, including research development, testing and evaluation, designed to develop or contribute to generalizable knowledge.

Human Subject: a living individual about whom an investigator conducting research obtains (1) data through intervention or interaction with the individual, or (2) identifiable private information 